\title{
Durability analysis of self consolidating concrete used in the Stalnaker Run Bridge
}

\author{
Zhanxiao Ma
}

Follow this and additional works at: https://researchrepository.wvu.edu/etd

\section{Recommended Citation}

Ma, Zhanxiao, "Durability analysis of self consolidating concrete used in the Stalnaker Run Bridge" (2016). Graduate Theses, Dissertations, and Problem Reports. 6127.

https://researchrepository.wvu.edu/etd/6127

This Thesis is protected by copyright and/or related rights. It has been brought to you by the The Research Repository @ WVU with permission from the rights-holder(s). You are free to use this Thesis in any way that is permitted by the copyright and related rights legislation that applies to your use. For other uses you must obtain permission from the rights-holder(s) directly, unless additional rights are indicated by a Creative Commons license in the record and/ or on the work itself. This Thesis has been accepted for inclusion in WVU Graduate Theses, Dissertations, and Problem Reports collection by an authorized administrator of The Research Repository @ WVU. For more information, please contact researchrepository@mail.wvu.edu. 


\title{
DURABILITY ANALYSIS OF SELF CONSOLIDATING CONCRETE USED IN THE STALNAKER RUN BRIDGE
}

\author{
Zhanxiao Ma \\ Thesis Submitted to the \\ College of Engineering and Mineral Resources \\ at West Virginia University \\ in Partial Fulfillment of the Requirements for the Degree of \\ Masters of Science \\ in \\ Civil Engineering \\ Roger Chen, Ph. D., Chair \\ Felicia Peng, Ph. D. \\ P. V. Vijay, Ph. D \\ Department of Civil and Environmental Engineering \\ Morgantown, West Virginia \\ April 2016
}

Keywords: Stalnaker Run Bridge; Self-Consolidating Concrete (SCC); Air-Void; RCPT; Freeze-Thaw; Durability 


\title{
Abstract \\ DURABILITY ANALYSIS OF SELF CONSOLIDATING CONCRETE USED IN THE \\ STALNAKER RUN BRIDGE
}

\author{
Zhanxiao Ma
}

Self-Consolidating Concrete (SCC) was used in the pre-tensioned box beams for the Stalnaker Run Bridge project in Elkin, WV. It was found that the SCC used in Stalnaker Run Bridge has a low freeze-thaw durability index. One of the SCC full-scale box beam was subjected to loading test at WVU structural laboratory until failure. Following the observed freeze-thaw behavior, this research study was proposed to quantify the SCC filling ability by saw-cutting the full-scale SCC test beam and to determine the cause of SCC beam's low freeze-thaw durability using the air-void analysis. Results from the coarse aggregate distribution analysis of the saw-cut cross sections and the core specimens of the SCC test beam show that the SCC beam exhibited significant segregation behavior. An air void analysis of the core specimens shows a high specific surface and spacing factor (SF); especially, the observed SF is about twice of the $0.2 \mathrm{~mm}$ suggested by ASTM C666. Additionally, the cored SCC beam specimens failed at 270 cycles, not meeting the ASTM C666 freeze-thaw requirement of 300 cycles. The permeability of the SCC was determined using the Rapid Chloride Penetration Test (RCPT) [ASTM C1202]. The results of the RCPT suggest that specimens from the test beam exhibited moderate chloride ion penetrability, which values higher than the allowable value of 1,500 Coulombs.

Laboratory SCC specimens were reproduced using the same mix design as was used for the SCC test beam. The laboratory cast SCC also exhibited a poor air void structure but with higher compressive strength. In order to better understand the durability effect of high temperature curing of SCC, half of the new casting specimens were cured at a higher temperature (as experienced by the SCC test beam) while half of the specimens were cured at room temperature. The compressive strength of high temperature cured SCC was higher for the first 3 days but lower at the 28 days compared to the room temperature cured specimens. The results indicated that high temperature curing had significant effect on concrete freeze-thaw durability and RCPT penetrability. The high temperature cured specimens failed at 270 freeze-thaw cycles while the room temperature specimens survived the 300 freeze-thaw cycles. 


\section{ACKNOWLEDGMENTS}

I would like to express my gratitude toward my research advisor, Dr. Roger Chen, for the invaluable guidance and assistance provided throughout my research. I would also like to thank the members of my research committee, Dr. Felicia Peng and Dr. P. V. Vijay, for there guidance in this research.

Thanks to West Virginia Department of Transportation Division of Highways for the funding of this project (RP\#221C, WVDOT). Also thanks to BASF Chemicals, Roanoke Cement for supporting the materials for this research.

I would like to thank my colleagues Yun Lin, Alper Yikici and Jared Hershberger who give me assistance and instruction in this study. Finally, I would like to thank my family and friends for their unconditional support in my studying.

This work also constitutes the final report of project RP\#221C submitted to WVDOT. 


\section{Table of Contents}

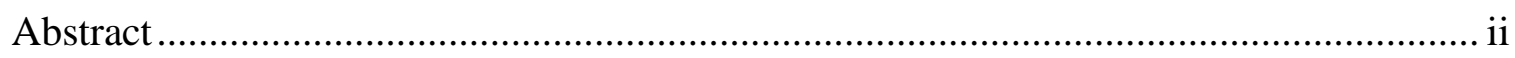

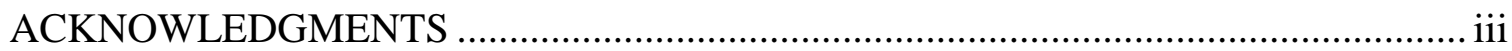

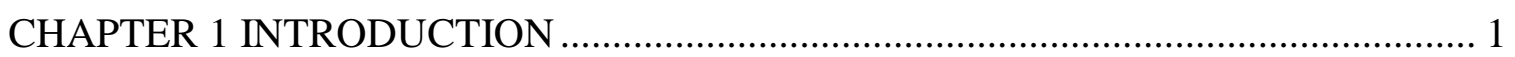

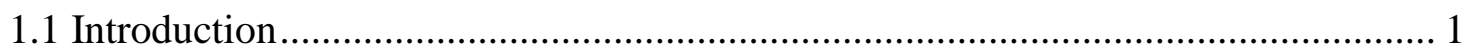

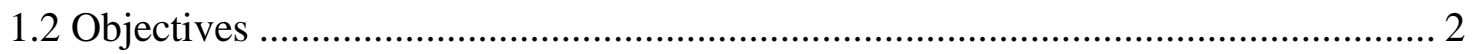

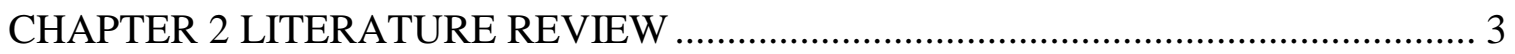

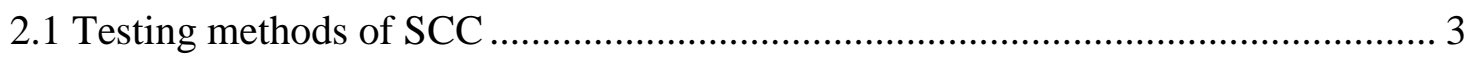

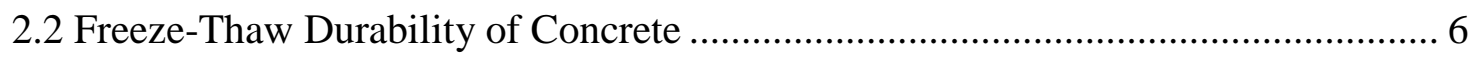

2.3 Coarse aggregate distribution in hardened concrete ……..................................... 8

2.4 Air Void Distribution of the Hardened Concrete.................................................... 9

2.5 RCPT (Rapid Chloride Penetration Test) ……………........................................ 10

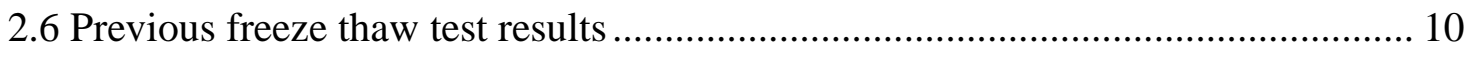

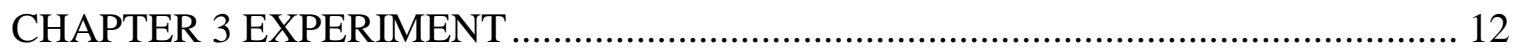

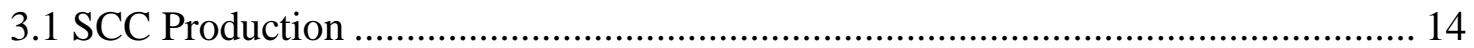

3.1.1 Mix design and casting .................................................................. 14

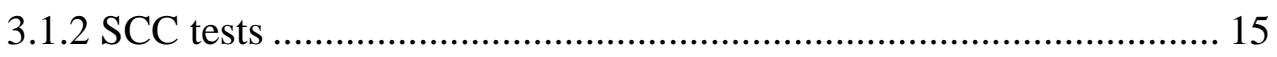

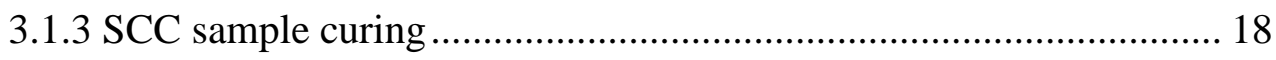

3.2 SCC Beam Saw-Cutting ……..................................................................... 19

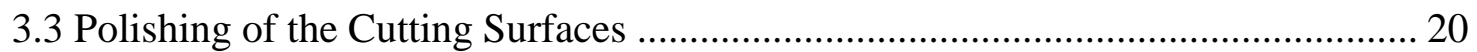

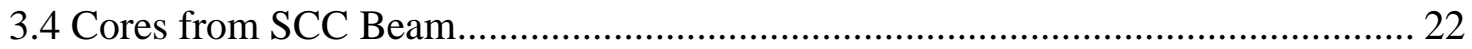

3.5 Coarse aggregate analysis .............................................................................. 24

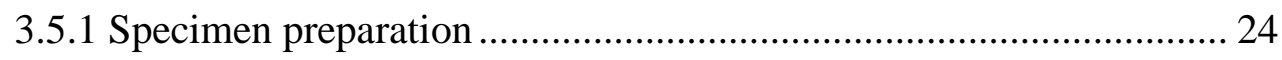

3.5.2 Coarse aggregate percentage analysis ........................................... 25

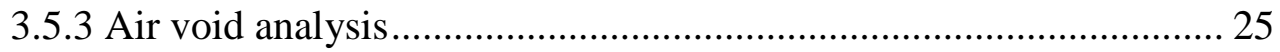




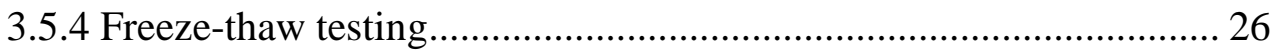

3.5.5 RCPT (Rapid chloride penetration test) ..................................... 30

CHAPTER 4 EXPERIMENTAL RESULTS AND DISCUSSION .............................. 33

4.1 Coarse aggregate distribution analysis results ................................................ 33

4.1.1 Coarse aggregate distribution in the core specimens from the SCC test beam 33

4.1.2 Coarse aggregate distribution within the cutting surfaces of the SCC test beam 34

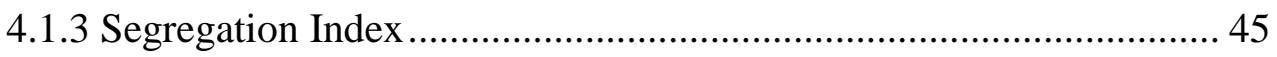

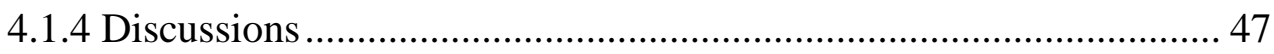

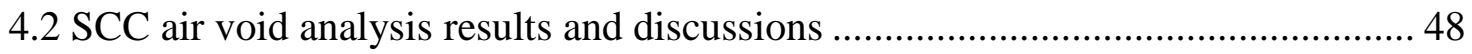

4.3 Compressive strength of the new casting SCC ................................................ 52

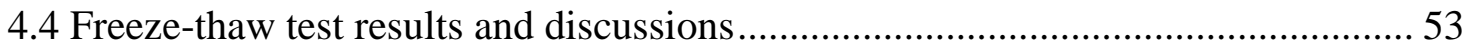

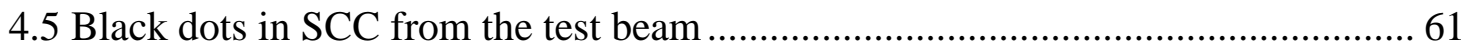

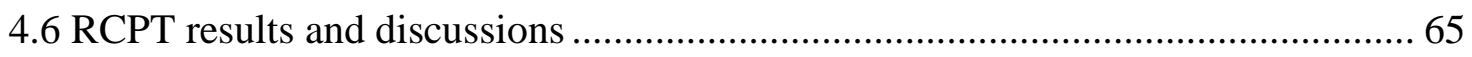

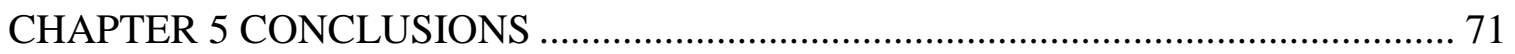

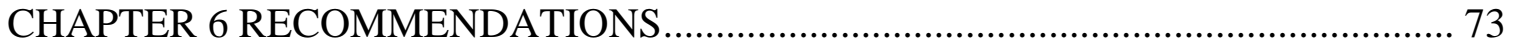

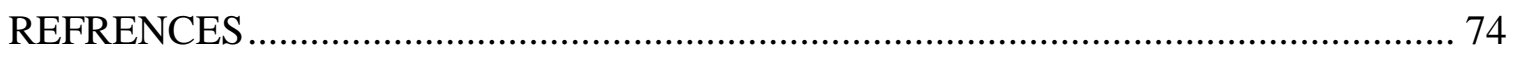

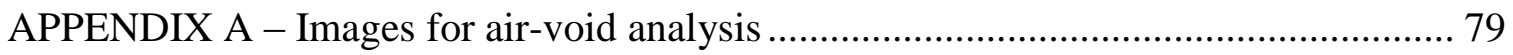




\section{LIST OF FIGURES}

Figure 1.1 - Full-Scale SCC beam from Stalnaker Run Bridge project.................................. 1

Figure 2.1 - VSI Criteria (ASTM C1611) ................................................................. 5

Figure 2.2 - Schematic of apparatus for forced resonance test (ASTM C215) ......................... 8

Figure 2.3 - Schematic of apparatus for impact resonance test (ASTM C215) ...................... 8

Figure 2.4 - Curing temperature for SCC beams during fabrication (Sweet, 2014) ................. 11

Figure 2.5 - Previous results of freeze-thaw durability of concrete specimens obtained during beam production of Stalnake Run bridge project (Sweet, 2014) ............................... 11

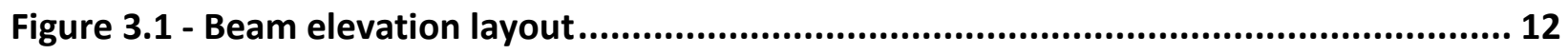

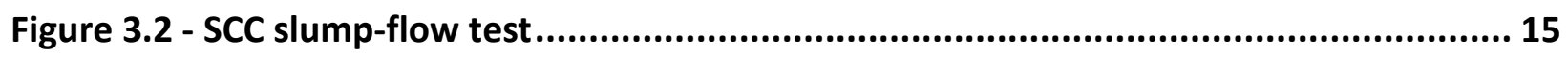

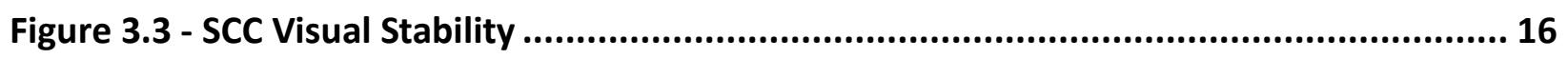

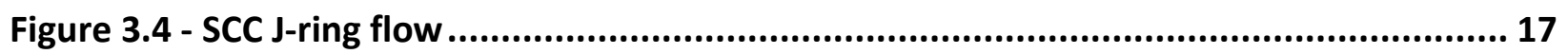

Figure 3.5 - Penetration apparatus.............................................................................. 18

Figure 3.6 - SCC curing temperature profile ............................................................... 19

Figure 3.7 - Saw-Cutting position of the full-Scale Test Beam............................................. 19

Figure 3.8 - Cross-Section Detailing of the Box Beam ................................................... 20

Figure 3.9 - SCC Full-Scale Beam after Three Cuts .......................................................... 20

Figure 3.10 - Cutting surface after grinding.................................................................. 21

Figure 3.11 - Cutting surface after polishing ......................................................... 21

Figure 3.12 - Cutting surface before (left) and after (right) polishing ............................... 22

Figure 3.13 - SCC filling around tendons ................................................................. 22

Figure 3.14 - Location of the cores viewing from top surface of the SCC beam ..................... 23

Figure 3.15 - Core specimens taken from the SCC beam ............................................ 23

Figure 3.16 - Core Specimens used for freeze-thaw test ............................................. 24

Figure 3.17 - Concrete Polisher............................................................................... 24

Figure 3.18 - Images of hardened specimen. (a) Before polishing; (b) After polishing ............ 25

Figure 3.19 - Black-colored surface with white-filled voids (taken using USB microscope)..... 26

Figure 3.20 - Temperature in concrete specimens and the freeze-thaw chamber ................. 27

Figure 3.21 - Test setup for measurement of fundamental transverse frequencies of freezethaw specimen......................................................................................... 28 
Figure 3.22 - Accelerometer response measured using LabVIEW .................................... 28

Figure 3.23 - Frequency domain of the acceleration after fast Fourier transform ................. 29

Figure 3.24 - Test setup for measurement of fundamental longitudinal frequencies of freeze-

thaw specimen $($ Sweet, 2014) .................................................................................... 29

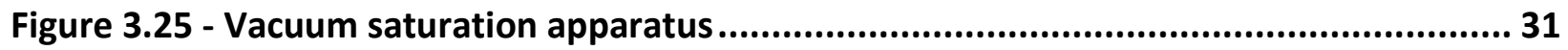

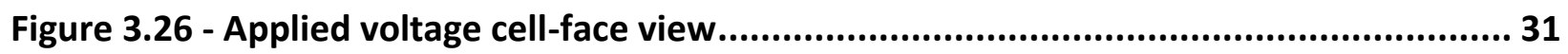

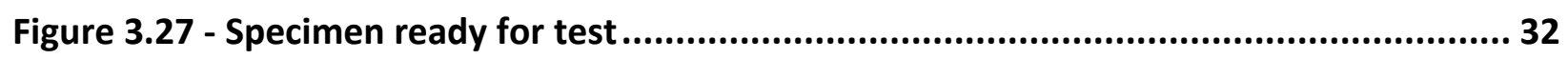

Figure 3.28 - Rapid chloride penetration test equipment............................................. 32

Figure 4.1 - Polished surfaces of the concrete cores taken from the SCC beam..................... 33

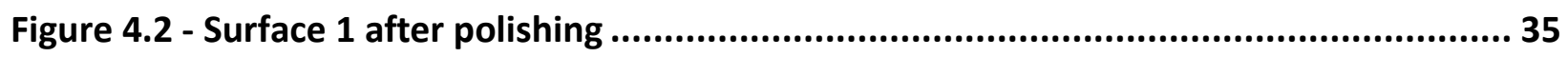

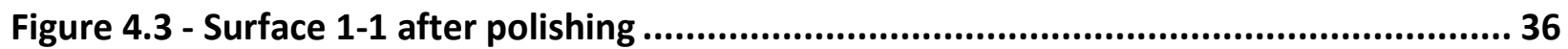

Figure 4.4- Surface 2 after polishing .................................................................... 36

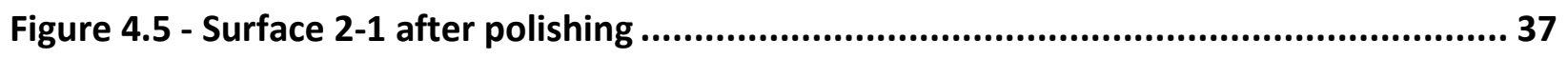

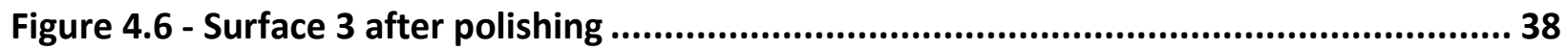

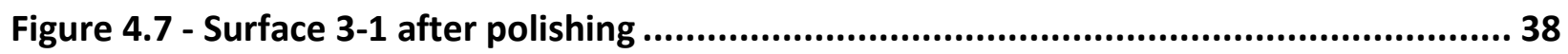

Figure 4.8 - Coarse aggregate percentage distribution at different sections ........................ 40

Figure 4.9 - Coarse aggregate percentage distribution on each saw-cut surface .................. 40

Figure 4.10 - Percentage difference between top and bottom in bottom sections (bottom percentage minus top percentage) ............................................................... 43

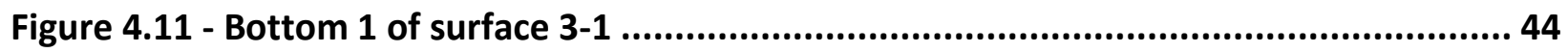

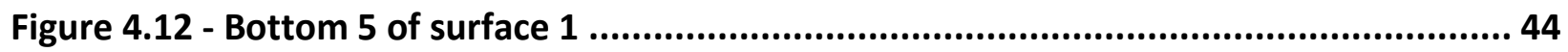

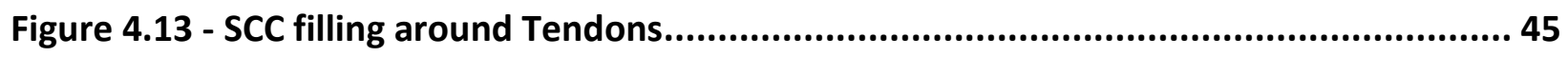

Figure 4.14 - Segregation index of the bottom sections of the SCC test beam .................... 47

Figure 4.15 - Air content relationship between fresh and hardened concrete (Kamal H. Khayat, 2002) 49

Figure 4.16 - Traditional concrete (left) and SCC (right) air void from previous results (Surface, 2013) 51

Figure 4.17 - Air bubble size distribution of traditional concrete used in Stalnaker Run Bridge (Surface, 2013). 51

Figure 4.18 - Air bubble size distribution of SCC test beam specimen from Stalnaker Run Bridge project 52

Figure 4.19 - Relative dynamic modulus of core specimens from SCC test beam using transverse frequency method 54 
Figure 4.20 - Relative dynamic modulus of high temperature cured specimens using transverse frequency method

Figure 4.21 - Relative dynamic modulus of normal temperature cured specimens using transverse frequency method

Figure 4.22 - Relative dynamic modulus of core specimens from SCC beam specimens using longitudinal frequency method

Figure 4.23 - Relative dynamic modulus of high temperature cured specimens using longitudinal frequency method 56

Figure 4.24 - Relative dynamic modulus of normal temperature cured specimens using longitudinal frequency method 56

Figure 4.25 - C2 and C4 after 120 freeze-thaw cycles ................................................. 57

Figure 4.26 - Length change of shrinkage prisms due to freeze-thaw cycles ....................... 58

Figure 4.27 - (a), (b) High temperature cured specimen under SEM; (c), (d) Normal temperature cured specimen under SEM .......................................................... 61

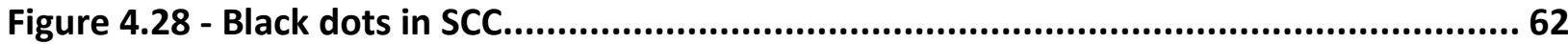

Figure 4.29 - SEM pictures of the black dots in SCC in three scales (a) $100 \mu \mathrm{m}$ (b) $10 \mu \mathrm{m}$. (c) $1 \mu \mathrm{m}$. 64

Figure 4.30 - SEM chemical components analysis of black dots ....................................... 64

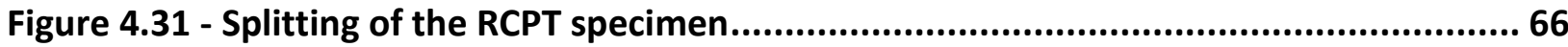

Figure 4.32 - PCPT specimens after silver nitrate test ............................................. 66

Figure 4.33 - RCPT results from Specimens B1 to B5 (a) Relationship between total charges passed and chloride migration coefficient; (b) Relationship between initial current and chloride migration coefficient. 


\section{LIST OF TABLES}

Table 2.1 - Required fresh properties for site acceptance of Class S-P concrete ..................... 3

Table 2.2 - Visual Stability Index Values (ASTM C1611) ................................................ 6

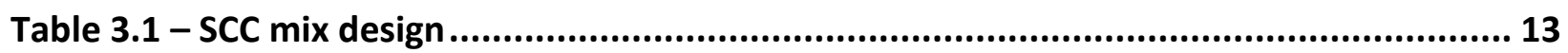

Table 3.2 - Blocking assessment (ASTM C1612) ........................................................ 16

Table 3.3 - Degree of static segregation resistance (ASTM C1712).................................... 18

Table 4.1 - Coarse aggregate percentage of cores taken from the SCC beam ....................... 34

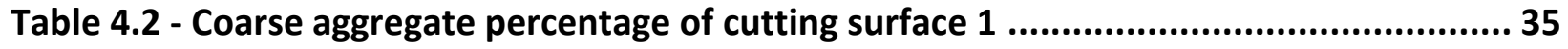

Table 4.3 - Coarse aggregate percentage of cutting surface 1-1 ......................................... 36

Table 4.4 - Coarse aggregate percentage of cutting surface 2 ......................................... 37

Table 4.5 - Coarse aggregate percentage of cutting surface $2-1$....................................... 37

Table 4.6 - Coarse aggregate percentage of cutting surface 3 ......................................... 38

Table 4.7 - Coarse aggregate percentage of cutting surface $3-1$..................................... 39

Table 4.8 - Bottom coarse aggregate distribution of surface 1 ......................................... 41

Table 4.9 - Bottom coarse aggregate distribution of surface 1-1 ................................... 41

Table 4.10 - Bottom coarse aggregate distribution of surface 2 .................................... 41

Table 4.11 - Bottom coarse aggregate distribution of surface $2-1$.................................. 42

Table 4.12 - Bottom coarse aggregate distribution of surface 3 ...................................... 42

Table 4.13 - Bottom coarse aggregate distribution of surface $3-1$..................................... 42

Table 4.14 - Hardened Visual Stability Index (HVSI) (IIlinois Test Procedure SCC-6).............. 46

Table 4.15 - Segregation index of core specimens ........................................................ 47

Table 4.16 - Air void properties of core specimens from SCC beam .................................... 49

Table 4.17 - Air void properties of new casting SCC ....................................................... 50

Table 4.18 - Compressive strength of the new casting SCC ......................................... 53

Table 4.19 - Coarse aggregate percentage of new casting SCC ........................................ 53

Table 4.20 - Results of Rapid Chloride Penetration Testing .............................................. 66

Table 4.21 - Chloride Ion Penetrability based on Charge Passed (ASTM C1202) ................... 67

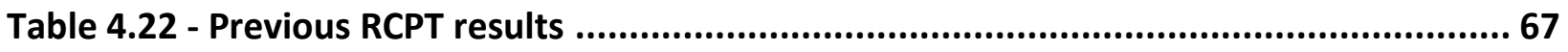




\section{CHAPTER 1 INTRODUCTION}

\subsection{Introduction}

Self-Consolidating Concrete (SCC) is known to be able to flow and consolidate under its own weight without any vibration while maintaining its homogeneity. The use of SCC for precast/prestressed applications has increased rapidly in the U.S. during the past 10 years mainly due to its labor savings. SCC also provides safer and quieter work conditions and better surface finish with much less bug holes or honeycombs. WVDOT and WVU researchers decided to explore the use of SCC for bridge construction through an IBRD project started in 2007 with support from the Federal Highway Administration (FHWA). As a part of the project, the Stalnaker Run Bridge, located on Old Route 219 in Elkins, WV was constructed using SCC and traditional concrete in caissons and prestressed beam construction. Three traditionally prestressed concrete beams and two SCC beams were built to serve on the superstructure and one of the two abutments was constructed with SCC caissons. The bridge was constructed during the summer of 2009 and has been opened to traffic since November 2009. The bridge has been under monitoring since the construction. Additionally, one identical full-scale SCC bridge beam was produced at the same time during the construction and was transported to WVU structural laboratory for testing. The full-scale SCC test beam is shown in Figure 1.1.

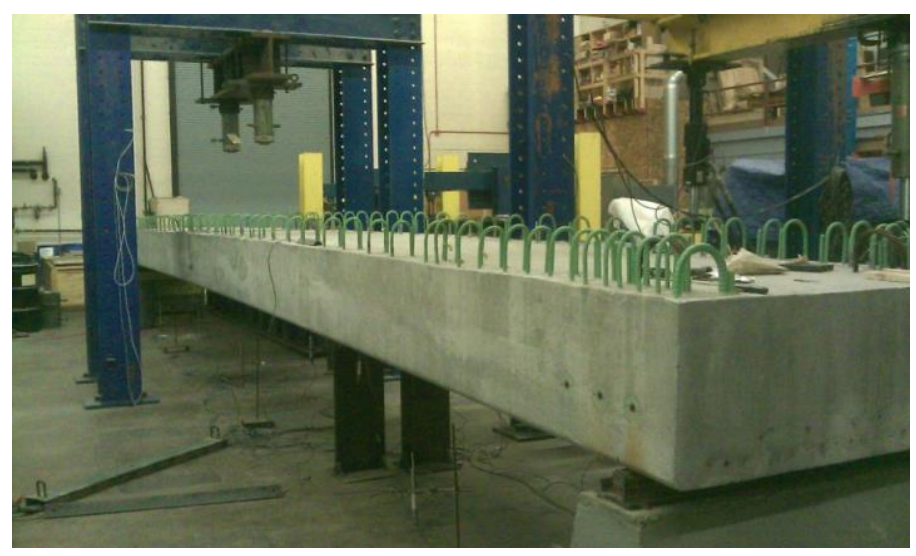

Figure 1.1 - Full-Scale SCC beam from Stalnaker Run Bridge project 
A good quality SCC needs to have good workability characteristics during the fabrication. These workability characteristics include filling ability, passing ability, filling capacity and segregation resistance. These characteristics were determined during the beam production following the ASTM test methods when SCC is still fresh and test results met with the requirements. Also, the design compressive strength was achieved during the construction.

The SCC's hardened properties and long-term durability are also important. The durability requirements were evaluated based on the Rapid Chloride Permeability Test (ASTM C1202) and the Freeze-Thaw durability (ASTM C666). RCPT test results indicate that the SCC used to produce the beams did not meet the requirements of the special provision ( $<1500$ coulombs). Freeze-Thaw test results also resulted in a durability factor for the SCC that is less than 80. These results imply that the prestressed SCC beams may have low long-term durability.

Six SCC freeze-thaw specimens were cast by the prestressed beam producer and sent to an independent laboratory for freeze-thaw testing. This batch was reported to have $5.3 \%$ air in the fresh state. Based on reports from the testing agency, testing of all six of the specimens was terminated prior to the 300 freeze-thaw cycles specified in the Stalnaker Run project provisions. The reason for the early termination, which took place after only 172 cycles, was because at that time the specimens had already experienced increases in length ranging from $0.11 \%$ to $0.13 \%$, and the measured dynamic moduli of the specimens ranged from $55 \%$ to $58 \%$ of that measured prior to exposure. Freeze-Thaw test results show that the durability factor is about 32 to 33 which does not meet the required durability factor specified in the project provision (>80). This freeze-thaw performance is unexpectedly low considering the strength and total air content, so the potential reasons for such performance, such as larger air voids within the overall air void structure, would warrant further investigation.

The filling ability of the SCC on the box-shape beam will be investigated by saw cutting the full-scale test beam. The freeze-thaw durability problem of the SCC used in the Stalnaker Run Bridge will be investigated using harden air-void analysis.

\subsection{Objectives}

The objectives of this study are to quantify the SCC filling ability by saw-cutting the full-scale test beam with petrographic analysis; to find out why the SCC beams has low freeze-thaw durability using the harden concrete air-void analysis. 


\section{CHAPTER 2 LITERATURE REVIEW}

\subsection{Testing methods of SCC}

Specific requirements for fresh state SCC depend on the type of application. There are several testing methods that have been developed to evaluate the fresh SCC quality according to the filling ability, passing ability and segregation resistance property of SCC. Table 2.1 shows requirements of site acceptance of the fresh SCC for prestressed concrete application.

Table 2.1 - Required fresh properties for site acceptance of Class S-P concrete (Chen et. al., 2012)

\begin{tabular}{|c|c|}
\hline Fresh Property & Acceptance Criteria \\
\hline Air Content (ASTM C173) & Target $\pm 2.0 \%$ \\
\hline Consistency (ASTM C1611) & $\begin{array}{c}\text { Target Spread } \pm 2.0 \text { in. } \\
\text { 2 seconds } \leq \text { Measured } T_{50} \leq 7 \text { seconds } \\
\text { Visual Stability Index } \leq 1.0\end{array}$ \\
\hline Passing Ability (ASTM C1621) & J-Ring Value $\leq 1.5$ in. \\
\hline $\begin{array}{c}\text { Rapid Segregation Resistance } \\
\text { (ASTM C1712) }\end{array}$ & $\begin{array}{c}\text { Penetration Depth (PD) } \leq 0.5 \text { in. } \\
\text { Unit Weight and Yield }\end{array}$ \\
\hline
\end{tabular}

The slump-flow for SCC is different from the slump test for TVC (ASTM C143), the slump-flow test for SCC is determined using ASTM C1611. Currently, the existing ASTM standards for testing fresh SCC are ASTM C1611/C1611M - 09b (Standard Test Method for Slump flow of Self-Consolidating Concrete) for slump-flow test, ASTM C1621/C1621M - 09b (Standard Test Method for Passing Ability of Self-Consolidating Concrete) for passing ability test, ASTM C1610/C1610M - 10 (Standard Test Method for Static Segregation of Self-Consolidating Concrete Using Column Technique) for segregation resistance test, and ASTM C1712 - 09 (Standard Test Method for Rapid Assessment of Static Segregation Resistance of Self-Consolidating Concrete Using Penetration Test) for segregation resistance test. Visual Stability Index (VSI) is also described in ASTM C1611. ASTM C1611 is a test used to determine the segregation resistance of 
fresh SCC. Since SCC has a low viscosity to make it more workable, the coarse aggregate and paste might be separated when casting and filling. In ASTM C1611, the VSI ranks the stability of SCC from 0 to 3 (Figure 2.1); 0 means no segregation and 3 means obvious segregation. Table 2.2 describes the criteria.

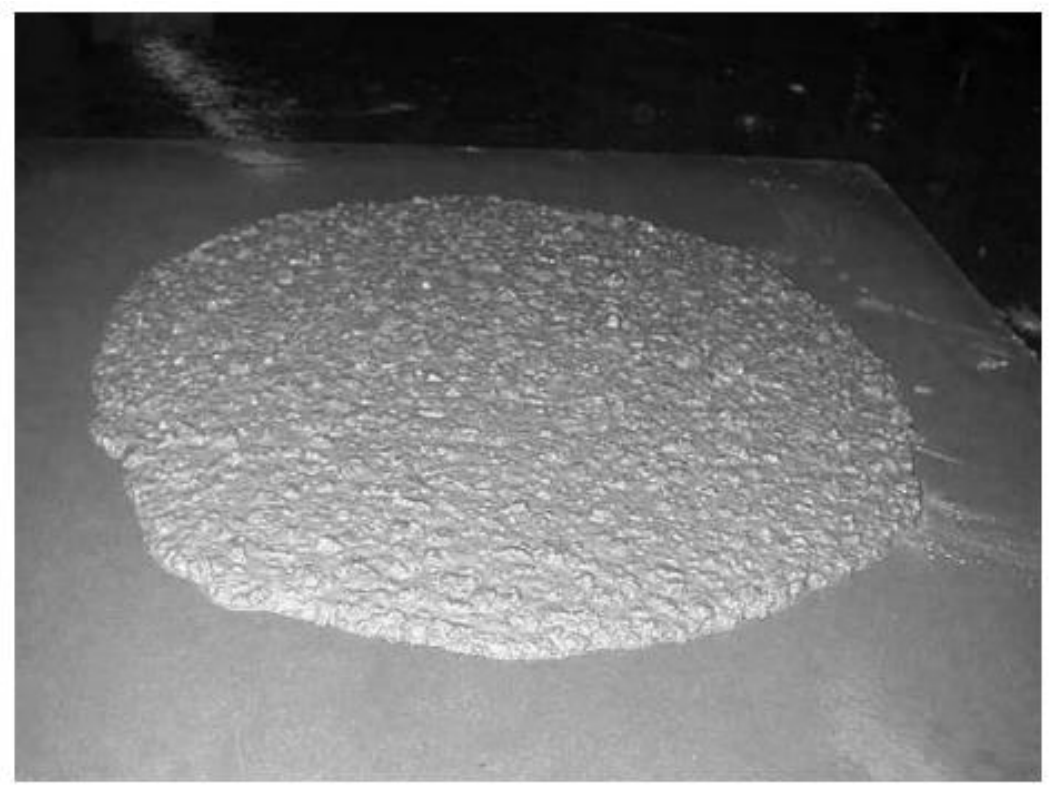

(a) VSI = 0 - Concrete Mass is Homogeneous and No Evidence of Bleeding

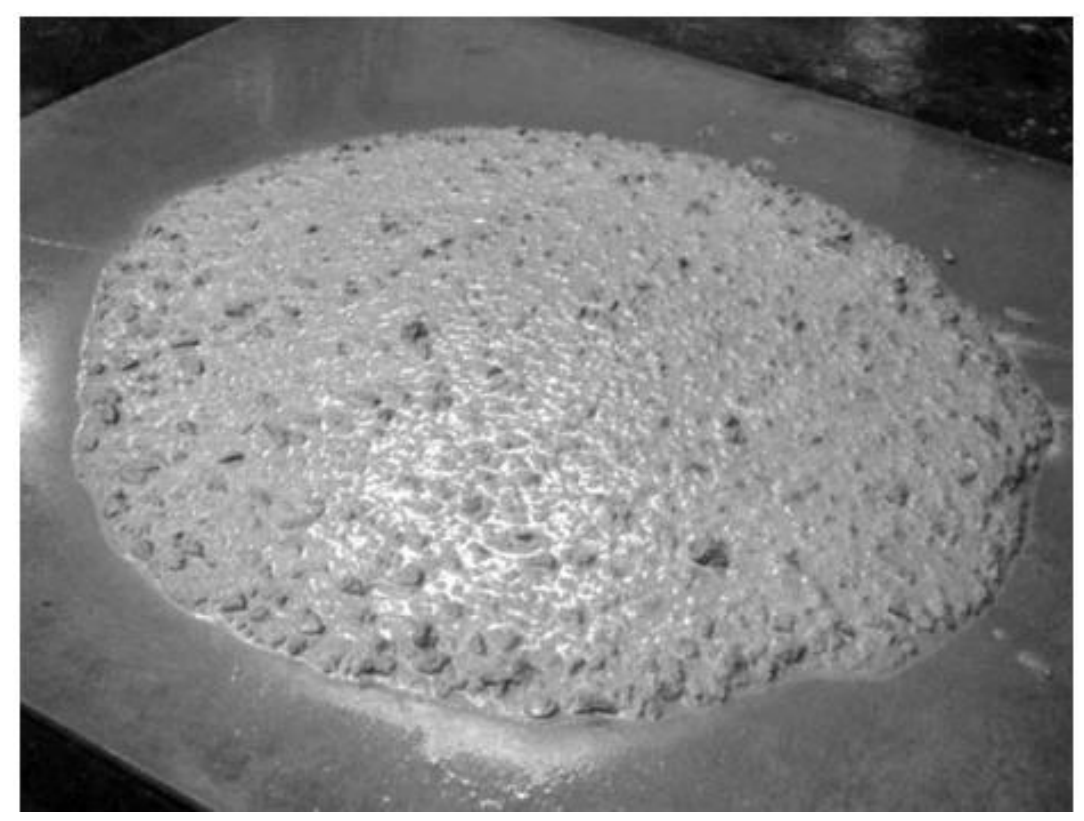

(b) VSI = 1 - Concrete Show Slight Bleeding Observed as a Sheen on the Surface 


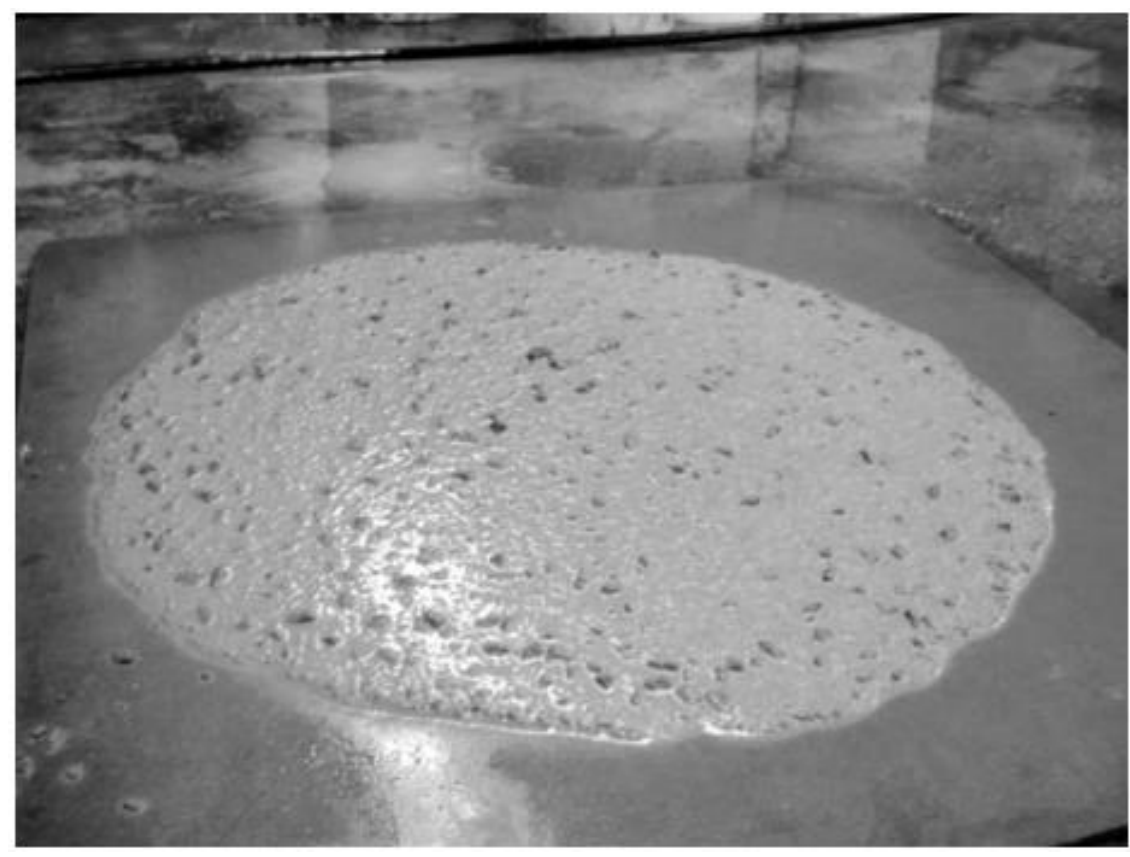

(c) VSI = 2 - Evidence of a Mortar Halo and Water Sheen

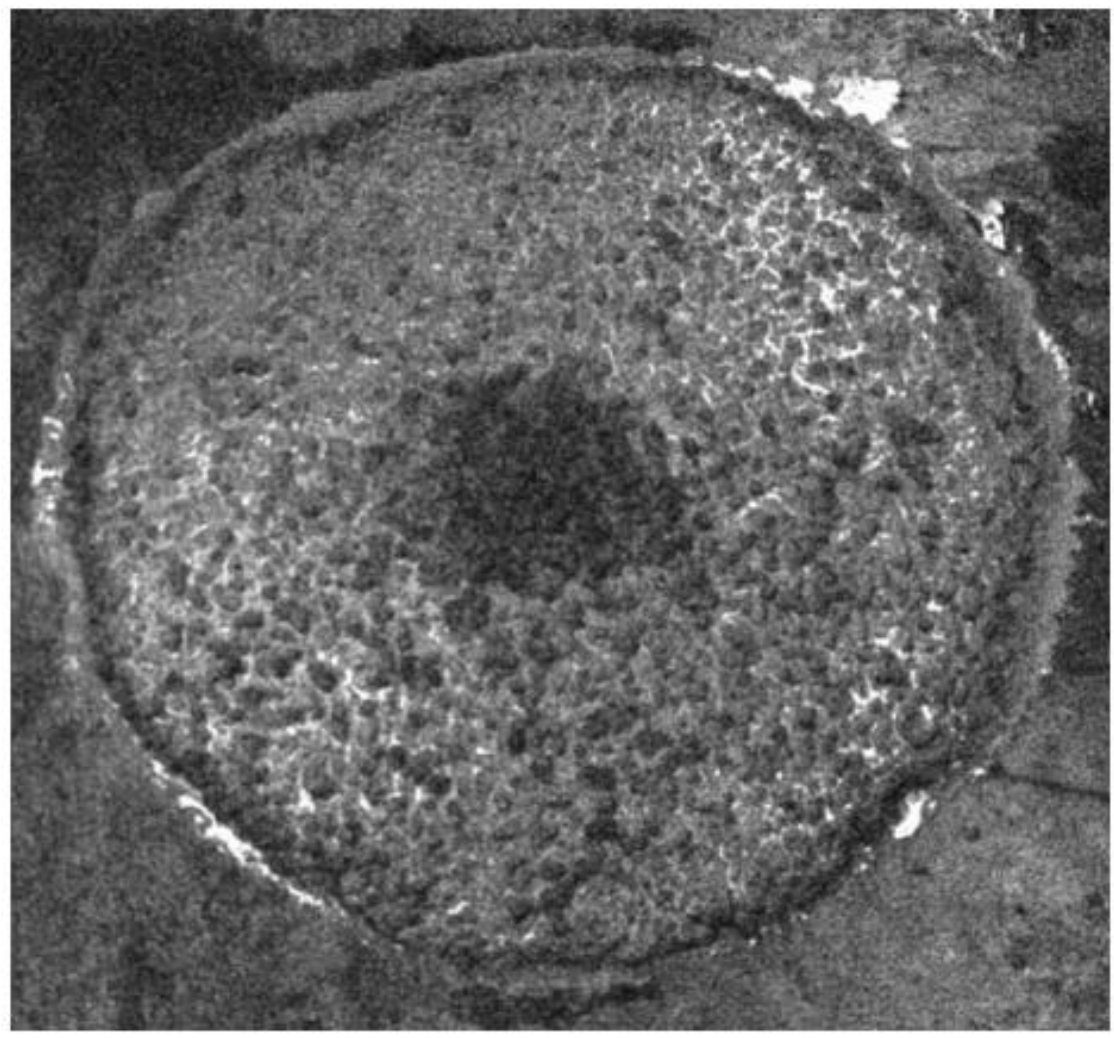

(d) VSI = 3 - Concrete of Coarse Aggregate at Center of Concrete Mass and Presence of a Mortar Halo

Figure 2.1 - VSI Criteria (ASTM C1611) 
Table 2.2 - Visual Stability Index Values (ASTM C1611)

\begin{tabular}{|c|c|}
\hline VSI Value & Criteria \\
\hline $0=$ Highly Stable & No evidence of segregation or bleeding. \\
\hline $1=$ Stable & $\begin{array}{l}\text { No evidence of segregation and slight bleeding observed } \\
\text { as a sheen on the concrete mass. }\end{array}$ \\
\hline 2 = Unstable & $\begin{array}{l}\text { A slight mortar halo } \leq 10 \mathrm{~mm}[\leq 0.5 \mathrm{in} \text {.] and/or aggregate } \\
\text { pile in the of the concrete mass. }\end{array}$ \\
\hline $\begin{array}{l}3=\text { Highly } \\
\text { Unstable }\end{array}$ & $\begin{array}{l}\text { Clearly segregating by evidence of a large mortar halo } \\
>10 \mathrm{~mm}[>0.5 \mathrm{in} .] \text { and/or a large aggregate pile in the } \\
\text { center of the concrete mass. }\end{array}$ \\
\hline
\end{tabular}

\subsection{Freeze-Thaw Durability of Concrete}

The freeze-thaw damage of concrete is one of the most critical damages that affect the durability of concrete structures, especially in cold climate regions. As we know, the volume of water increases when water freezes, if the concrete inside doesn't have enough space for ice to expand, the tensile stresses develop in concrete. Micro cracking may occur if the tensile stress exceeds the tensile strength of concrete. Researchers found that the concrete will not be damaged by freeze-thaw if the concrete is dry or impermeable (CP Tech Center 2009). However, most of concrete structures are exposed to rain and snow. The freeze-thaw cycles damage the concrete, and then the reinforcement in the concrete may be susceptible to corrosion, especially in the bridge decks due to the salt used for snow treatments, which can accelerate reinforcement corrosion.

The freeze-thaw durability can be determined by freeze-thaw test using ASTM C666, Standard Test Method for Resistance of Concrete to Rapid Freezing and Thawing. This method includes two procedures, one is rapid freezing and thawing in water and another one is rapid freezing in air and thawing in water. The specimens can be prism or cylinder, the width, depth or diameter of the specimens used shall greater than 3 inches but no greater than 5 inches, and the length of the specimens shall not less than 11 inches nor more than 16 inches. The specimens should be cured for 14 days before testing. Specimens cutting from hardened concrete should be immersed in saturated lime water at $73.4 \pm 3^{\circ} \mathrm{F}$ for 48 hours before testing. The freezing and thawing cycle for the test consist lowering the temperature of specimens from 40 to $0{ }^{\circ} \mathrm{F}$ and raising it from 0 to $40^{\circ} \mathrm{F}$. The total time for one cycle should be more than 2 and less than 5 hours, the thawing time should be more than $25 \%$ of the total time. 
Specimens should be tested for fundamental transverse frequency and measure length change with the specimens at intervals not exceeding 36 cycles of exposure to the freezing and thawing cycles. ASTM C666 provides the method to calculate the relative dynamic modulus of elasticity $p_{c}$ in the following equation:

$$
p_{c}=\left(\frac{n_{1}^{2}}{n_{2}^{2}}\right) \times 100
$$

Where:

$P_{c}=$ relative dynamic modulus of elasticity after $\mathrm{c}$ cycles, percent

$n_{l}=$ transverse frequency at 0 cycle

$n_{2}=$ transverse frequency after $\mathrm{c}$ cycles.

According to the result of relative dynamic modulus of elasticity calculated, the durability factor can be calculated in the following equation:

$$
D F=\frac{P N}{M}
$$

Where:

$D F=$ durability factor

$P=$ relative dynamic modulus of elasticity at $\mathrm{N}$ cycles, $\%$

$N=$ number of cycles at which $P$ reached the specified minimum value or the specified number of cycles at which the test is to be terminated

$M=$ specified number of cycles at which the test is to be terminated.

The frequency test was followed ASTM C215 Standard Test Method for Fundamental Transverse, Longitudinal, and Torsional Resonant Frequencies of concrete specimens. There are two methods for the frequency test, forced resonance test and impact resonance test. 


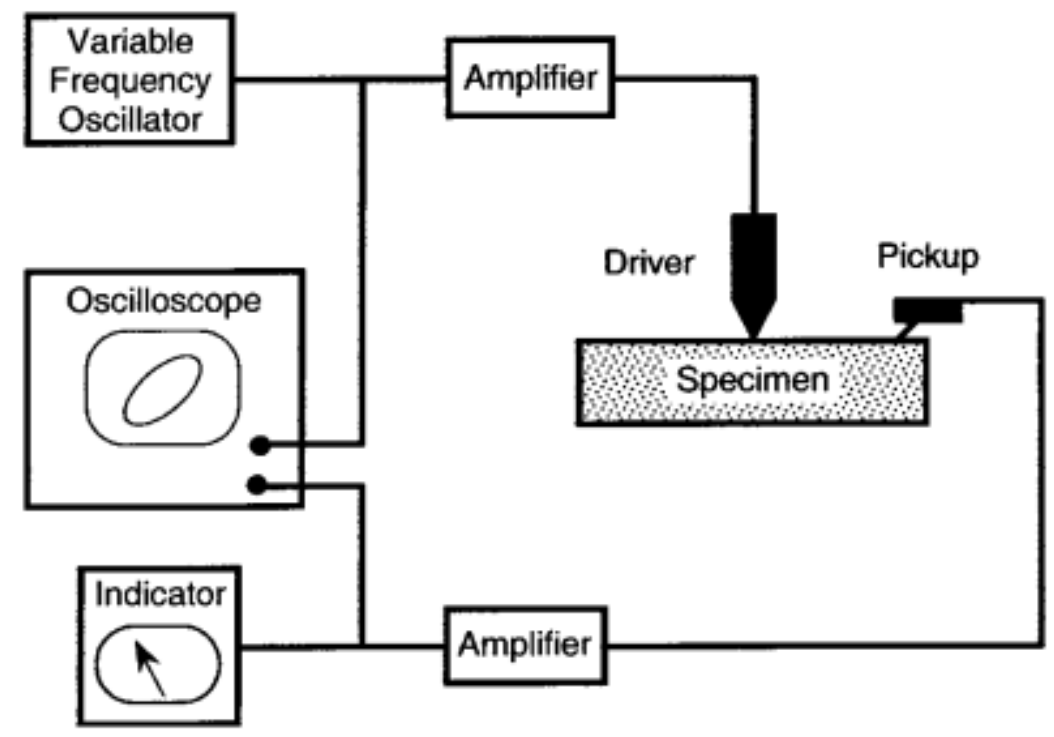

Figure 2.2 - Schematic of apparatus for forced resonance test (ASTM C215)

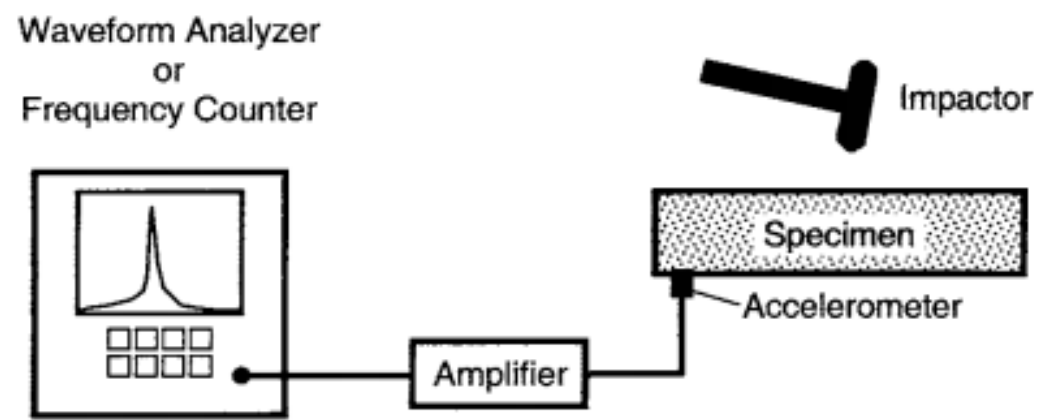

Figure 2.3 - Schematic of apparatus for impact resonance test (ASTM C215)

\subsection{Coarse aggregate distribution in hardened concrete}

SCC is easy to have segregation problem, the segregation resistance of SCC can be assessed by ASTM C1610 (Visual Stability Index) when concrete is in fresh state. For the Hardened VSI analysis, $10 \mathrm{~cm}$ by $10 \mathrm{~cm}$ ( 4 inch by 4 inch) cylinder cast or cored from hardened concrete beam can be used, the cylinder is first saw-cut longitudinally, and then the surface is polished and scanned. After the preparation is done, a program JMicroVision can be used for petrographic analysis. The different locations of the beams will be analyzed by this way to evaluate the filling ability and the segregation condition of the SCC. 


\subsection{Air Void Distribution of the Hardened Concrete}

In order to improve the freeze-thaw durability of concrete, air entraining admixture is used to make concrete has a proper air entrainment. Well-distributed air voids can provide additional spaces for ice to expand, which thus reduces the stress in the concrete and improves the freezethaw durability. The air voids in hardened concrete are produced by mixing procedure or air entraining admixtures. The air voids produced by physical mixing are called entrapped, while the air voids produced by air entraining admixtures are termed entrained. The two different types of voids can be distinguished by the shape and size. Usually, entrapped air voids are larger than one millimeter while entrained air voids are always smaller than one millimeter (Michael Scott, 1997). Hover conducted the research about the properties of concrete with air voids and found air entraining chemical admixtures can reduce segregation, settlement and bleeding (Hover, 2006).

The most important air-void parameters are spacing factor and specific surface. Air content can also affect concrete's workability, cohesiveness, segregation resistance and compressive strength. For a given volume of air, the specific surface indicates the relative number and size of air bubbles. A larger number of small bubbles is good for concrete freeze thaw durability. Spacing factor indicates the distance for water to travel before getting into an air bubble to reduce the pressure from the expansion of ice. ASTM C457 suggests the specific surface greater $24 \mathrm{~mm}^{2} / \mathrm{mm}^{3}$ and the spacing factor is less than $0.2 \mathrm{~mm}$ (0.008 in). ASTM C231 provides a method to test the air void content of freshly mixed concrete. The air void analysis of hardened concrete follows ASTM C457 "Standard Test Method for Microscopical Determination of Parameters of Air-Void System in Hardened Concrete". The linear traverse method and modified point-count method both need to conduct manually using a microscope. It usually requires 4-6 hours using these methods.

Another computerized automatic hardened air void analysis method was developed at Michigan Tech University. The computer program is called Bubble Counter, analyzing highresolution digital image scanned by a flatbed scanner (Carlson, 2005). Before the analysis, the surface of specimens were polished and painted black, then filled with white powder. This method can eliminate the operator's subjectivity and much faster than the manual methods. Radlinski, et al. (2010) reported relationship between air-void system and the freeze-thaw durability from hardened concrete air void images using flatbed scanner. 


\subsection{RCPT (Rapid Chloride Penetration Test)}

Corrosion of reinforcement inside concrete is one of most common damage on concrete structures. RCPT was developed to measure the resistance of concrete to chloride ion permeability. ASTM C1202 Standard Test Method for Electrical Indication of Concrete's Ability to Resist Chloride Ion Penetration provides the method for RCPT. 2' x 4" disc specimens are used in this test. The circumferential surface is coated using water and salt resistant coating. The specimens are placed in the vacuum container and kept at a pressure less than $50 \mathrm{~mm} \mathrm{Hg}$ for three hours. A container is filled with de-aerated water during the running of vacuum pump and kept running for another hour. The specimen is soaked under water in the container for $18 \pm 2$ hours. After the preparation of the specimen, a $60 \mathrm{~V}$ power supply will be used to the two ends of the specimen and current readings are recorded every 30 minutes. Then the concrete chloride ion penetrability can be determined based on the total charge passed from the RCPT results. After the RCP Testing, the specimens can be used for silver nitrate solution test (NT BUILD 492, 1999) which is a method to measure the migration depth of chloride ions after RCPT using the reaction between silver nitrate and chloride ions. This test can be used to determine the chloride migration coefficient in concrete.

\subsection{Previous freeze thaw test results}

Three SCC prestressed box beams were produced for Stalnaker Run Bridge Replacement Project (WV State Project S342-219-45.13 00, Federal Project BR-00219(126), located on County Route 219/86 in Randolph County, WV), two of the SCC beams together with three traditional prestressed concrete box beams were used on the Stalnaker Run Bridge, one of the SCC beams produced was used as a test beam and shipped to West Virginia University laboratory. The SCC test beam was tested at WVU structural laboratory until failure and then transported to WVDOH, currently lies in the WVDOH yard in Monagalia County close to Grafton road. The batch used in the SCC prestressed box beams casting was reported to have 5.3\% air content in the fresh state. The box beams were steam cured and the temperature profile in concrete is shown in Figure 2.4. 


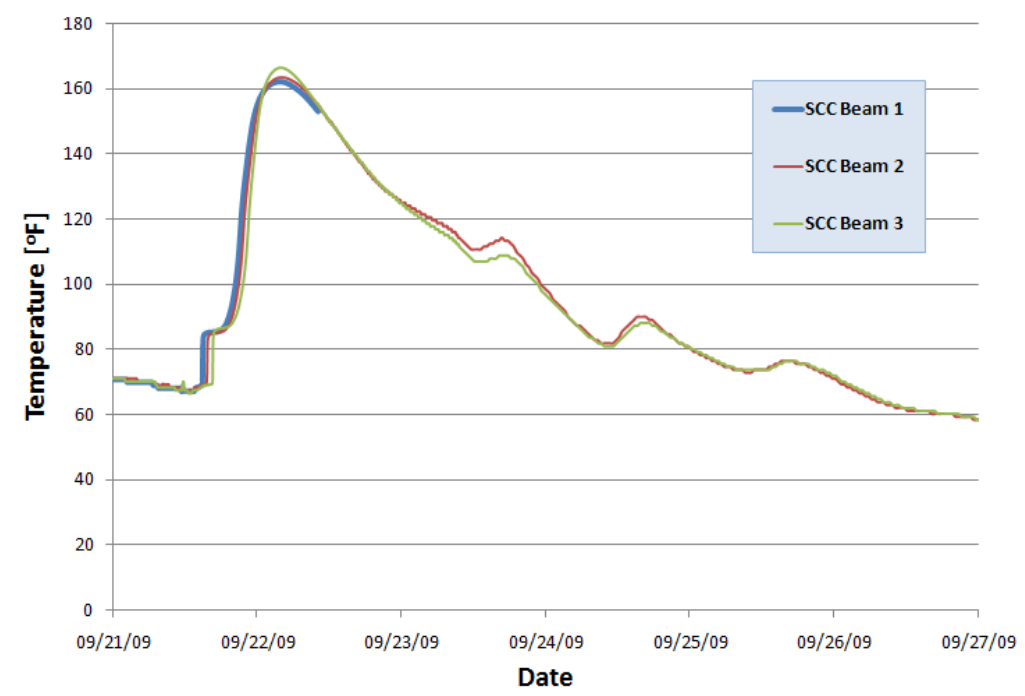

Figure 2.4 - Curing temperature for SCC beams during fabrication (Sweet, 2014)

Freeze-thaw specimens were cast simultaneously when traditional concrete beams and selfconsolidating beams were being cast. All the specimens were steam cured together with the beams. After the curing, the specimens were tested for freeze thaw durability in the laboratory. Figure 2.5 shows that the traditional concrete exhibited better freeze-thaw durability than the SCC used in the beam production.

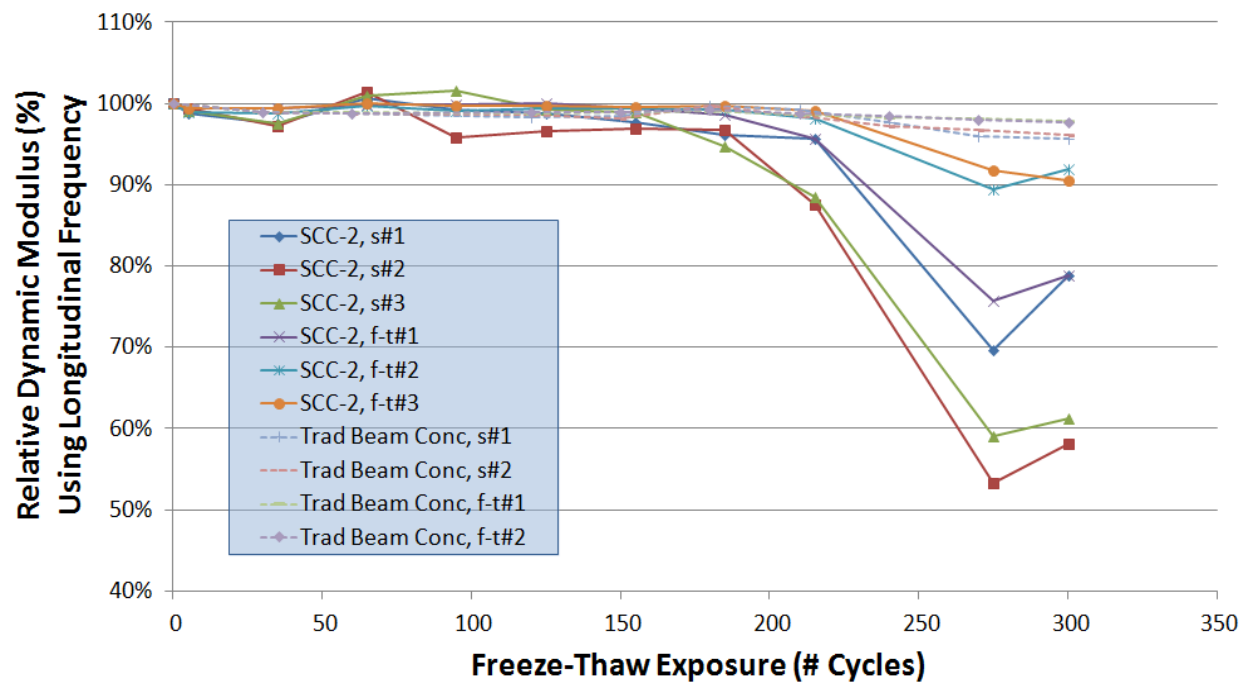

Figure 2.5 - Previous results of freeze-thaw durability of concrete specimens obtained during beam production of Stalnake Run bridge project (Sweet, 2014) 


\section{CHAPTER 3 EXPERIMENT}

The full-scale SCC test beam will be saw-cut for coarse aggregate distribution analysis and core samples will be retrieved for the air-void image samples. The beam will be kept in the DOH yard (close to $119 \mathrm{~N}$ and Grafton road in Monongalia County). The SCC beam will be saw-cut on three cross-sections. 4-inch diameter vertical cores at several locations will be taken and perform compressive strength, air void analysis, RCPT and freeze-thaw resistance testing.

a. Cross-sections on the box section of the beam will be saw-cut at three different positions as shown in Figure 3.1Error! Reference source not found., and the cutting surfaces will be polished using a hand-held polishing machine in order to conduct petrographic analysis, such as aggregate distribution, segregation, filling and passing characteristics of the hardened SCC on the box beam. Image analysis will be performed to determine large aggregate distribution throughout the polished cross sections. Furthermore, aggregate content and paste content will be determined and results will be compared with the original concrete mix design.

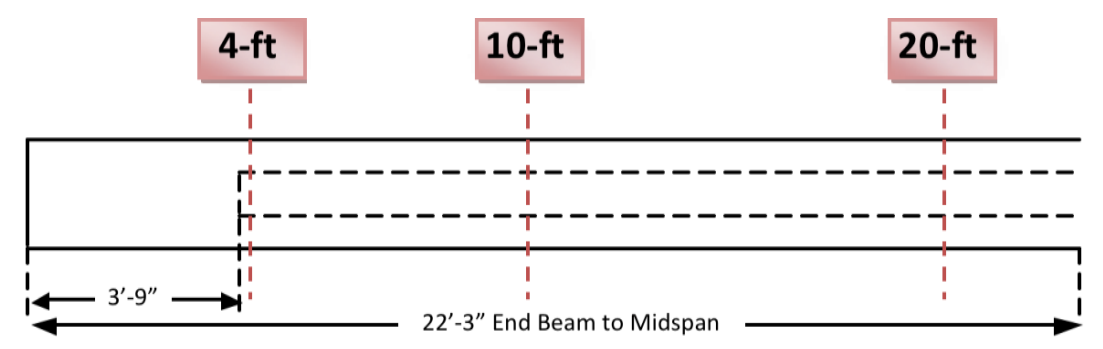

Figure 3.1 - Beam elevation layout

b. In total, eighteen 4"-diameter cores will be taken at different locations along the beam length. Four cores will be used for Freeze-Thaw testing, while eight cores will be used for air void analysis (ASTM C475) and six cores for RCPT (ASTM C1202) testing. Results will be compared with the previous cylinder test results.

c. Air void analysis will be performed using image analysis software following ASTM C475. To obtain hardened concrete air void parameters, concrete specimens will be cut, polished and colored to maximize the contrast between air voids and the cement paste. Scanned surface images will be analyzed using computerized image analysis. 
Results from the Stalnaker Run Bridge project show that both SCC and traditional concrete used in the beam production have high RCPT values and the SCC has a very low freeze-thaw durability index. Therefore, the durability of the precast SCC beams is of concern.

The cause of the poor freeze-thaw durability of the SCC mix used in the Stalnaker Run prestressed beam production will be investigated. Air-void specific surface, spacing factor and size distribution will be studied to determine the correlation between the SCC air-void properties and the freeze/thaw durability. In addition to tests of concrete core specimens taken from the laboratory beam, the SCC mix (Table 3.1) used for the Stalnaker Run Bridge beams will be replicated as closely as possible in the laboratory to create additional test specimens.

Table 3.1 - SCC mix design

\begin{tabular}{|l|r|}
\hline Material & Amount \\
\hline Cement, lb & 735 \\
\hline Silica Fume, lb & 75 \\
\hline Coarse Agg, lb & 1469 \\
\hline Fine Agg, lb & 1415 \\
\hline Water, lb & 284 \\
\hline w/cm & 0.35 \\
\hline HRWRA,fl.oz. & 115.03 \\
\hline VMA, fl. oz. & 14.99 \\
\hline AEA, fl. oz. & 23.00 \\
\hline Delvo, fl. oz. & 23.00 \\
\hline
\end{tabular}

The SCC mix design shown in Table 3.1 is identical to what was used in the SCC bridge beams. The exact type of cement will be used, as will the same fine aggregate and coarse aggregate. The chemical admixtures appropriated for this replication will be the same as those used in the beam production.

Specimens for freeze-thaw testing will be cast and tested according to ASTM C666. Also $4 \times 8$ cylindrical specimens will be cast for compressive strength test (at 1, 3, 7 and 28 days), hardened air void analysis and RCPT. Since the bridge beam and original specimens were steam cured, a mechanism simulating high-temperature steam curing will be developed for all of the specimens. A thermocouple will be inserted into one of the cylinders to ensure that the center of the concrete reaches the same internal temperature that the beam reached. The durability factor of 
the SCC will be calculated based on the dynamic properties of the test specimens after exposure to 300 freeze-thaw cycles.

\subsection{SCC Production}

\subsubsection{Mix design and casting}

The mix design used for this research is the same as the Stalnaker Run Bridge SCC mix design as shown in Table 3.1Error! Reference source not found.. The exact type of cement was ordered from Roanoke Cement Company as well as the use of the same fine aggregate and coarse aggregate. Additionally, the chemical admixtures appropriated for this replication were the same as those used in the beam production and were ordered from BASF prior to casting. The moisture content of aggregates was found following ASTM C566 - Standard Test Method for Total Evaporable Moisture Content of Aggregate by Drying.

$$
p=\frac{100(\mathrm{w}-d)}{d}
$$

Where: $p=$ moisture content, as a percent

$$
\begin{aligned}
& w=\text { original mass } \\
& d=\text { mass after drying }
\end{aligned}
$$

It was determined that the moisture content of coarse aggregate was approximately $1 \%$. The moisture content of the sand was determined to be approximately $1.65 \%$. The moisture content of coarse aggregate at Saturated Surface Dry (SSD) condition was 0.3\%, which was provided by the quarries. The SSD moisture content of fine aggregate was tested following the AASHTO T84, the SDD moisture content of fine aggregate was determined to be $1.1 \%$.

The SCC was cast following ASTM C192 (2013). A laboratory drum mixer was used for the mixing. Totally $3 \mathrm{ft}^{3} \mathrm{SCC}$ was produced for SCC testing and samples. Six freeze-thaw prisms were cast with dimensions of 3"X4"x16" using steel molds. Additionally, four shrinkage prisms with dimensions 3"x 3"x11.25" were also cast for freeze-thaw testing, which will be used to measure the length change due to freeze-thaw using length comparator. Totally more than 20 of the 4" 8 " cylinders were cast which will be used for compressive strength test, RCPT, and air void analysis. 


\subsubsection{SCC tests}

(1) Slump-Flow Test

The purpose of slump-flow testing is to determine the flowability and segregation resistance of fresh SCC. Following ASTM C1611, the slump flow testing of the SCC used the same kind of slump cone as traditional concrete slump test and a nonabsorbent, smooth, rigid plate having a minimum diameter of $915 \mathrm{~mm}$ (36 in). The slump cone was held firmly in the center of the board with the smaller opening facing down as shown in Figure 3.2, and was filled in a continuous manner. After it was slightly overfilled and leveled, the slump cone was then raise up above the board at a distance of $225 \mathrm{~mm}$ using a steady upward lift with no lateral or torsional motion. After the flowing stopped, measure the diameter of the maximum spread $\left(\mathrm{d}_{1}\right)$ and second diameter $\left(d_{2}\right)$ of the circular spread at an angle approximately perpendicular to the first measured diameter. The slump flow is the average of $d_{1}$ and $d_{2}$. An acceptable total spread of SCC is typically between 22 and 30 inches. The slump flow of this mixing was measured to be 25 inches.
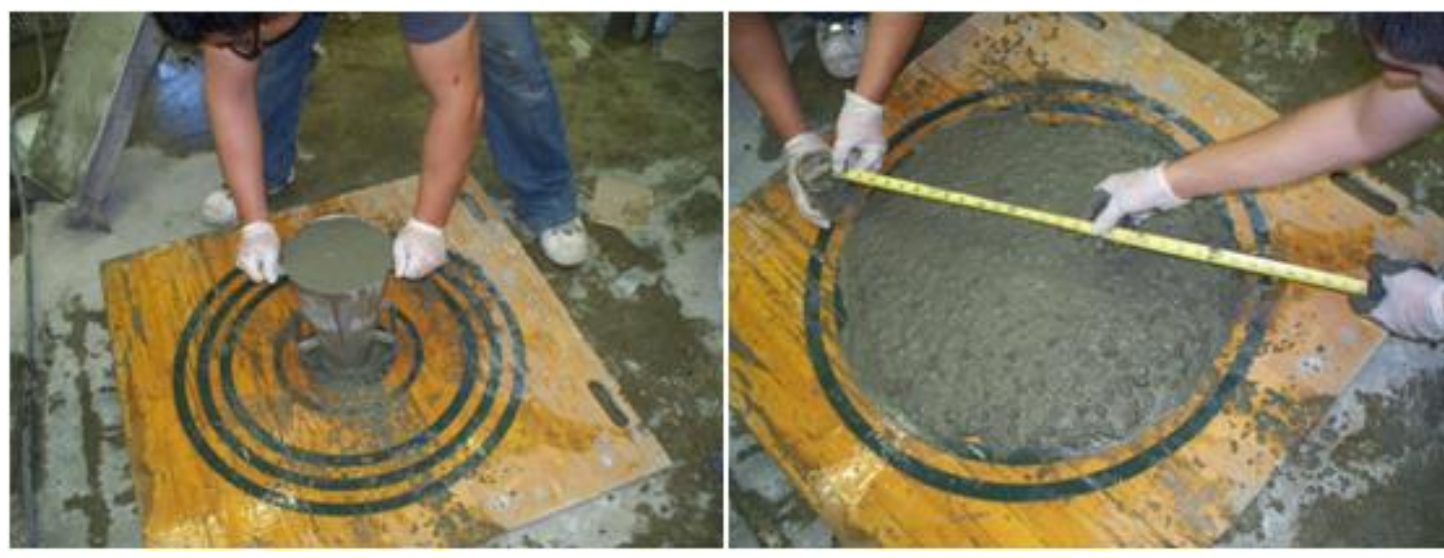

Figure 3.2 - SCC slump-flow test

(2) $T_{50}$ test

The $\mathrm{T}_{50}$ test is used to determine the SCC's viscosity, it was measured as the amount of total time it takes for concrete in the slump flow test to reach a diameter of 20 inch (or $50 \mathrm{~cm}$ ). The acceptable time it takes is baetween 2 and 7 seconds. For this casting, the T50 was measured as 3 seconds. This suggests the SCC had an acceptable viscosity and the concrete had a good flowability and workability.

(3) Visual Stability Index (VSI) 
As shown in Figure 3.3, the SCC showed slight bleeding around the edges and did not exhibit evidence of segregation, therefore the VSI was determined to be 1 for this batch based on ASTM C1611 criteria.

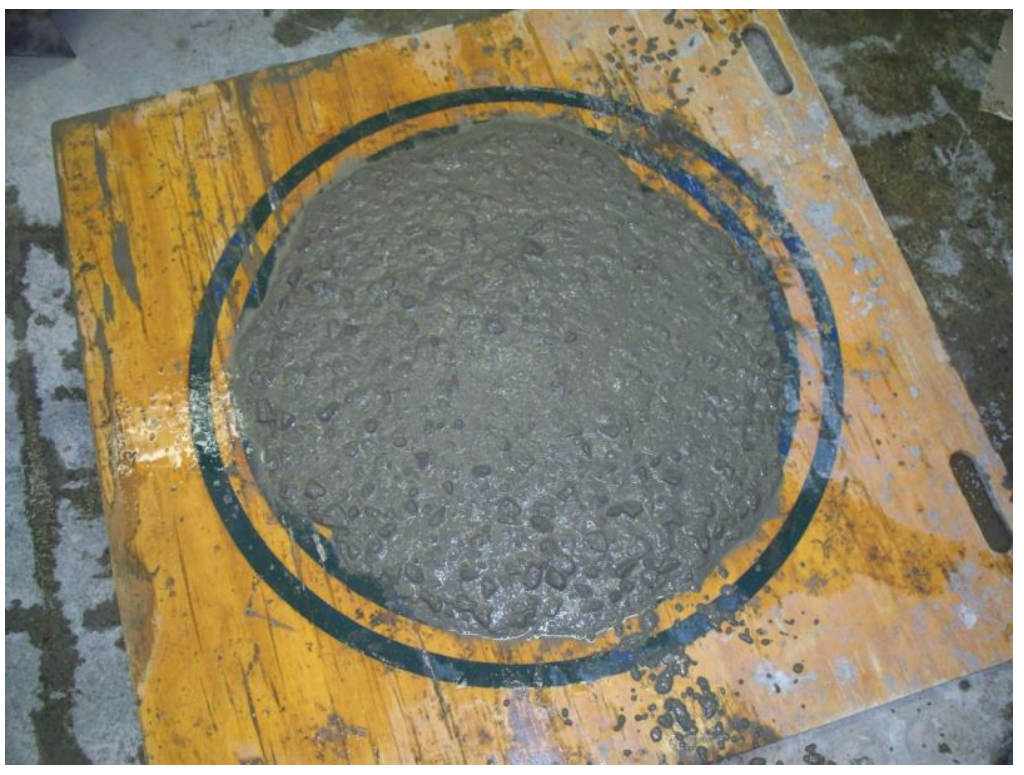

Figure 3.3 - SCC Visual Stability

(4) J-ring test

J-ring test is used to measure the passing ability of SCC and is determined by ASTM C1612. A steel J-ring was placed around the slump flow cone, then the same procedure was used as in the slump-flow test. The difference between slump flow and J-ring flow indicates the passing ability of SCC as shown in Table 3.2. The J-ring was measured to be 23.5 in for this mixing. The difference between slump flow and J-ring flow was 1.5 in, which means minimal to noticeable blocking.

Table 3.2 - Blocking assessment (ASTM C1612)

\begin{tabular}{cl}
\hline \multicolumn{1}{c}{ Difference Between } & \multicolumn{1}{c}{ Blocking Assessment } \\
\hline Slump Flow and J-Ring Flow & No visible blocking \\
\hline to $25 \mathrm{~mm}$ [0 to 1 in.] & Minimal to noticeable blocking \\
$>25$ to $50 \mathrm{~mm}$ [ $>1$ to 2 in.] & Noticeable to extreme blocking \\
\hline $50 \mathrm{~mm}[>2$ in.] & \\
\hline
\end{tabular}




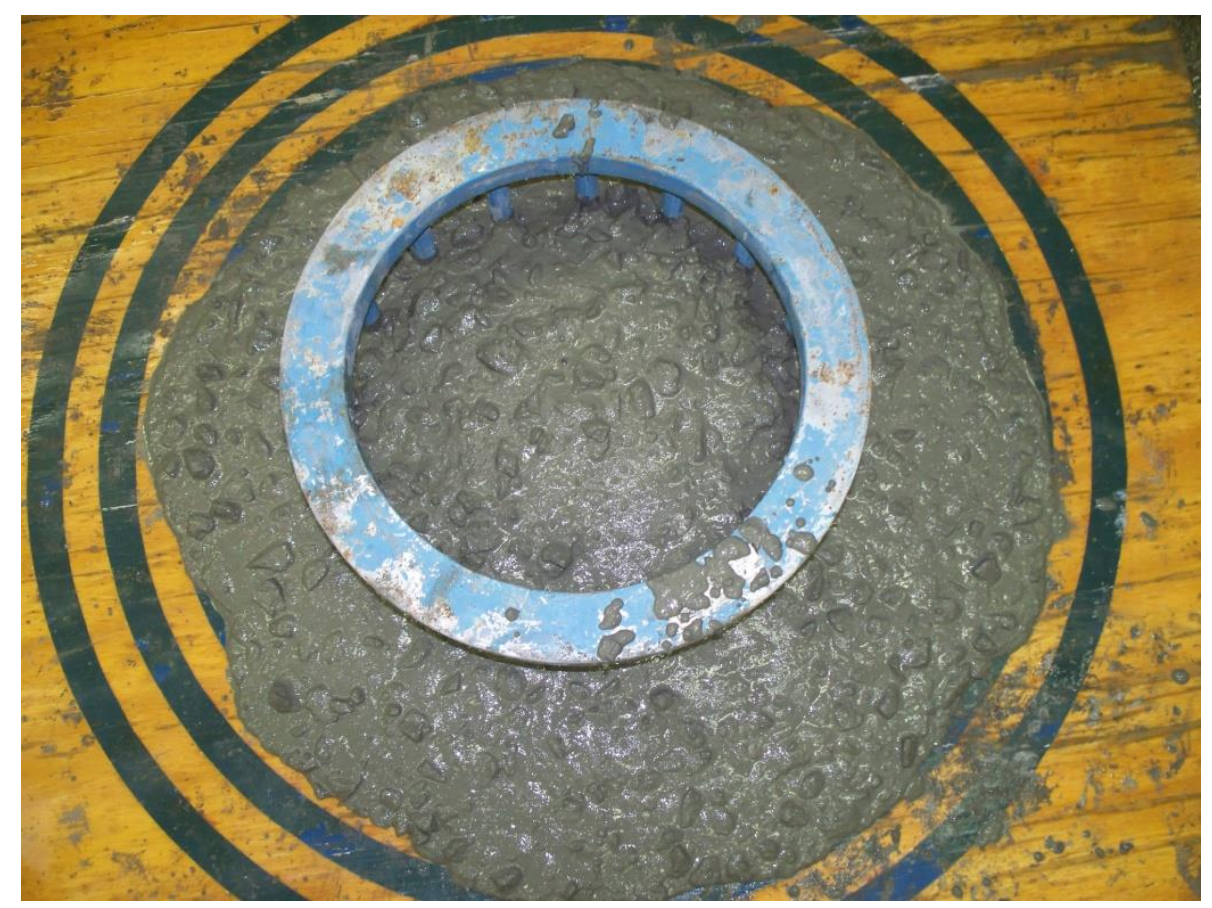

Figure 3.4 - SCC J-ring flow

(5) Air content in fresh SCC

The air content in concrete affects its compressive strength and freeze-thaw durability. The air content test was performed according to ASTM C231, Standard Test Method for Air content of Freshly Mixed Concrete by the Pressure Method, using an air meter. The air content of the fresh SCC was determined to be approximately 4\%, which is less than the air content of the SCC used in the Stalnaker Run bridge beam production (5.3\%).

(6) Rapid Static Segregation Resistance Test

Rapid static segregation resistance test is used to provide a rapid assessment of static segregation resistance of normal-weight SCC. Following ASTM C1712, a penetration apparatus was used as shown in Figure 3.5. This apparatus was placed on fresh concrete and released the set screw and lowered the hollow cylinder carefully to the surface of concrete. The initial reading when the hollow cylinder just touched the surface was taken and finial reading after $30 \pm 2 \mathrm{~s}$ and the depth it penetrated was calculated. The penetration depth indicates the degree of static segregation as shown in Table 3.3. For this casting, the penetration depth was 0.25 inches (6.35 $\mathrm{mm}$ ), the degree of static segregation resistance was determined to be resistant using Table 3.3. 


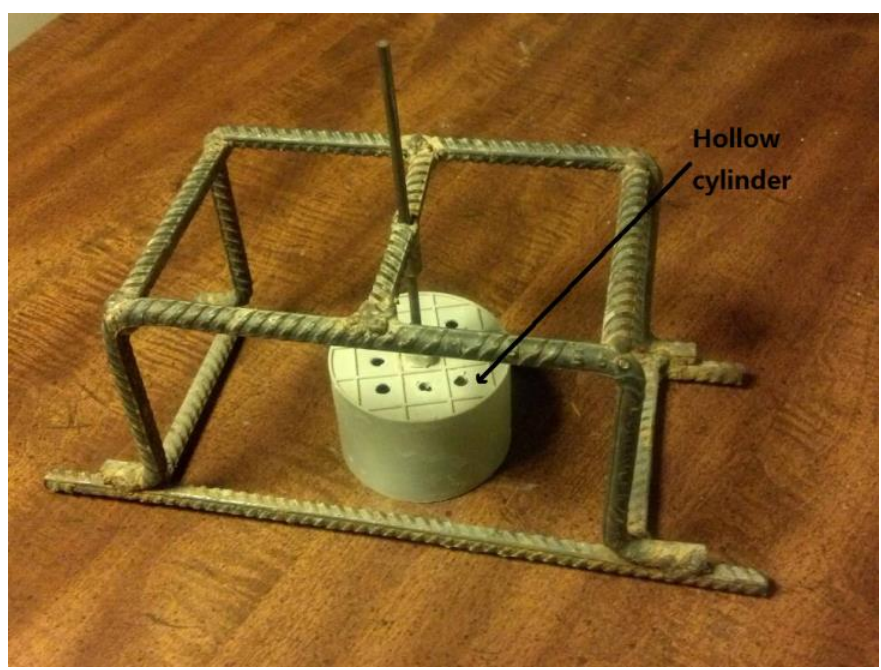

Figure 3.5 - Penetration apparatus

Table 3.3 - Degree of static segregation resistance (ASTM C1712)

\begin{tabular}{ll}
\hline Penetration depth $(P d)$ & $\begin{array}{l}\text { Degree of static segregation } \\
\text { resistance }\end{array}$ \\
$P d \leq 10 \mathrm{~mm}$ & Resistant \\
$10 \mathrm{~mm}<P d<25 \mathrm{~mm}$ & Moderately resistant \\
$P d \geq 25 \mathrm{~mm}$ & Not resistant \\
\hline
\end{tabular}

\subsubsection{SCC sample curing}

After the casting of the specimens, all the cylinders were covered with caps, and the freezethaw specimens were covered with wet burlap and a plastic tarp to prevent moisture loss. All the specimens were left to cure at room temperature for 6 hours.

Since the bridge beam and the original specimens taken during the beam production were steam cured, after the SCC had set for 6 hours, half of them were put into a high-temperature curing tank to simulate the high temperature steam curing used for the bridge beam. Two electric water heaters and a mechanical mixer were used to heat the water in the curing tank uniformly. One of the cylinders in the high-temperature tank had an embedded temperature sensor to record the temperature inside the cylinders. Figure 3.6 shows the temperature profile within the cylinders during the high temperature curing process. The temperature increased from room temperature to $160{ }^{\circ} \mathrm{F}$ in about 6 hours which is similar to the SCC test beam steam curing temperature profile (Figure 2.4) and then let it cool down by itself. Figure 3.6 shows the curing temperature profile 
comparison between the SCC test beam and the newly cast SCC at WVU laboratory. The other half of the SCC specimens were put into room-temperature curing tanks for a direct comparison with the high-temperature curing specimens.

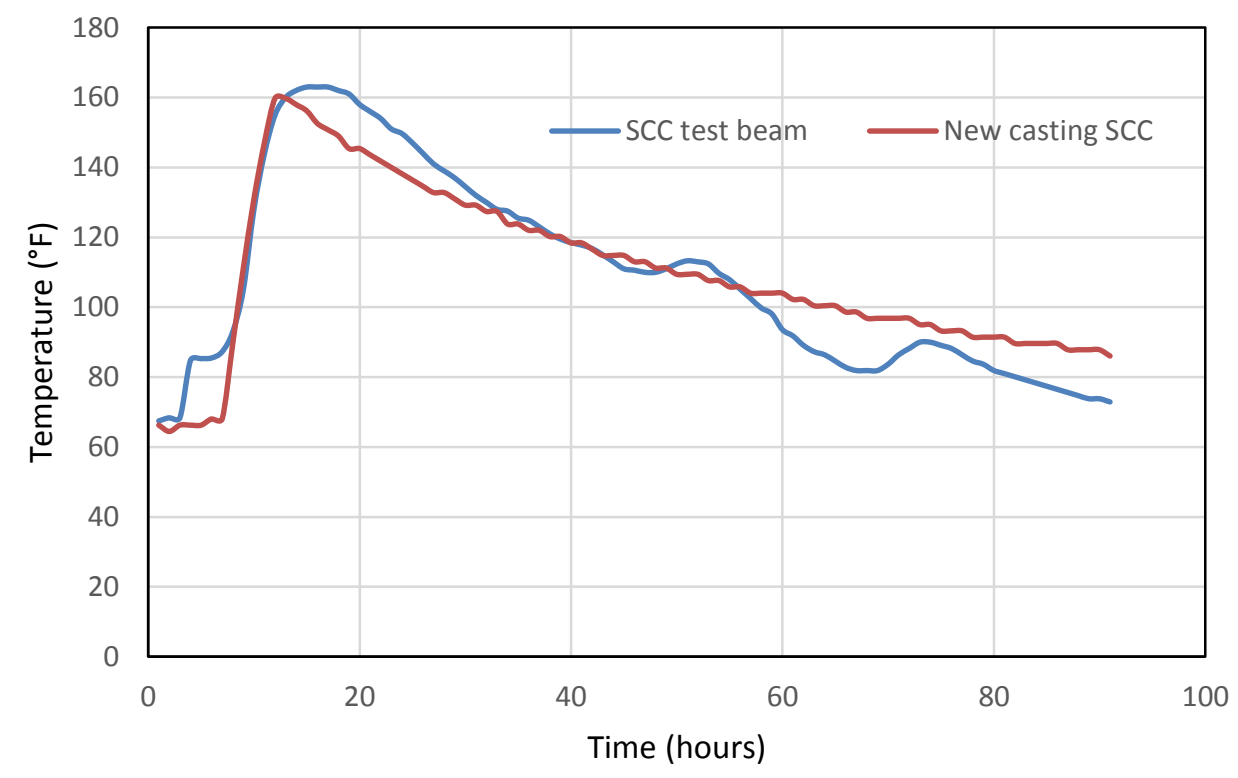

Figure 3.6 - SCC curing temperature profile

\subsection{SCC Beam Saw-Cutting}

In order to perform petrographic analysis, three sections were saw-cut on the full-scale test beam. One of the cutting positions was changed from the original proposed position ( $20 \mathrm{ft}$ from the end) to $16 \mathrm{ft}$ from the end because the mid-span of the beam (close to the $20 \mathrm{ft}$ section) contains many large cracks from the bending failure after the loading test. The saw cutting positions are shown in Figure 3.7.

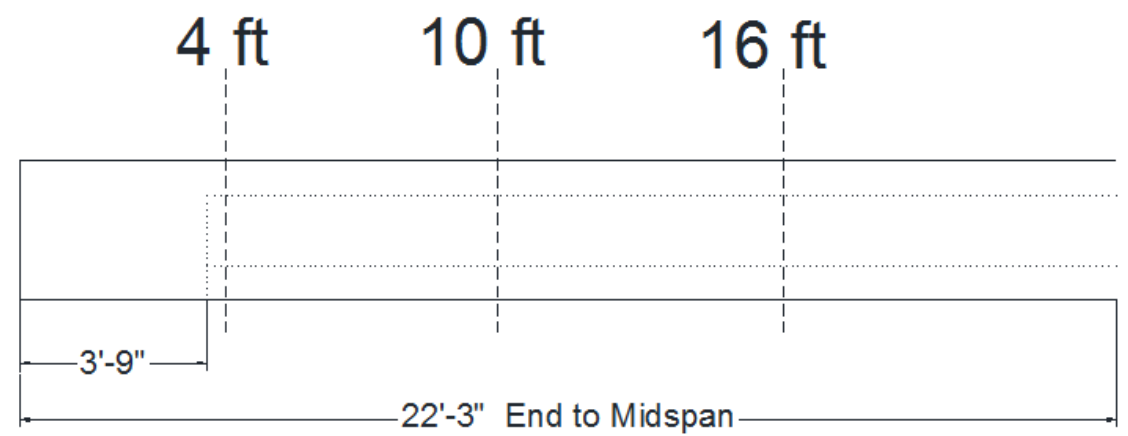

Figure 3.7 - Saw-Cutting position of the full-Scale Test Beam 


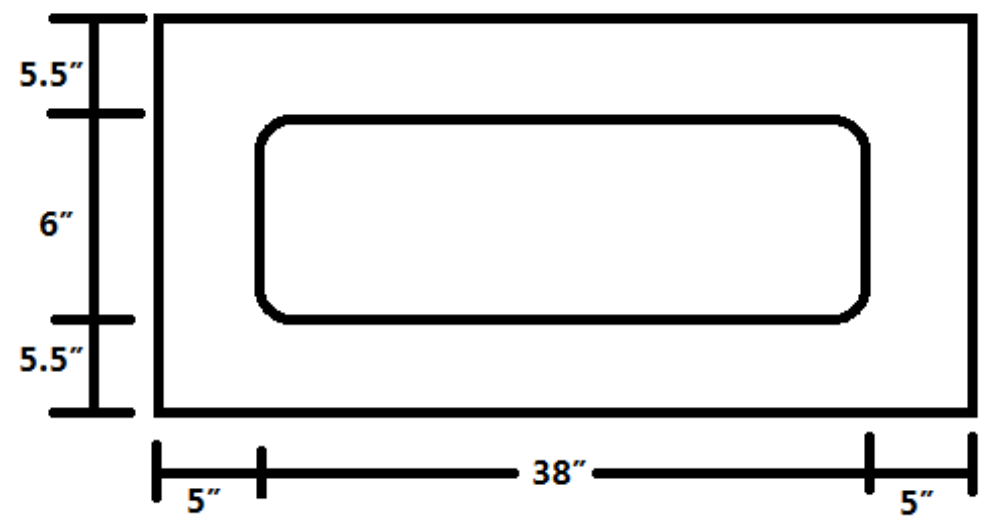

Figure 3.8 - Cross-Section Detailing of the Box Beam

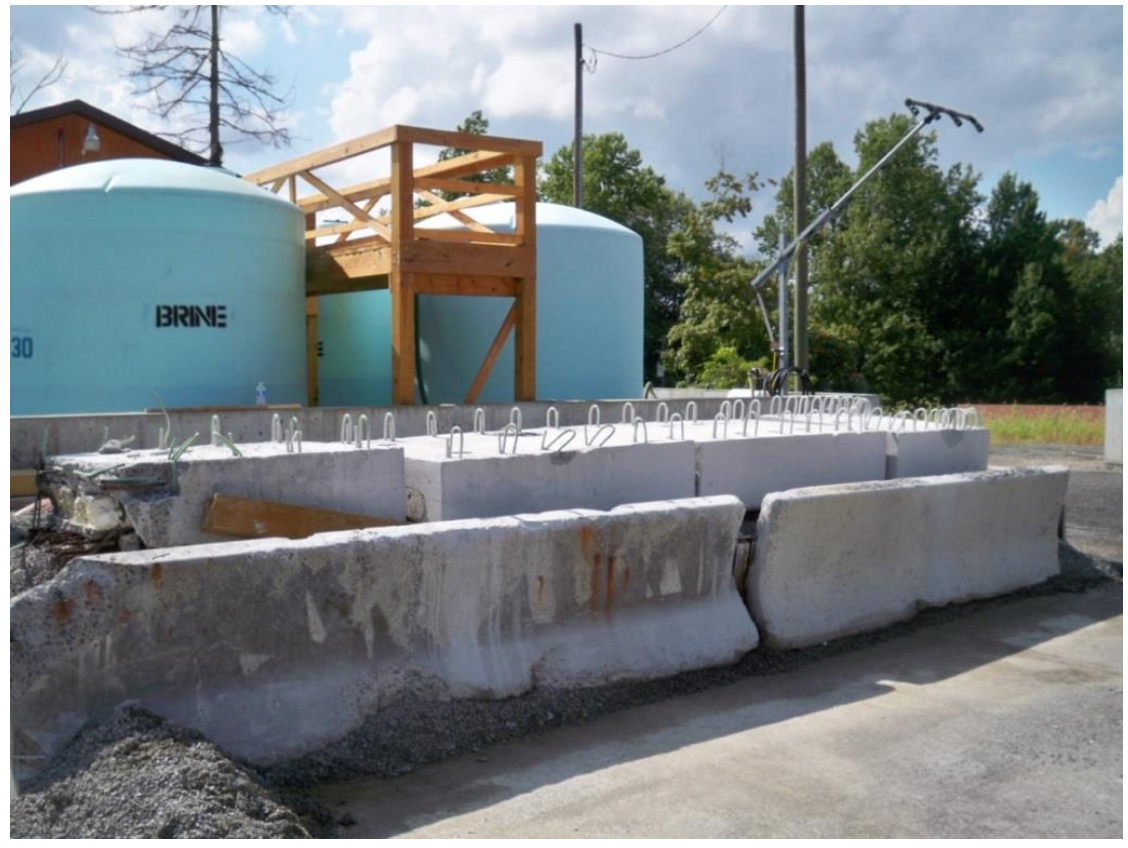

Figure 3.9 - SCC Full-Scale Beam after Three Cuts

\subsection{Polishing of the Cutting Surfaces}

The cutting surfaces needed to be polished in order to see the aggregate distribution, filling and passing characteristics, aggregate segregation, and bond condition. The polishing process has two steps: the first step was to grind the surface roughly; the second step was to use a hand polisher with different polish papers to polish the surface to make the surface smooth such that the aggregates and cement paste can be distinguished clearly. The larger ridges were removed using the grinding wheel. Figure 3.10 shows a section after grinding. 


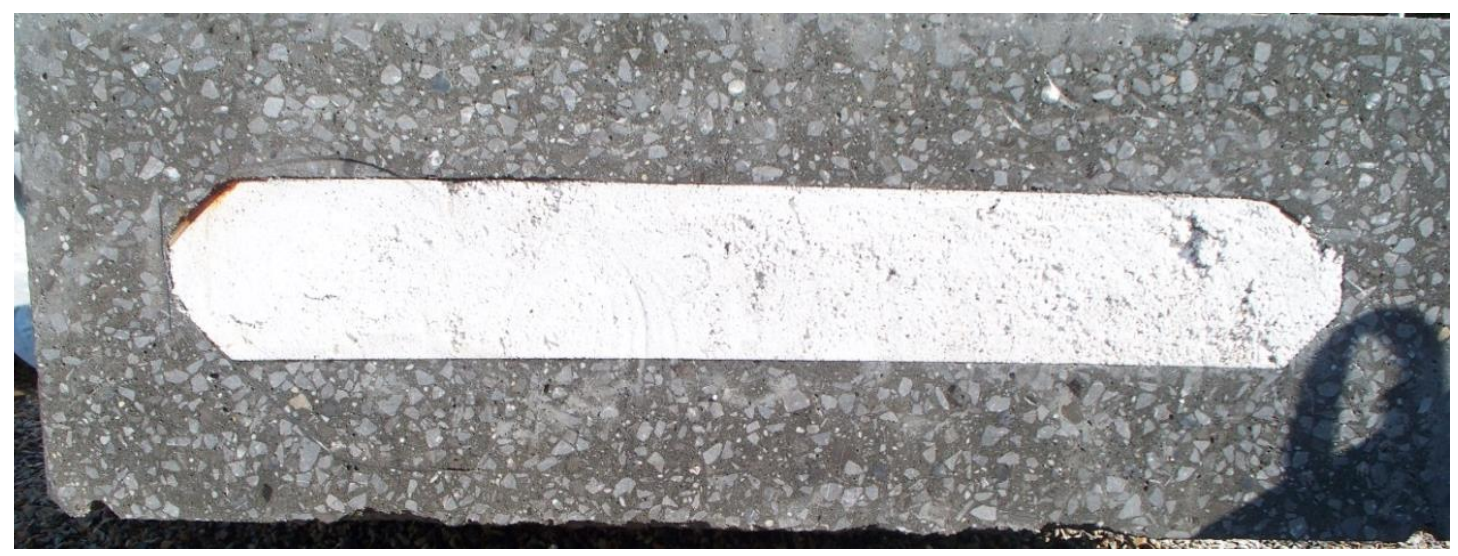

Figure 3.10 - Cutting surface after grinding

The surface was then hand polished using a wet-polisher, the dust caused by polishing process was removed by water. The polisher has different polishing pads, the polishing pads used for the polishing, in sequence, had grits of 50, 100, 200, 400, and 800. Although the polisher can use 1500 grit pad, it was determined that 800 was adequate for the aggregate analysis, so a maximum grit of 800 was used for the polishing. Figure 3.11 shows the section after polishing. From this picture, we can visually generate a preliminary estimation of the SCC's filling, passing and segregation situation. However, a more accurate inspection will be conducted following the polishing of the beam using computer image analysis. Figure 3.12 shows the surface before and after polishing. Figure 3.12 shows the surface area around the tendons.

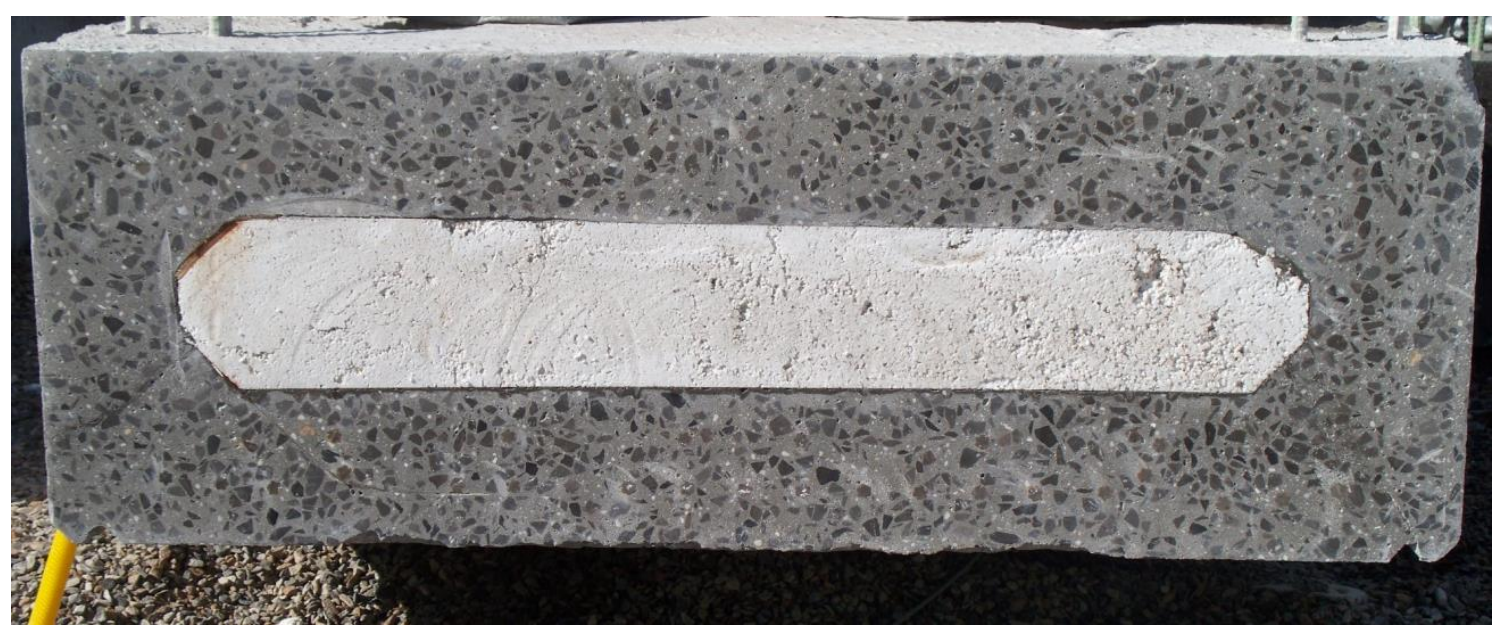

Figure 3.11 - Cutting surface after polishing 

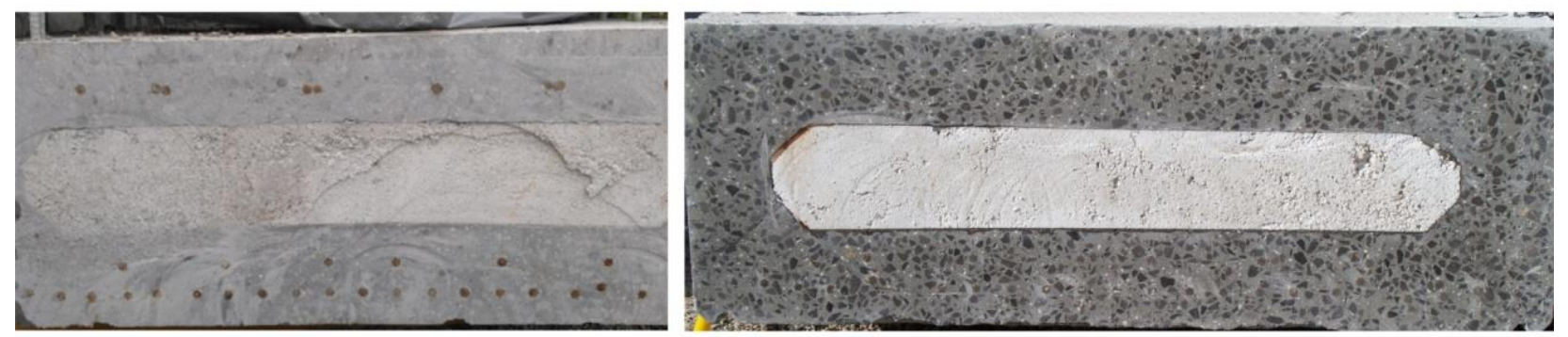

Figure 3.12 - Cutting surface before (left) and after (right) polishing

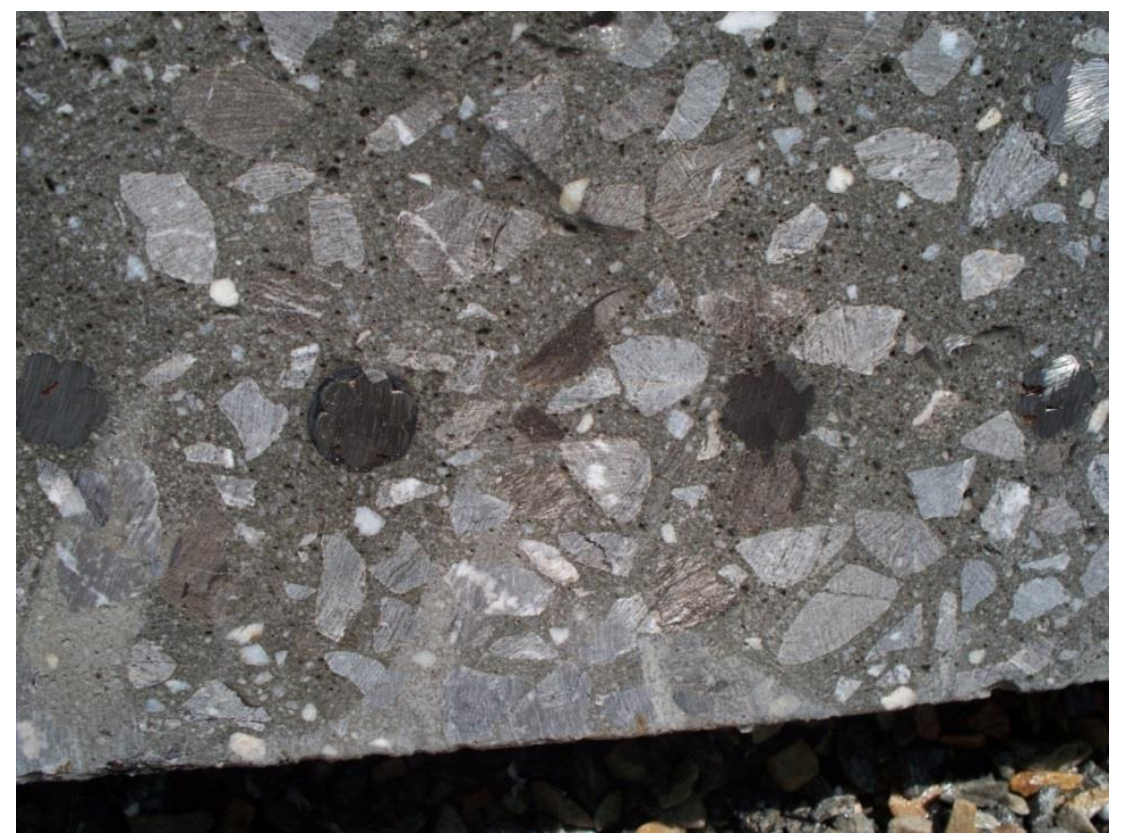

Figure 3.13 - SCC filling around tendons

\subsection{Cores from SCC Beam}

For aggregate and air void analysis of the SCC beam, several specimens were cored from the beam. Figure 3.14 shows the location of eight core specimens taken from the top surface of the SCC beam. Picture of these specimens are shown in Figure 3.15. 


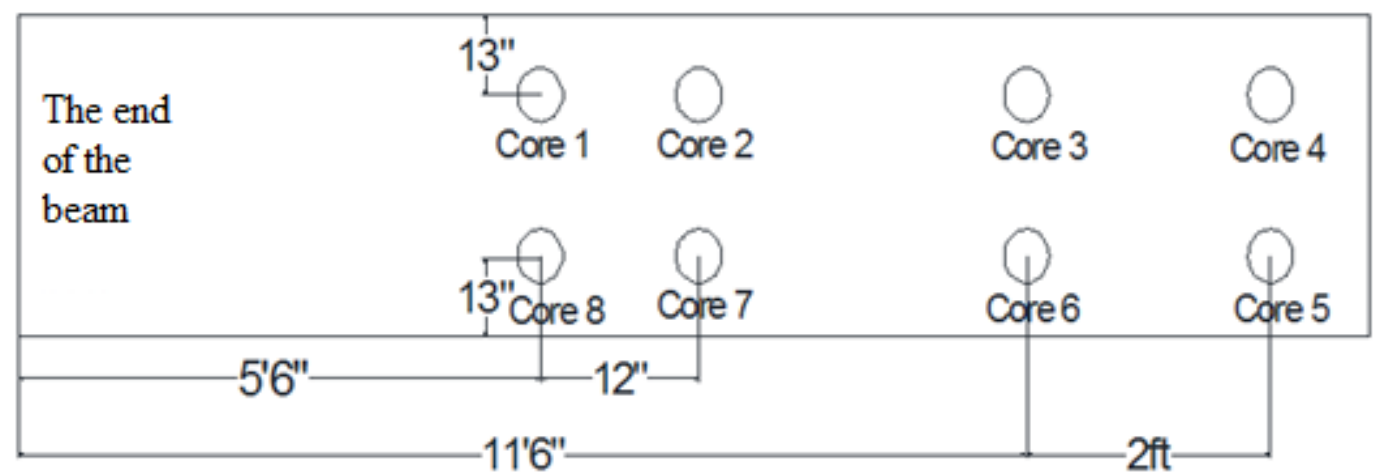

Figure 3.14 - Location of the cores viewing from top surface of the SCC beam

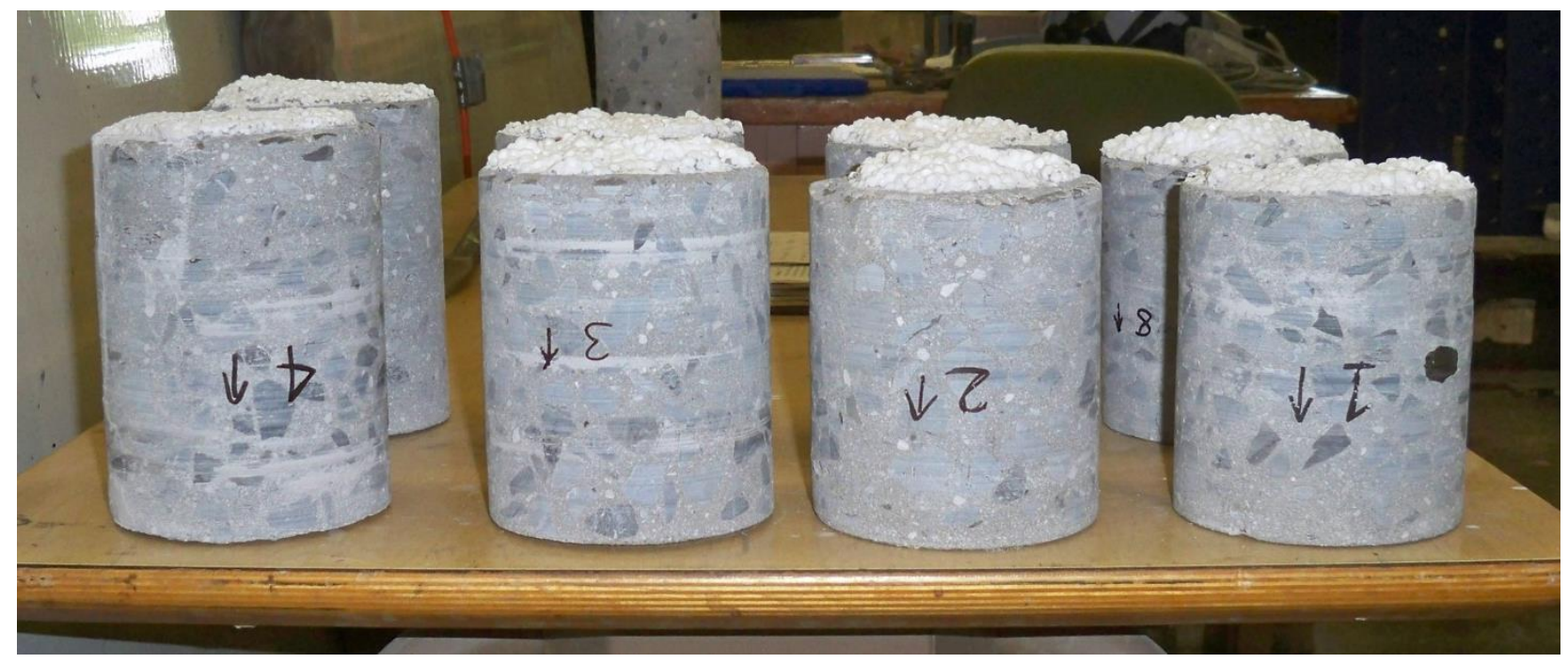

Figure 3.15 - Core specimens taken from the SCC beam

In addition, 4 core specimens were taken at $2.75 \mathrm{ft}$ and $3.5 \mathrm{ft}$ from the end of the beam for freeze-thaw testing (Figure 3.16). Three of them are 11 inches long and one of them is 9 inches long. Also, 6 core specimens were taken for RCPT. All the core specimens are 4 inches in diameter. All of the specimens taken from the beam were cured in lime-saturated water at normal temperature before testing. 


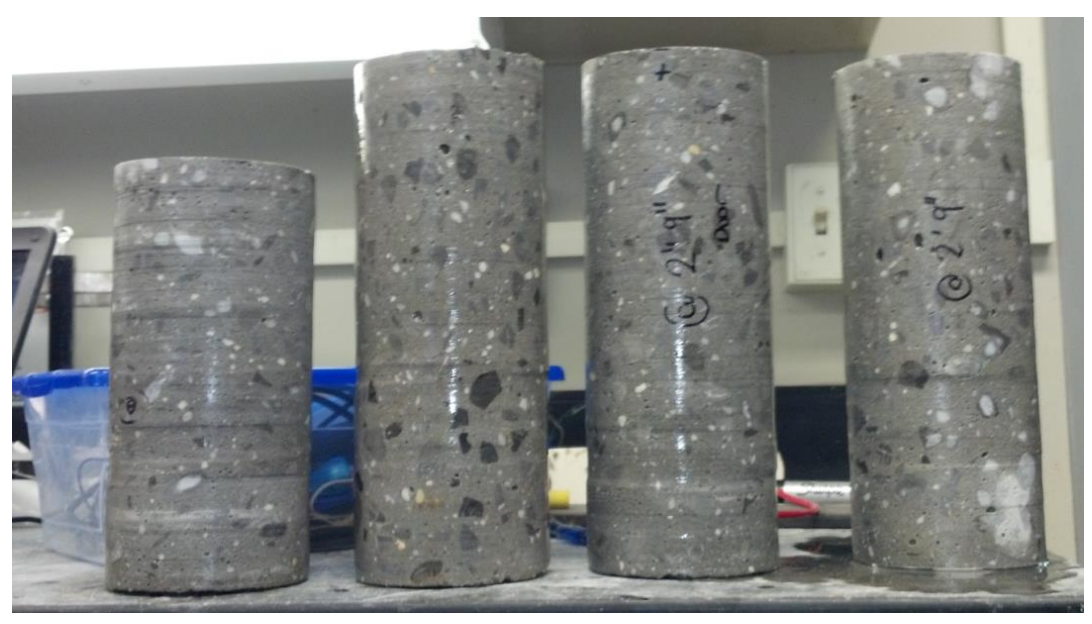

Figure 3.16 - Core Specimens used for freeze-thaw test

\subsection{Coarse aggregate analysis}

\subsubsection{Specimen preparation}

For the purpose of assessing the uniformity of aggregate distribution, these samples taken from the beam were first cut longitudinally using a diamond edged saw, and then the surfaces were prepared using the polish machine (Figure 3.17). The polishing pads used in this process have grits of $80,220,600$ and 1200 . Through this polishing process, the surface became smooth and glossy making it is easy to distinguish between paste and aggregates.

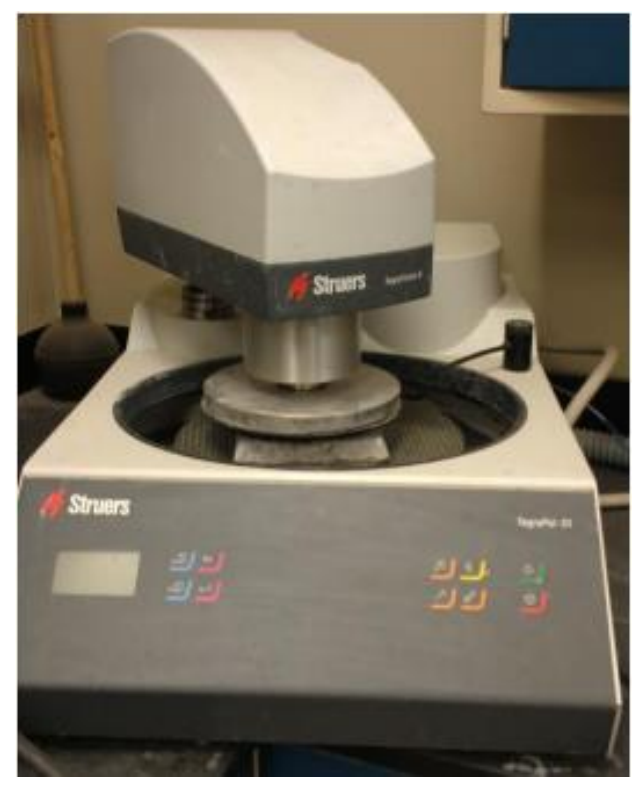

Figure 3.17 - Concrete Polisher 
After the polishing procedure, the surface of each section was cleaned with water and using compressed air to remove the powder by polishing in the air voids. After the preparation of the specimens, the surface of each section was scanned to create a high-resolution image using a flatbed scanner. The difference of the surface, before and after polishing, can be seen in Figure 3.18 .
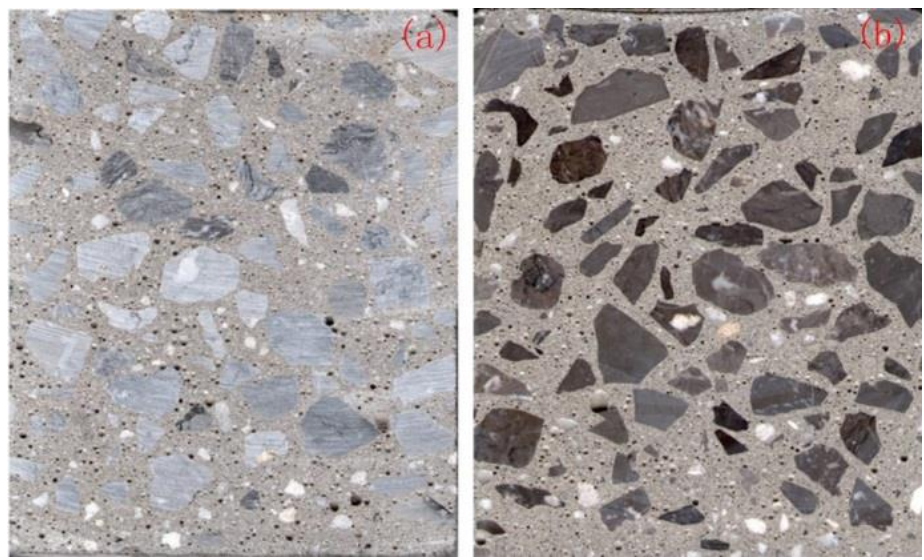

Figure 3.18 - Images of hardened specimen. (a) Before polishing; (b) After polishing

\subsubsection{Coarse aggregate percentage analysis}

A computer software called JMicroVision was used to quantify the percent of coarse aggregate and its distribution on the cross sectional surface of the sample. Before the analysis, one needs to define the boundaries of the analysis area because sometimes the edges of the surface were not polished adequately which could not be identified by the program. Defining the boundaries could avoid the rough unfinished edges of the samples. The program could separate the objects based on the colors and sizes. The thresholds can be adjusted easily to distinguish the paste and aggregates using the program. The coarse aggregate area percentage was determined for each of the cores samples.

\subsubsection{Air void analysis}

After performing the aggregate analysis, the polished surface was painted with black ink using permanent marker, and white Barium Sulfate powder was used to fill all voids after the ink was completely dry. The white powder was tamped into the voids using a rubber stopper and the 
excess powder was wiped from the surface. To ensure all the voids were filled completely, an USB microscope was used to check the void filling condition on the surface as shown in Figure 3.19.
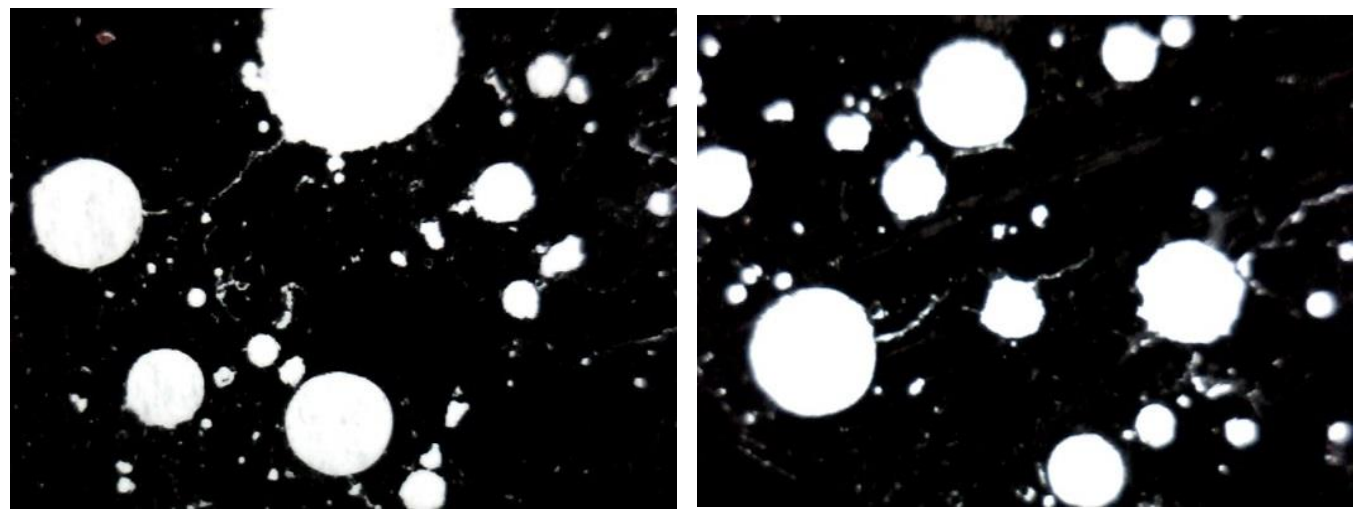

Figure 3.19 - Black-colored surface with white-filled voids (taken using USB microscope)

After the preparation, the surface was scanned into a TIF image file at a resolution of 3200 dpi in 8-bit grayscale mode using an EPSON STYLUS NX110 flatbed scanner. The scan was performed in a dark room. The automatic air void analysis was performed using the Bubble counter program. ASTM C457 provides the equations to calculate the air system parameters. Bubblecounter uses linear traverse method. Bubblecounter is a script which works in Adobe Photoshop. Before running the air-void system, the threshold was defined by the "Set White Balance" function, and the traverses and the aggregate percentage obtained from coarse aggregate analysis was entered. Once air void analysis was finished, the parameter of the air void system was output to a CSV file.

\subsubsection{Freeze-thaw testing}

The freeze thaw test follows ASTM C666 procedure A, Rapid Freezing and Thawing in Water. In total, six 3"x4"x16" prisms, four 3"x 3"x 11.25" shrinkage prisms from newly cast SCC and four 4-in diameter cores taken from the SCC beam. These samples were put into freeze-thaw machine with container 14 days after the new casting, all the specimens were cured in limesaturated water.

The freezing and thawing cycle for the test consist lowering the temperature of specimens from 4 to $-18{ }^{\circ} \mathrm{C}\left[ \pm 2{ }^{\circ} \mathrm{C}\right]$ and raising it from -18 to $4{ }^{\circ} \mathrm{C}$. One freeze thaw prism with thermocouple inside was used to measure the temperature inside the specimen during freeze-thaw, and the 
temperature control was adjusted according to the measured temperature. Figure 3.20 shows the measured temperature inside the concrete specimen and the temperature in the freeze-thaw chamber.

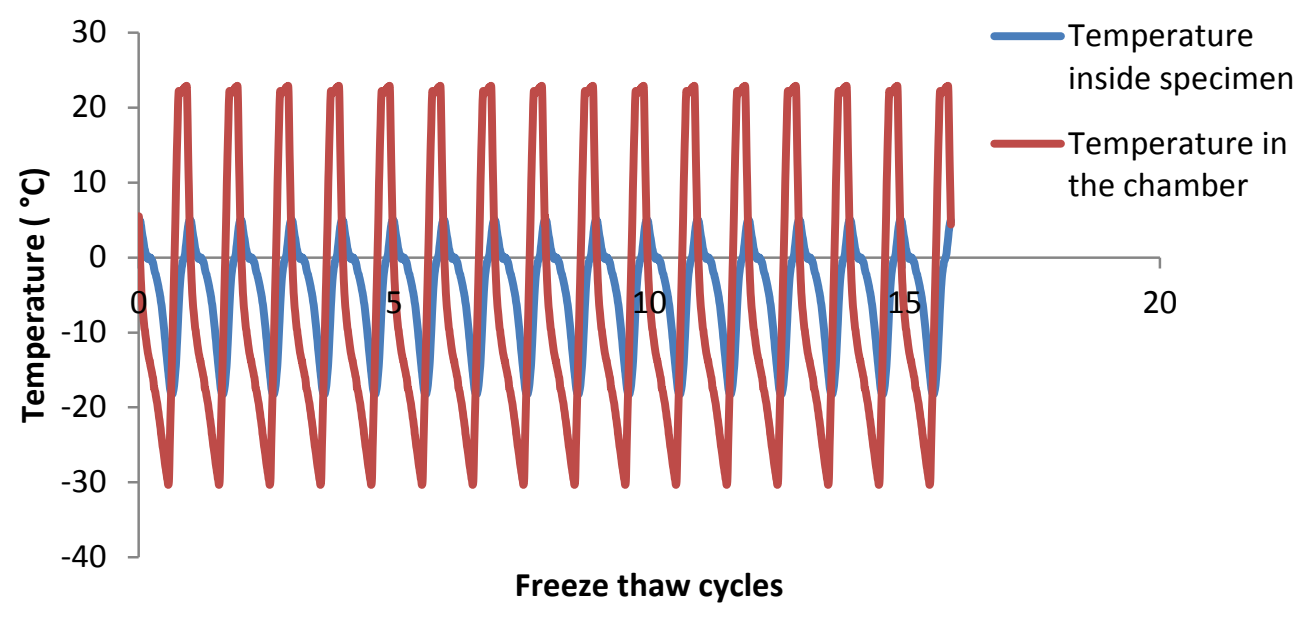

Figure 3.20 - Temperature in concrete specimens and the freeze-thaw chamber

The frequency test was followed ASTM C215 Standard Test Method for Fundamental Transverse, Longitudinal, and Torsional Resonant Frequencies of concrete Specimens. The first method for the freeze thaw specimens is the impact resonance test. An accelerometer was places at the end of the specimen. A hammer was used to strike the center of the specimen. National Instruments data acquisition system (Figure 3.21) was used to record accelerometer response with a typical time history shown in Figure 3.22. 


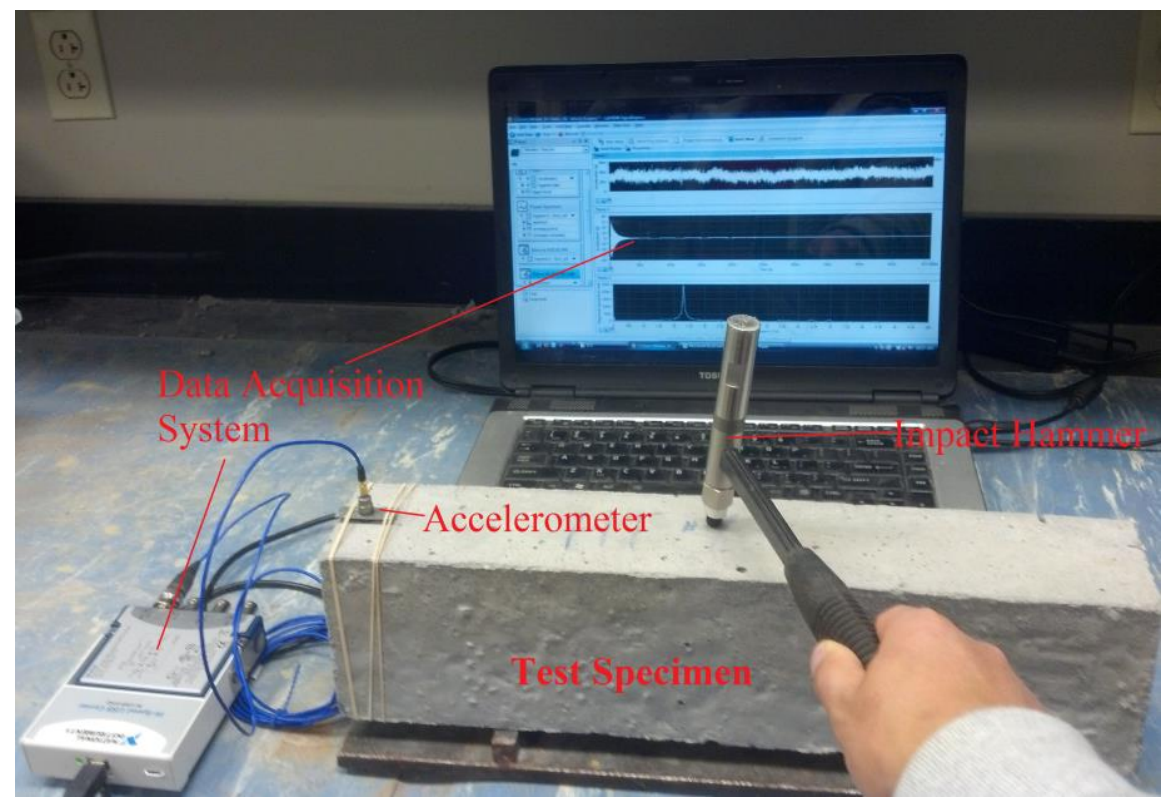

Figure 3.21 - Test setup for measurement of fundamental transverse frequencies of freeze-thaw specimen

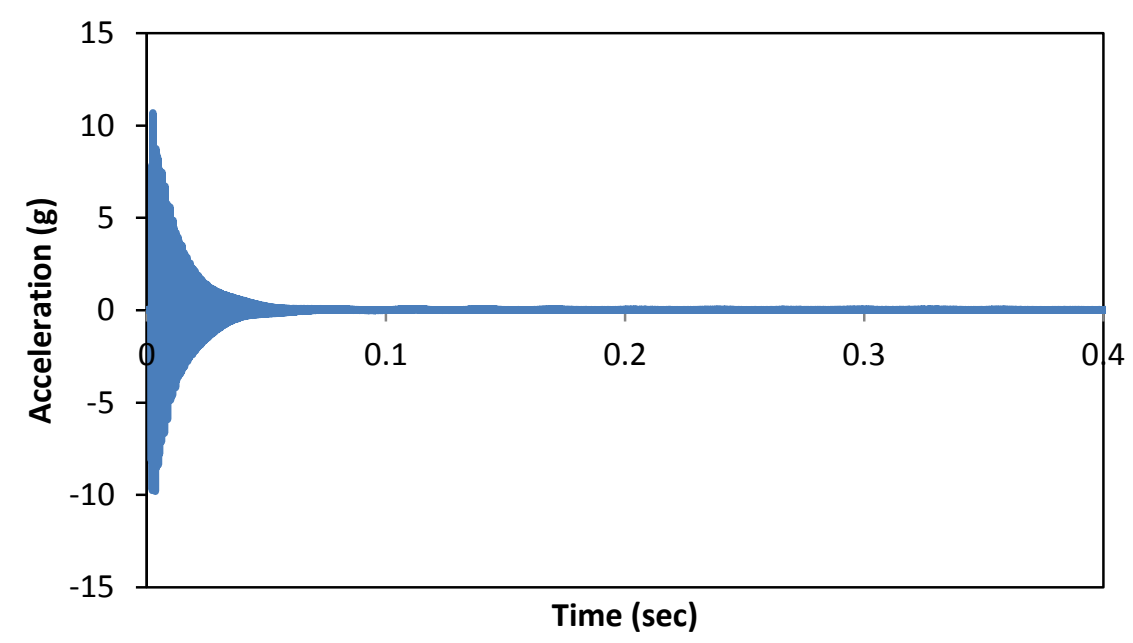

Figure 3.22 - Accelerometer response measured using LabVIEW

Once the accelerometion verse time data was recorded, the time domain can be converted to frequency domain as shown in Figure 3.23 by LabVIEW using fast Fourier transform. 


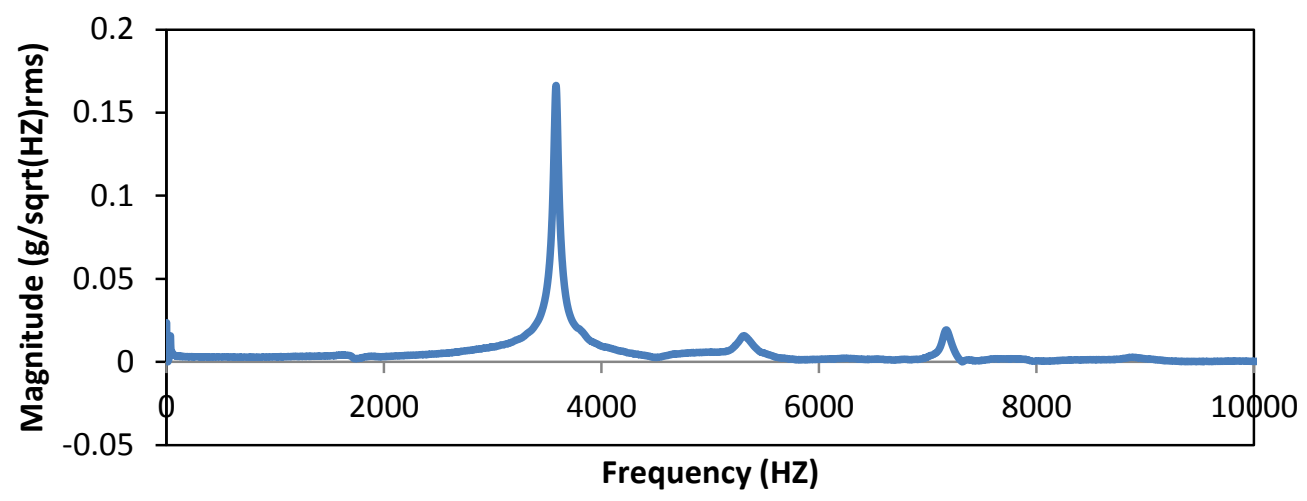

Figure 3.23 - Frequency domain of the acceleration after fast Fourier transform

Another method used is the forced longitudinal resonance test (Figure 3.24). This method was used to confirm the transverse impact resonance test result. A driver is placed at the end of the prism connected to the machine with adjustable frequency and pick-up is placed at the other end. Both the driver and pick-up are connected to an oscilloscope with indicator. By adjusting the driver's frequency, when the indicator gets the maximum reading, the driving frequency shown at that time is the resonant frequency of the specimen.

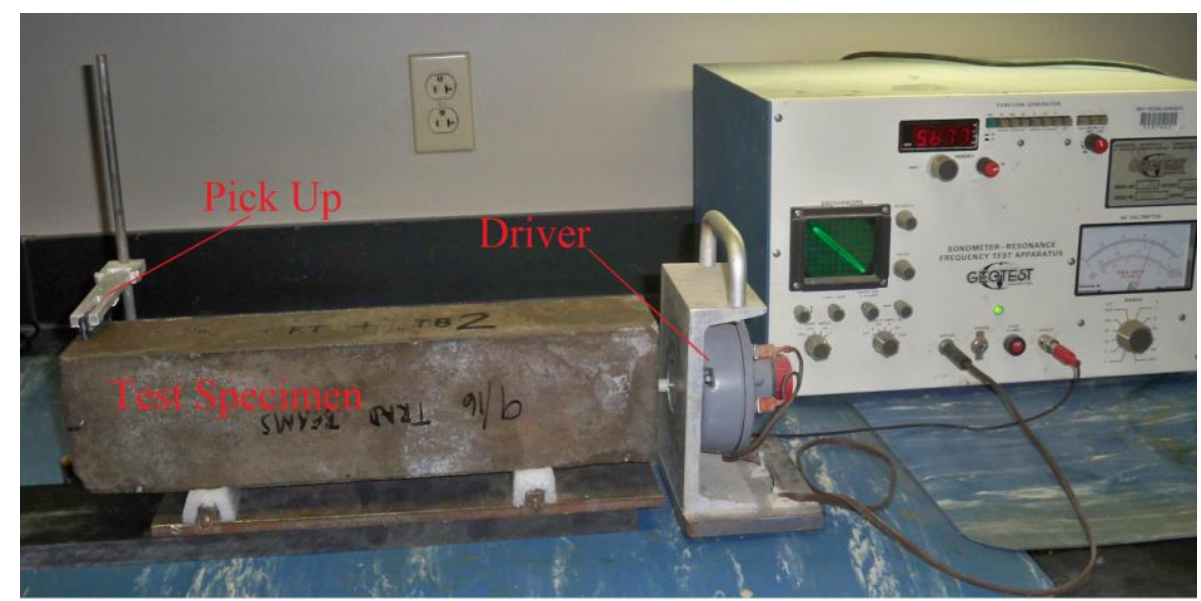

Figure 3.24 - Test setup for measurement of fundamental longitudinal frequencies of freeze-thaw specimen (Sweet, 2014)

During the freeze-thaw testing, the length change of the shrinkage prisms was also tested using a length comparator following ASTM C 666. ASTM C 666 states that 0.10\% expansion may 
be used to mark the end of the freeze-thaw cycle using the optional length change test. Length change of the specimens can be obtained by the following equations:

$$
L_{c}=\frac{\left(l_{2}-l_{1}\right)}{L_{g}} \times 100
$$

where:

$L_{\mathrm{c}}=$ length change of the specimens after C cycles, \%

$l_{1}=$ length comparator reading at 0 cycles,

$l_{2}=$ length comparator reading at $\mathrm{C}$ cycles, and

$L_{\mathrm{g}}=$ gage length between the innermost ends of the gage studs.

After each frequency and length change test, all the specimens were put back into the freeze thaw machine for the next 30 freeze-thaw cycles.

\subsubsection{RCPT (Rapid chloride penetration test)}

The cylinder specimens were cut into 2 inch thickness disc (4-in diameter) specimens. There are two specimens from high temperature curing and two specimens from normal temperature curing from the newly cast SCC specimens, and a total of seven specimens from the SCC test beam were prepared for the RCPT. The circumferential surfaces were coated with water and salt resistant epoxy seal. The specimens were put into vacuum container with pressure pump, and keep the vacuum pressure less than $50 \mathrm{~mm} \mathrm{Hg}$ for 3 hours, then open water stopcock and drain de-aerated water into container to cover the specimens with vacuum pump still running to maintain the pressure. After the water stopcock was closed, the vacuum pump was kept running for another hour. The specimens were soaked under water for $18 \pm 2$ hours with vacuum line stopcock closed. 


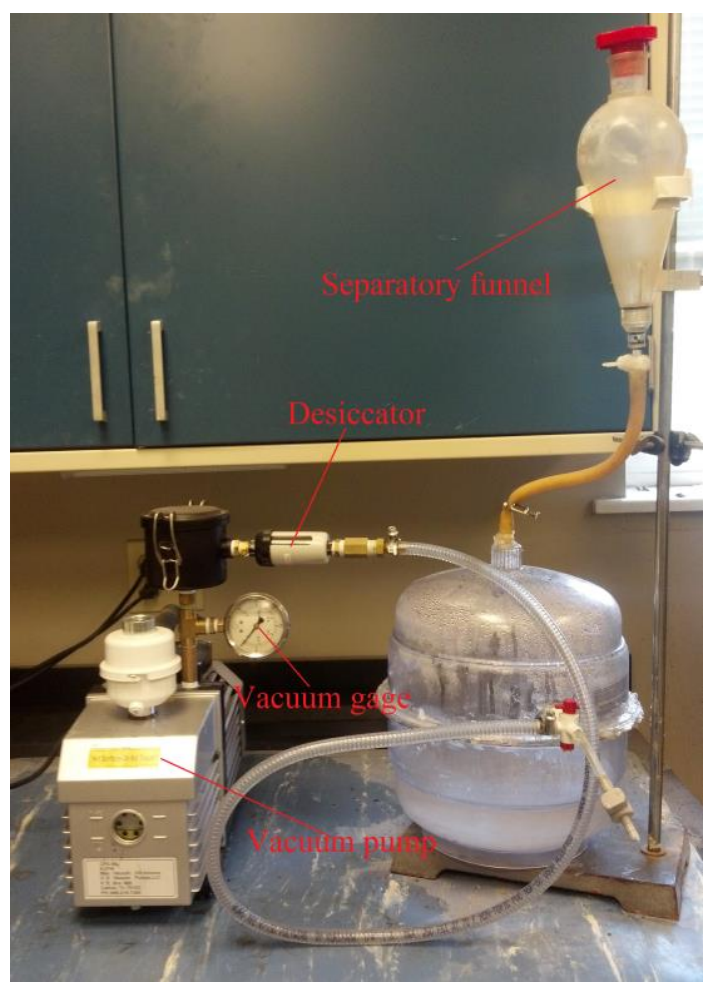

Figure 3.25 - Vacuum saturation apparatus

After the preparation of the specimens, the specimens were put into applied voltage cells and sealed with silicon. One end of the cell filled with $3.0 \%$ sodium chloride solution by mass in distilled water was connected to the negative pole of 60 Volt DC power supply and another end filled with $0.3 \mathrm{~N}$ sodium hydroxide solution in distilled water was connected to the positive pole of the $60 \mathrm{~V}$ power supply.

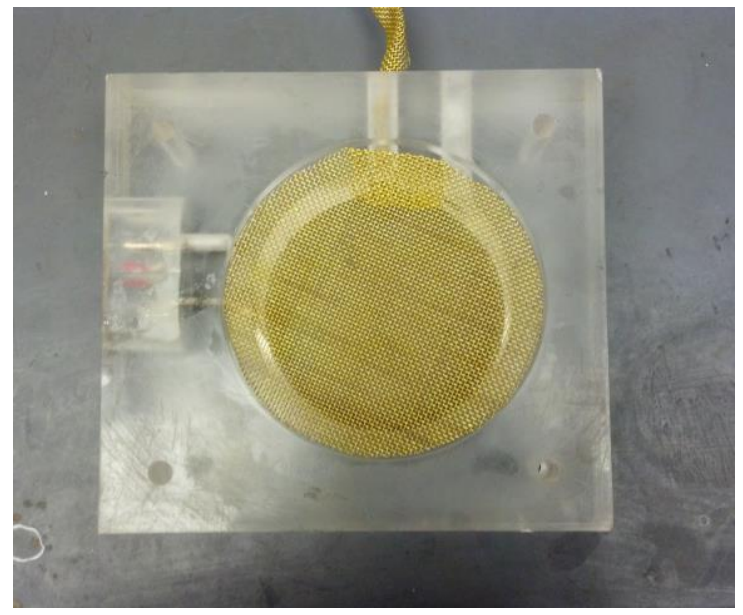

Figure 3.26 - Applied voltage cell-face view 


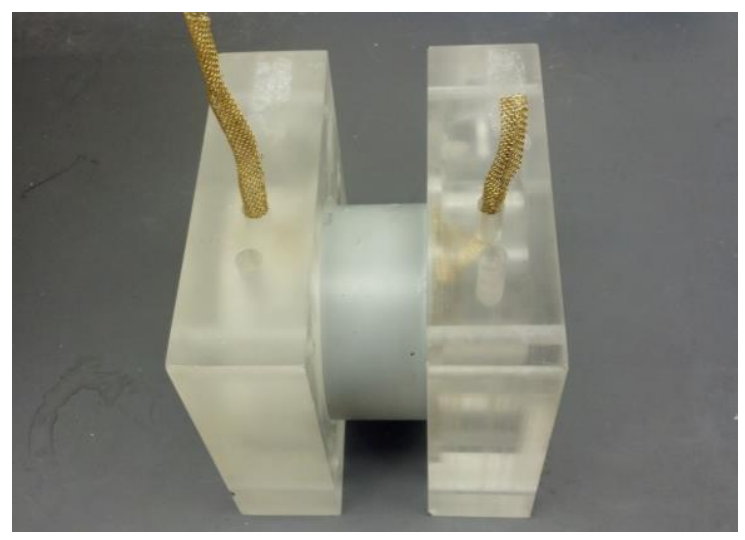

Figure 3.27 - Specimen ready for test

The test lasts for 6 hours. The electric current was recorded at 30 minutes interval and the following equation was used to obtain the total coulomb value.

$$
Q=900\left(I_{0}+2 I_{30}+2 I_{60}+\ldots .+2 I_{300}+2 I_{330}+2 I_{360}\right)
$$

where: $Q$ is coulombs,

$I_{0}$ is current after power is applied,

$I_{\mathrm{t}}$ is current at $\mathrm{t}$ minutes after voltage is applied.

The equipment used to perform the testing is shown in Figure 3.28.

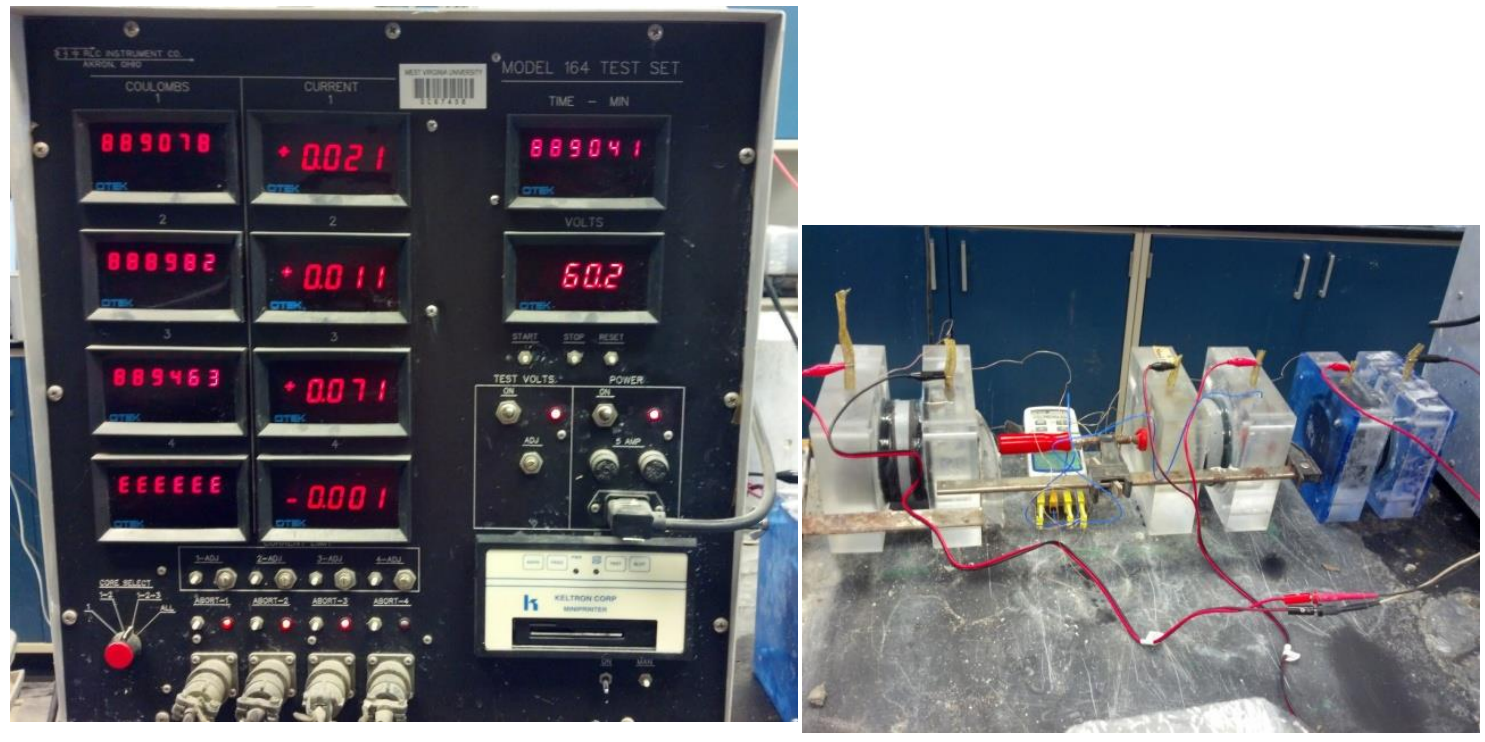

Figure 3.28 - Rapid chloride penetration test equipment 


\section{CHAPTER 4 EXPERIMENTAL RESULTS AND DISCUSSION}

\subsection{Coarse aggregate distribution analysis results}

\subsubsection{Coarse aggregate distribution in the core specimens from the SCC test beam}

All the cores used for aggregate distribution analysis were taken from the top section of the SCC test beam. Each core has a constant 4" diameter but with varying heights as shown in Figure 4.1. All the cores were cut vertically into two parts. The cutting surfaces were grinded and then polished using different polishing papers. Each core surface was divided into two equal parts (top and bottom area) to investigate the coarse aggregate distribution at different heights of the core samples. After the preparation of the cutting surfaces, JMicroVision program was used to process the digital images of the polished surface to determine the coarse aggregate distribution. The comparisons of the total percentage and the difference between top and bottom area of the coarse aggregates of the eight samples are shown in Table 4.1.

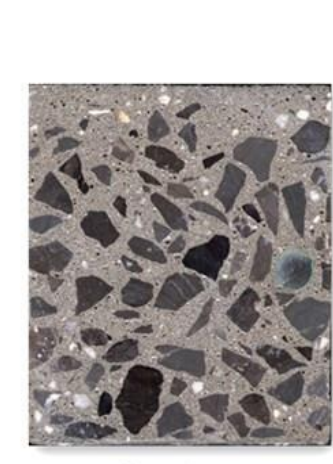

Core 1

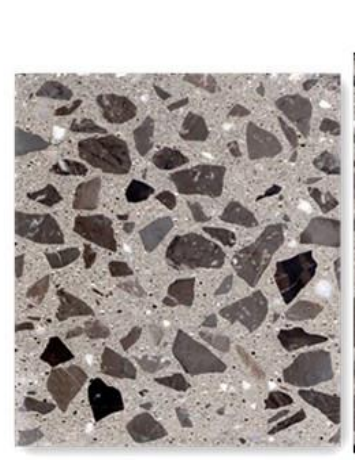

Core 8

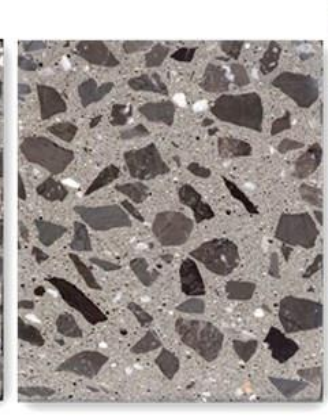

Core 2

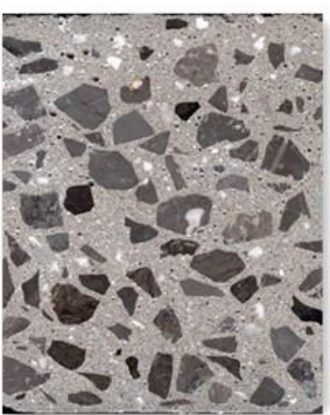

Core 7

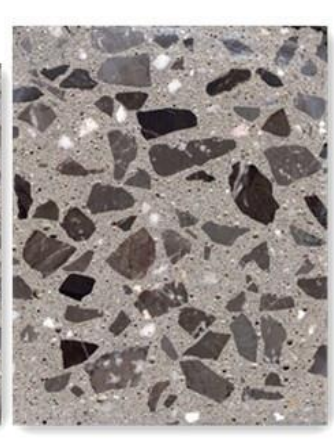

Core 3

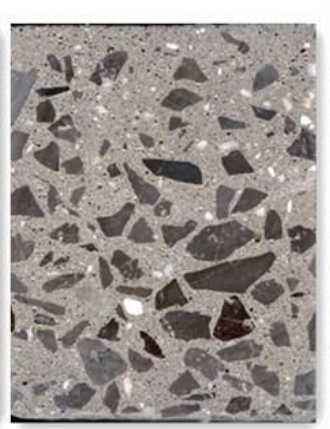

Core 6

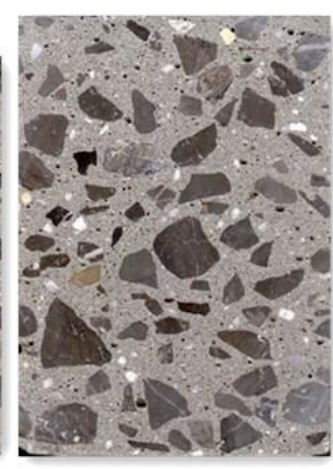

Core 4

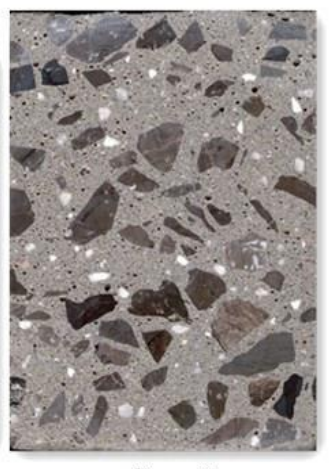

Core 5

Figure 4.1 - Polished surfaces of the concrete cores taken from the SCC beam 
Table 4.1 - Coarse aggregate percentage of cores taken from the SCC beam

\begin{tabular}{|c|c|c|c|c|c|c|c|c|c|}
\hline & core1 & core2 & core3 & core4 & core5 & core6 & core7 & core8 & Average \\
\hline $\begin{array}{c}\text { Coarse } \\
\text { aggregate \% by } \\
\text { total area }\end{array}$ & $37.82 \%$ & $34.94 \%$ & $34.63 \%$ & $34.14 \%$ & $29.64 \%$ & $32.18 \%$ & $34.45 \%$ & $37.37 \%$ & $34.26 \%$ \\
\hline $\begin{array}{c}\text { Coarse } \\
\text { aggregate \% } \\
\text { by top area }\end{array}$ & $32.10 \%$ & $33.15 \%$ & $34.45 \%$ & $29.97 \%$ & $27.43 \%$ & $23.76 \%$ & $32.65 \%$ & $33.41 \%$ & $30.71 \%$ \\
\hline $\begin{array}{c}\text { Coarse } \\
\text { aggregate \% by } \\
\text { bottom area }\end{array}$ & $41.29 \%$ & $36.24 \%$ & $35.20 \%$ & $38.61 \%$ & $32.02 \%$ & $40.83 \%$ & $35.93 \%$ & $41.23 \%$ & $37.79 \%$ \\
\hline $\begin{array}{c}\text { Difference } \\
\text { between top } \\
\text { and bottom }\end{array}$ & $9.19 \%$ & $3.09 \%$ & $0.75 \%$ & $8.64 \%$ & $4.59 \%$ & $17.08 \%$ & $3.29 \%$ & $7.82 \%$ & $6.85 \%$ \\
\hline Total Area (in $\left.{ }^{2}\right)$ & 19.0 & 19.2 & 19.5 & 22.5 & 22.5 & 20.5 & 20.0 & 18.5 & 20.21 \\
\hline
\end{tabular}

As shown in Table 4.1, the aggregate percentage difference between top and bottom portion of the tested core samples ranges from $0.75 \%$ to $17.08 \%$ with an average difference of approximately $6.85 \%$. The bottom area always exhibited a higher coarse aggregate concentration compared to the top area. Core 6 has the highest difference at 17.08\% while Core $1(9.19 \%)$ and Core $4(8.64 \%)$ also have relatively large variations between top and bottom areas. This indicates that the top section of the SCC beam might have an apparent segregation behavior. According to the mix design, the coarse aggregate percentage can be calculated as $32.2 \%$ (assuming a specific gravity of 2.7 for the limestone coarse aggregate). From Table 4.1, the coarse aggregate percentage by average of the eight cores is $34.26 \%$ which is $2.06 \%$ higher than the theoretical value. The coarse aggregate percentage of core 5 is $2.56 \%$ lower and core 1 is $5.77 \%$ higher than the theoretical value.

\subsubsection{Coarse aggregate distribution within the cutting surfaces of the SCC test beam}

The SCC test beam was cut three times to expose 6 surfaces. Each cutting surface of the SCC beam was divided into 12 sections - five sections at the top, two sections at the middle and five sections at the bottom because the cross section was too large for a single page image analysis. 
The top and bottom images have similar dimensions. The coarse aggregate percentage of these sections was calculated using the images from the saw-cutting surfaces.

The analysis boundary of each image was reduced to account for any imperfections along the edge during cutting or polishing. Before the analysis, the images will be checked to see if all the coarse aggregates were well polished. For those aggregates areas that the images could not be recognized by the software, manual corrections were done during image analysis. In order to ensure consistent results, the top and bottom sections have at most 8 inches in width when the images were analyzed, while the size of these sections varied slightly to skip imperfections. All the reinforcement and tendon areas were excluded in the total area calculation. Figure 4.2 to 4.8 show the pictures of the saw-cutting surfaces after polishing. Table 4.2 to 4.8 show their calculated coarse aggregate distribution.

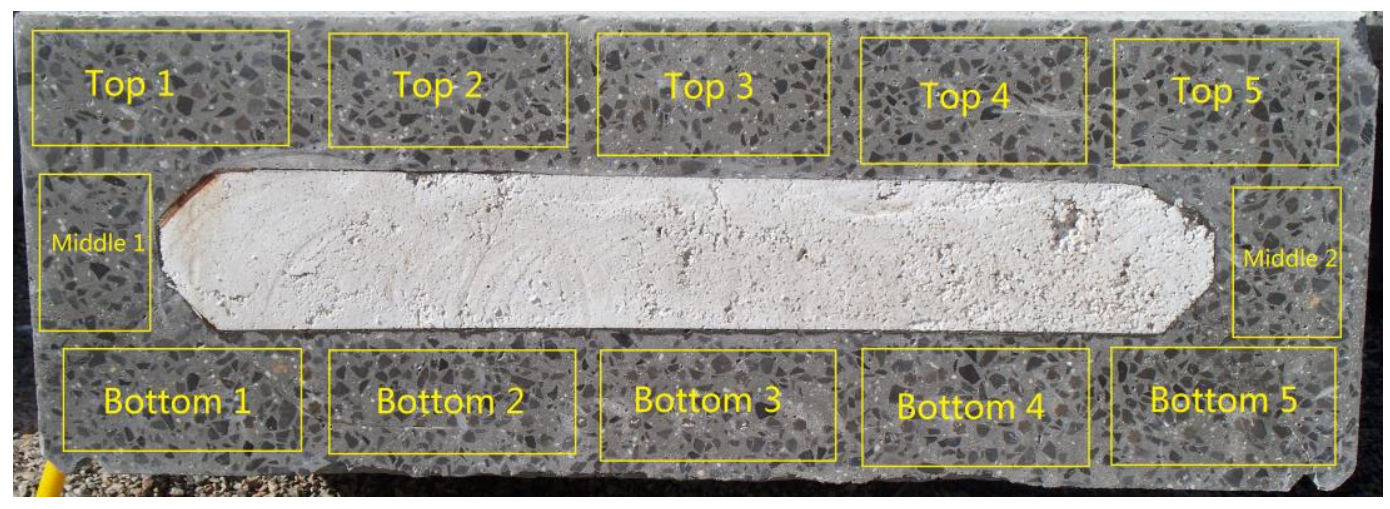

Figure 4.2 - Surface 1 after polishing

Table 4.2 - Coarse aggregate percentage of cutting surface 1

\begin{tabular}{|c|c|c|c|c|c|}
\hline Location & Top 1 & Top 2 & Top3 & Top4 & Top5 \\
\hline $\begin{array}{c}\text { Coarse Aggregate \% } \\
\text { by area }\end{array}$ & $33.86 \%$ & $36.95 \%$ & $32.73 \%$ & $27.45 \%$ & $27.83 \%$ \\
\hline Location & Bottom 1 & Bottom 2 & Bottom 3 & Bottom 4 & Bottom5 \\
\hline $\begin{array}{c}\text { Coarse Aggregate \% } \\
\text { by area }\end{array}$ & $31.85 \%$ & $33.58 \%$ & $28.82 \%$ & $30.96 \%$ & $30.72 \%$ \\
\hline Location & Middle 1 & Middle 2 & & & \\
\hline $\begin{array}{c}\text { Coarse Aggregate \% } \\
\text { by area }\end{array}$ & $26.17 \%$ & $32.13 \%$ & & & \\
\hline
\end{tabular}




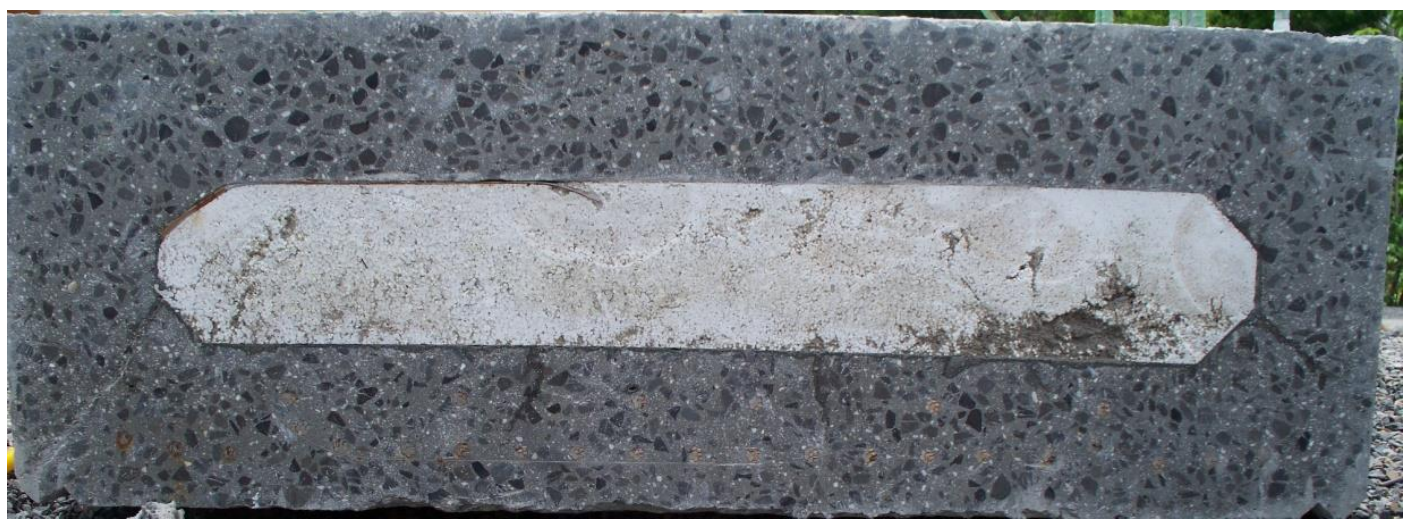

Figure 4.3 - Surface 1-1 after polishing

Table 4.3 - Coarse aggregate percentage of cutting surface 1-1

\begin{tabular}{|c|c|c|c|c|c|}
\hline Location & Top 1 & Top 2 & Top3 & Top4 & Top5 \\
\hline $\begin{array}{c}\text { Coarse Aggregate \% } \\
\text { by area }\end{array}$ & $30.36 \%$ & $36.51 \%$ & $28.46 \%$ & $31.80 \%$ & $29.92 \%$ \\
\hline Location & Bottom 1 & Bottom 2 & Bottom 3 & Bottom 4 & Bottom5 \\
\hline $\begin{array}{c}\text { Coarse Aggregate \% } \\
\text { by area }\end{array}$ & $30.33 \%$ & $29.67 \%$ & $28.21 \%$ & $32.84 \%$ & $27.06 \%$ \\
\hline Location & Middle 1 & Middle 2 & & & \\
\hline $\begin{array}{c}\text { Coarse Aggregate \% } \\
\text { by area }\end{array}$ & $28.72 \%$ & $23.19 \%$ & & & \\
\hline
\end{tabular}

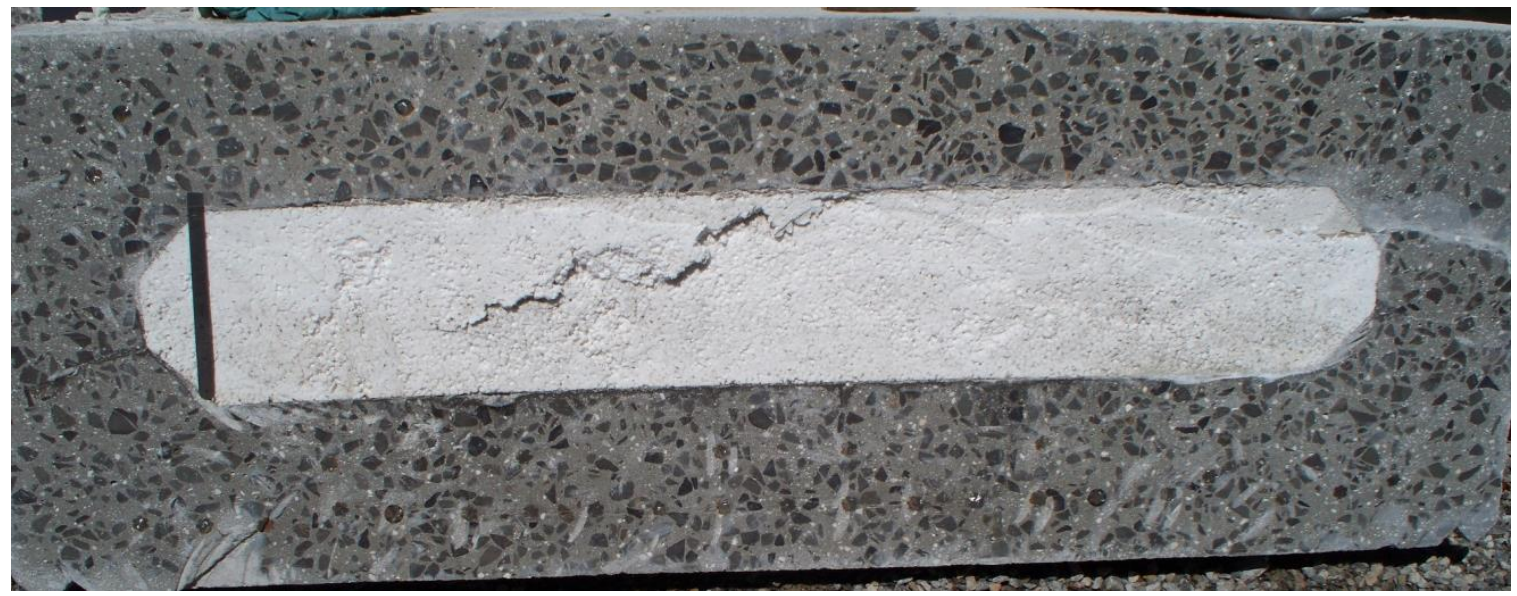

Figure 4.4- Surface 2 after polishing 
Table 4.4 - Coarse aggregate percentage of cutting surface 2

\begin{tabular}{|c|c|c|c|c|c|}
\hline Location & Top 1 & Top 2 & Top3 & Top4 & Top5 \\
\hline $\begin{array}{c}\text { Coarse Aggregate } \% \\
\text { by area }\end{array}$ & $23.58 \%$ & $34.01 \%$ & $36.35 \%$ & $33.95 \%$ & $29.97 \%$ \\
\hline Location & Bottom 1 & Bottom 2 & Bottom 3 & Bottom 4 & Bottom5 \\
\hline $\begin{array}{c}\text { Coarse Aggregate \% } \\
\text { by area }\end{array}$ & $29.07 \%$ & $25.64 \%$ & $28.82 \%$ & $27.85 \%$ & $29.54 \%$ \\
\hline Location & Middle 1 & Middle 2 & & & \\
\hline $\begin{array}{c}\text { Coarse Aggregate } \% \\
\text { by area }\end{array}$ & $34.05 \%$ & $32.79 \%$ & & & \\
\hline
\end{tabular}

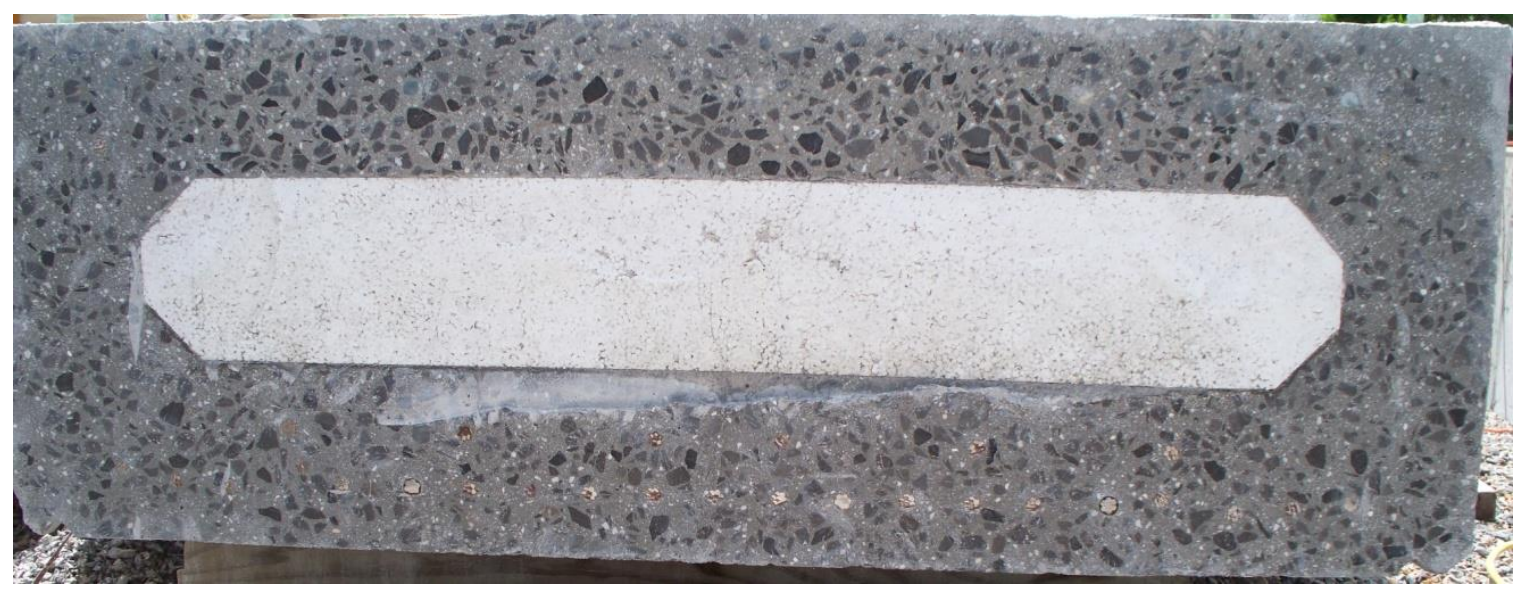

Figure 4.5 - Surface 2-1 after polishing

Table 4.5 - Coarse aggregate percentage of cutting surface 2-1

\begin{tabular}{|c|c|c|c|c|c|}
\hline Location & Top 1 & Top 2 & Top3 & Top4 & Top5 \\
\hline $\begin{array}{c}\text { Coarse Aggregate \% } \\
\text { by area }\end{array}$ & $26.40 \%$ & $34.89 \%$ & $30.47 \%$ & $33.21 \%$ & $25.70 \%$ \\
\hline Location & Bottom 1 & Bottom 2 & Bottom 3 & Bottom 4 & Bottom5 \\
\hline $\begin{array}{c}\text { Coarse Aggregate \% } \\
\text { by area }\end{array}$ & $32.21 \%$ & $28.74 \%$ & $30.06 \%$ & $30.41 \%$ & $29.84 \%$ \\
\hline Location & Middle 1 & Middle 2 & & & \\
\hline $\begin{array}{c}\text { Coarse Aggregate \% } \\
\text { by area }\end{array}$ & $29.62 \%$ & $32.62 \%$ & & & \\
\hline
\end{tabular}




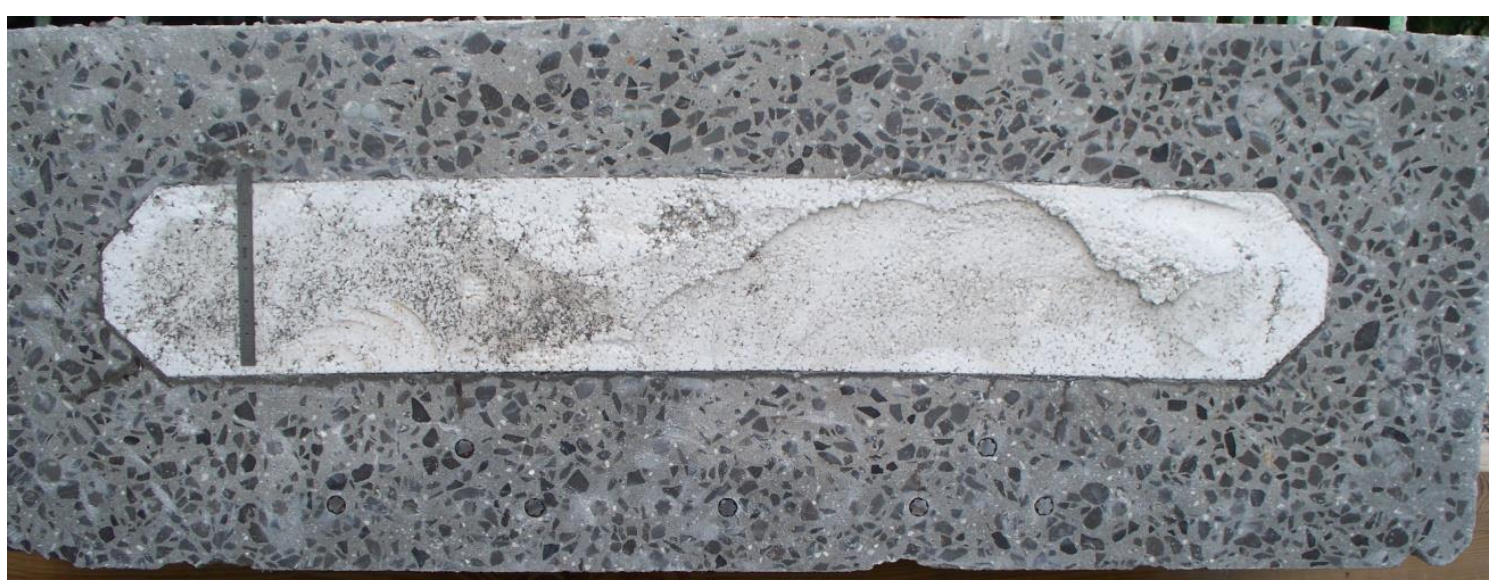

Figure 4.6 - Surface 3 after polishing

Table 4.6 - Coarse aggregate percentage of cutting surface 3

\begin{tabular}{|c|c|c|c|c|c|}
\hline Location & Top 1 & Top 2 & Top3 & Top4 & Top5 \\
\hline $\begin{array}{c}\text { Coarse Aggregate \% } \\
\text { by area }\end{array}$ & $28.12 \%$ & $32.78 \%$ & $33.40 \%$ & $33.67 \%$ & $30.33 \%$ \\
\hline Location & Bottom 1 & Bottom 2 & Bottom 3 & Bottom 4 & Bottom5 \\
\hline $\begin{array}{c}\text { Coarse Aggregate \% } \\
\text { by area }\end{array}$ & $32.34 \%$ & $29.74 \%$ & $25.67 \%$ & $29.46 \%$ & $32.40 \%$ \\
\hline Location & Middle 1 & Middle 2 & & & \\
\hline $\begin{array}{c}\text { Coarse Aggregate \% } \\
\text { by area }\end{array}$ & $33.32 \%$ & $34.01 \%$ & & & \\
\hline
\end{tabular}

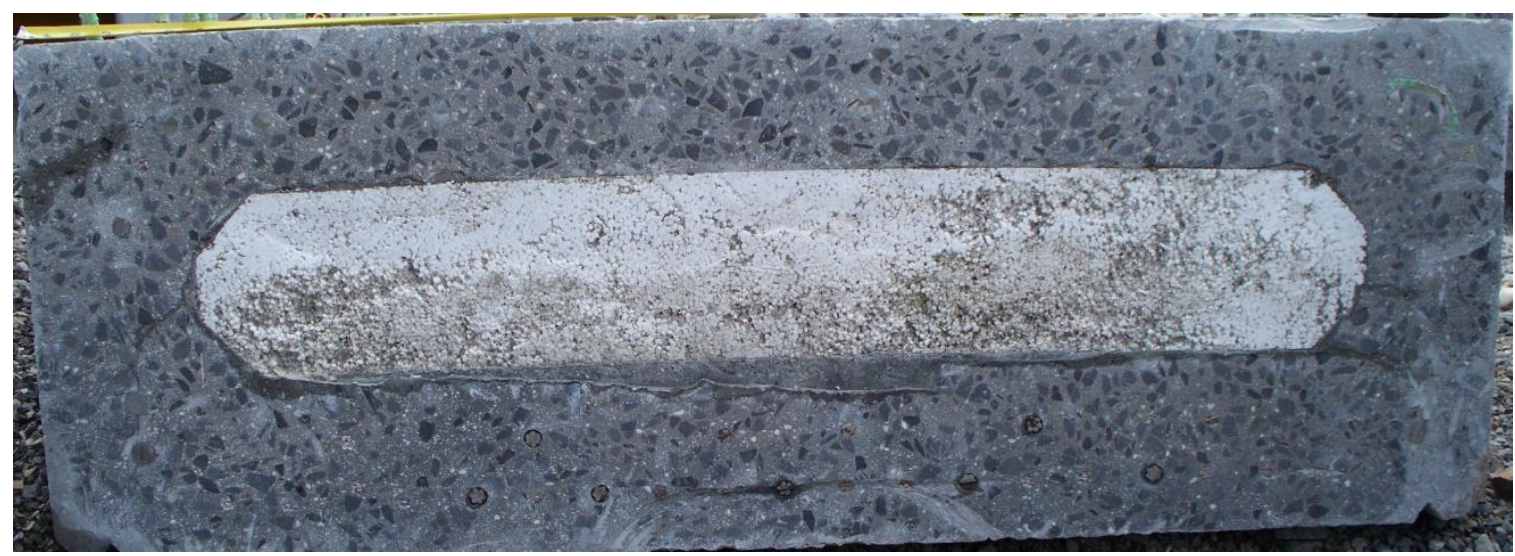

Figure 4.7 - Surface 3-1 after polishing 
Table 4.7 - Coarse aggregate percentage of cutting surface 3-1

\begin{tabular}{|c|c|c|c|c|c|}
\hline Location & Top 1 & Top 2 & Top3 & Top4 & Top5 \\
\hline $\begin{array}{c}\text { Coarse Aggregate } \% \\
\text { by area }\end{array}$ & $23.68 \%$ & $34.04 \%$ & $37.74 \%$ & $39.24 \%$ & $24.93 \%$ \\
\hline Location & Bottom 1 & Bottom 2 & Bottom 3 & Bottom 4 & Bottom5 \\
\hline $\begin{array}{c}\text { Coarse Aggregate \% } \\
\text { by area }\end{array}$ & $26.36 \%$ & $28.56 \%$ & $24.59 \%$ & $29.21 \%$ & $30.65 \%$ \\
\hline Location & Middle 1 & Middle 2 & & & \\
\hline $\begin{array}{c}\text { Coarse Aggregate } \% \\
\text { by area }\end{array}$ & $33.30 \%$ & $30.92 \%$ & & & \\
\hline
\end{tabular}

The Surface 1-1, 2-1, 3-1 are located on the opposite sides of surface 1, 2 and 3. From Table 4.2 to Table 4.7, the percentage of coarse aggregate in different locations changes from $22.56 \%$ to $38.77 \%$. Some distinct difference can easily be seen from Figure 4.2 to Figure 4.7. For example, top 1 and top 5 of surface 2-1 have very little coarse aggregates but top 2 and top 4 has significantly higher coarse aggregates as shown in Figure 4.5 and Table 4.5. All the cores taken from the SCC beam are located at the top 2 or top 4 sections of the cutting surfaces. The Top 2 and top 4 sections of all the six surfaces show slightly higher percentage as compared to the other sections, the average percentage of these sections is about $34.74 \%$ which is consistent with the average result of the core specimens (34.28\%). As shown in Figure 4.8, the top sections contain more coarse aggregates than the bottom sections. In general, top 1 and top 5 have fewer aggregates than the rest of the top sections. Bottom 1 and bottom 5 usually have more aggregates than the rest of the bottom sections. The variation of the aggregate percentage among the bottom sections of the SCC test beam is less than that of the top sections. Figure 4.9 shows the coarse aggregate percentage distributed among different sections on each saw-cut surface.

It was also noticed from the core samples (taken from the top sections of the beam) that compared to the core specimens, the coarse aggregate percentage variation of the bottom section of the SCC test beam is less than that of the top section, which indicates a more homogenous distribution in the bottom section. However, different locations at the bottom sections still have a large variation of coarse aggregate percentage (ranging from $24.59 \%$ to $33.58 \%$ ), such as bottom 3 of surface $3-1$ and bottom 2 of surface 2 only have $24.59 \%$ and $25.64 \%$ average coarse aggregate percentage, respectively. A high majority (25 out of 30) of the saw-cut surface bottom sections from the SCC test beam have an aggregate percentage lower than the theoretical value (32.2\%). 


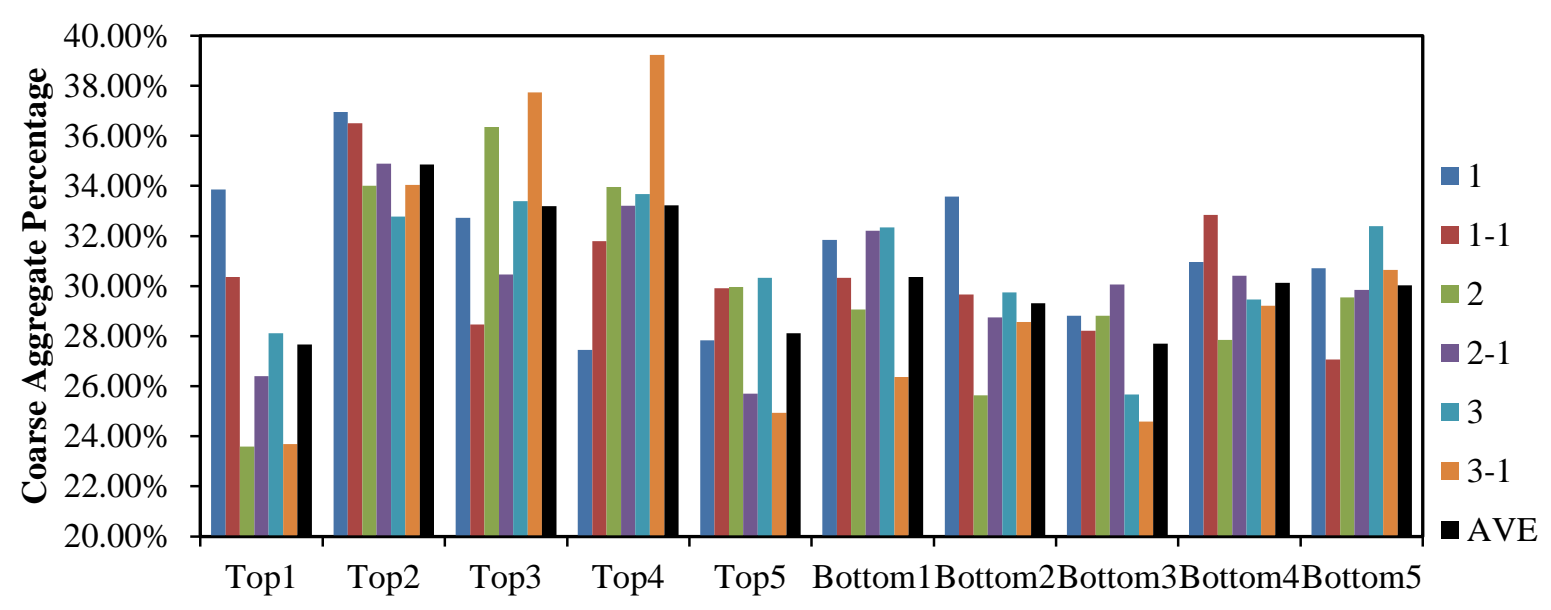

Figure 4.8 - Coarse aggregate percentage distribution at different sections

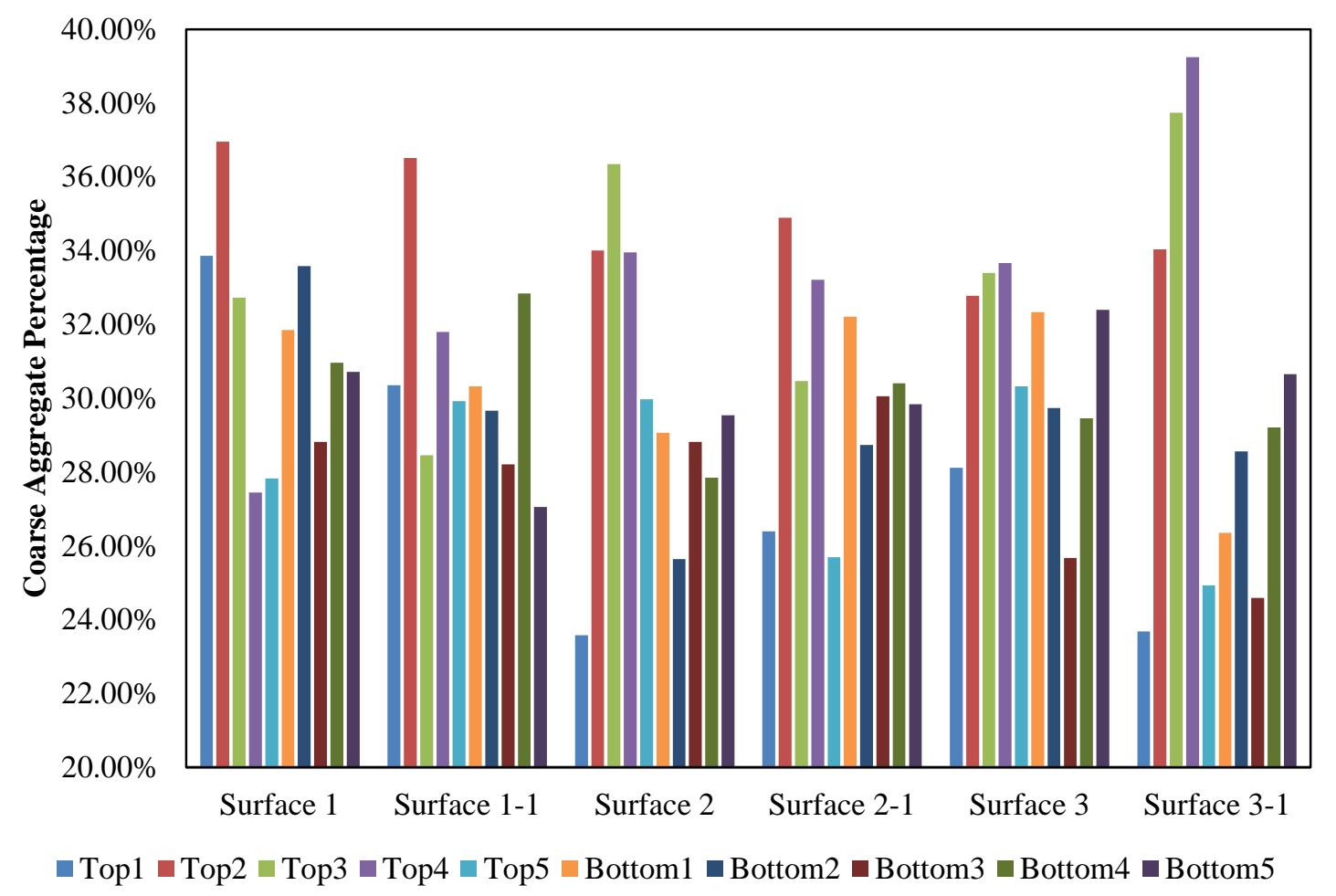

Figure 4.9 - Coarse aggregate percentage distribution on each saw-cut surface

The prestressed SCC beam has a large number of prestressed tendons located at the bottom sections of the beam. To investigate the passing ability of the SCC around the tendons, all the 
bottom sections were divided into two equal parts (top and bottom) to analyze the coarse aggregate distribution around the tendon area. The results are shown in the following tables (Table 4.8 to Table 4.13). In the table, for each bottom section, the coarse aggregate percentage of top and bottom portion of that sectional area is shown together with the coarse aggregate percentage of the total sectional area. In Table 4.11, bottom 2 and bottom 3 of surface $2-1$ were not divided because surface 2-1 has a large scar at the top area of bottom 2 and bottom 3 sections (Table 4.5).

Table 4.8 - Bottom coarse aggregate distribution of surface 1

\begin{tabular}{|c|c|c|c|c|c|}
\hline & bottom1 & bottom2 & bottom3 & bottom4 & bottom5 \\
\hline $\begin{array}{c}\text { Coarse aggregate percentage by } \\
\text { total area }\end{array}$ & $31.85 \%$ & $33.58 \%$ & $28.82 \%$ & $30.96 \%$ & $30.72 \%$ \\
\hline $\begin{array}{c}\text { Coarse aggregate percentage by } \\
\text { top area }\end{array}$ & $32.01 \%$ & $33.12 \%$ & $30.36 \%$ & $32.86 \%$ & $34.12 \%$ \\
\hline $\begin{array}{c}\text { Coarse aggregate percentage by } \\
\text { bottom area }\end{array}$ & $31.62 \%$ & $33.86 \%$ & $27.12 \%$ & $29.37 \%$ & $26.69 \%$ \\
\hline $\begin{array}{c}\text { Difference between top and } \\
\text { bottom }\end{array}$ & $-0.39 \%$ & $0.74 \%$ & $-3.24 \%$ & $-3.49 \%$ & $-7.43 \%$ \\
\hline \begin{tabular}{c} 
Segregation index, P \\
\hline
\end{tabular} & $-1.22 \%$ & $2.20 \%$ & $-11.24 \%$ & $-11.27 \%$ & $-24.19 \%$ \\
\hline
\end{tabular}

Table 4.9 - Bottom coarse aggregate distribution of surface 1-1

\begin{tabular}{|c|c|c|c|c|c|}
\hline & bottom1 & bottom2 & bottom3 & bottom4 & bottom5 \\
\hline $\begin{array}{c}\text { Coarse aggregate percentage } \\
\text { by total area }\end{array}$ & $30.33 \%$ & $29.67 \%$ & $28.21 \%$ & $32.84 \%$ & $27.06 \%$ \\
\hline $\begin{array}{c}\text { Coarse aggregate percentage } \\
\text { by top area }\end{array}$ & $30.61 \%$ & $28.91 \%$ & $30.41 \%$ & $36.25 \%$ & $26.81 \%$ \\
\hline $\begin{array}{c}\text { Coarse aggregate percentage } \\
\text { by bottom area }\end{array}$ & $29.54 \%$ & $30.33 \%$ & $26.14 \%$ & $29.64 \%$ & $27.06 \%$ \\
\hline $\begin{array}{c}\text { Difference between top and } \\
\text { bottom }\end{array}$ & $-1.07 \%$ & $1.41 \%$ & $-4.27 \%$ & $-6.62 \%$ & $0.25 \%$ \\
\hline \begin{tabular}{c} 
Segregation index, P \\
\hline
\end{tabular} & $-3.53 \%$ & $4.75 \%$ & $-15.14 \%$ & $-20.16 \%$ & $0.92 \%$ \\
\hline
\end{tabular}

Table 4.10 - Bottom coarse aggregate distribution of surface 2

\begin{tabular}{|l|l|l|l|l|l|}
\hline & bottom1 & bottom2 & bottom3 & bottom4 & bottom5 \\
\hline
\end{tabular}




\begin{tabular}{|c|c|c|c|c|c|}
\hline $\begin{array}{c}\text { Coarse aggregate percentage } \\
\text { by total area }\end{array}$ & $29.07 \%$ & $25.64 \%$ & $28.82 \%$ & $27.85 \%$ & $29.54 \%$ \\
\hline $\begin{array}{c}\text { Coarse aggregate percentage } \\
\text { by top area }\end{array}$ & $30.01 \%$ & $22.51 \%$ & $26.40 \%$ & $30.29 \%$ & $31.64 \%$ \\
\hline $\begin{array}{c}\text { Coarse aggregate percentage } \\
\text { by bottom area }\end{array}$ & $28.48 \%$ & $28.95 \%$ & $31.08 \%$ & $25.33 \%$ & $27.46 \%$ \\
\hline $\begin{array}{c}\text { Difference between top and } \\
\text { bottom }\end{array}$ & $-1.53 \%$ & $6.44 \%$ & $4.67 \%$ & $-4.96 \%$ & $-4.18 \%$ \\
\hline Segregation index, P & $-5.26 \%$ & $25.12 \%$ & $16.20 \%$ & $-17.81 \%$ & $-14.15 \%$ \\
\hline
\end{tabular}

Table 4.11 - Bottom coarse aggregate distribution of surface 2-1

\begin{tabular}{|c|c|c|c|c|c|}
\hline & bottom1 & bottom2 & bottom3 & bottom4 & bottom5 \\
\hline $\begin{array}{c}\text { Coarse aggregate percentage } \\
\text { by total area }\end{array}$ & $32.21 \%$ & $28.74 \%$ & $30.06 \%$ & $30.41 \%$ & $29.84 \%$ \\
\hline $\begin{array}{c}\text { Coarse aggregate percentage } \\
\text { by top area }\end{array}$ & $33.24 \%$ & - & - & $32.04 \%$ & $29.97 \%$ \\
\hline $\begin{array}{c}\text { Coarse aggregate percentage } \\
\text { by bottom area }\end{array}$ & $31.25 \%$ & - & - & $28.94 \%$ & $29.66 \%$ \\
\hline $\begin{array}{c}\text { Difference between top and } \\
\text { bottom }\end{array}$ & $-1.99 \%$ & - & - & $-3.10 \%$ & $-0.31 \%$ \\
\hline Segregation index, P & $-6.18 \%$ & - & - & $-10.19 \%$ & $-1.04 \%$ \\
\hline
\end{tabular}

Table 4.12 - Bottom coarse aggregate distribution of surface 3

\begin{tabular}{|c|c|c|c|c|c|}
\hline & bottom1 & bottom2 & bottom3 & bottom4 & bottom5 \\
\hline $\begin{array}{c}\text { Coarse aggregate percentage } \\
\text { by total area }\end{array}$ & $32.34 \%$ & $29.74 \%$ & $25.67 \%$ & $29.46 \%$ & $32.40 \%$ \\
\hline $\begin{array}{c}\text { Coarse aggregate percentage } \\
\text { by top area }\end{array}$ & $30.11 \%$ & $29.37 \%$ & $22.67 \%$ & $27.45 \%$ & $35.01 \%$ \\
\hline $\begin{array}{c}\text { Coarse aggregate percentage } \\
\text { by bottom area }\end{array}$ & $34.58 \%$ & $30.47 \%$ & $28.57 \%$ & $31.46 \%$ & $30.02 \%$ \\
\hline $\begin{array}{c}\text { Difference between top and } \\
\text { bottom }\end{array}$ & $4.47 \%$ & $1.11 \%$ & $5.91 \%$ & $4.01 \%$ & $-4.99 \%$ \\
\hline Segregation index, P & $13.82 \%$ & $3.73 \%$ & $23.02 \%$ & $13.61 \%$ & $-15.40 \%$ \\
\hline
\end{tabular}

Table 4.13 - Bottom coarse aggregate distribution of surface 3-1

\begin{tabular}{|l|l|l|l|l|l|}
\hline & bottom1 & bottom2 & bottom3 & bottom4 & bottom5 \\
\hline
\end{tabular}




\begin{tabular}{|c|c|c|c|c|c|}
\hline $\begin{array}{c}\text { Coarse aggregate } \\
\text { percentage by total area }\end{array}$ & $26.36 \%$ & $28.56 \%$ & $24.59 \%$ & $29.21 \%$ & $30.65 \%$ \\
\hline $\begin{array}{c}\text { Coarse aggregate } \\
\text { percentage by top area }\end{array}$ & $21.56 \%$ & $25.59 \%$ & $24.15 \%$ & $29.02 \%$ & $33.60 \%$ \\
\hline $\begin{array}{c}\text { Coarse aggregate } \\
\text { percentage by bottom area }\end{array}$ & $31.61 \%$ & $31.19 \%$ & $24.86 \%$ & $29.33 \%$ & $27.60 \%$ \\
\hline $\begin{array}{c}\text { Difference between top and } \\
\text { bottom }\end{array}$ & $10.05 \%$ & $5.60 \%$ & $0.71 \%$ & $0.31 \%$ & $-6.00 \%$ \\
\hline Segregation index, P & $38.13 \%$ & $19.61 \%$ & $2.89 \%$ & $1.06 \%$ & $-19.58 \%$ \\
\hline
\end{tabular}

Figure 4.10 shows the percentage difference between top and bottom of all the bottom sections of the six saw-cut surfaces. The percentage difference was calculated by the bottom percentage minus the top percentage shown in the above tables. The largest percentage difference of $10.05 \%$ can be seen on the bottom 1 section of Surface 3-1. The aggregate percentage difference between top and bottom areas of all these bottom sections in the SCC test beam ranges from $0.25 \%$ to $10.05 \%$.

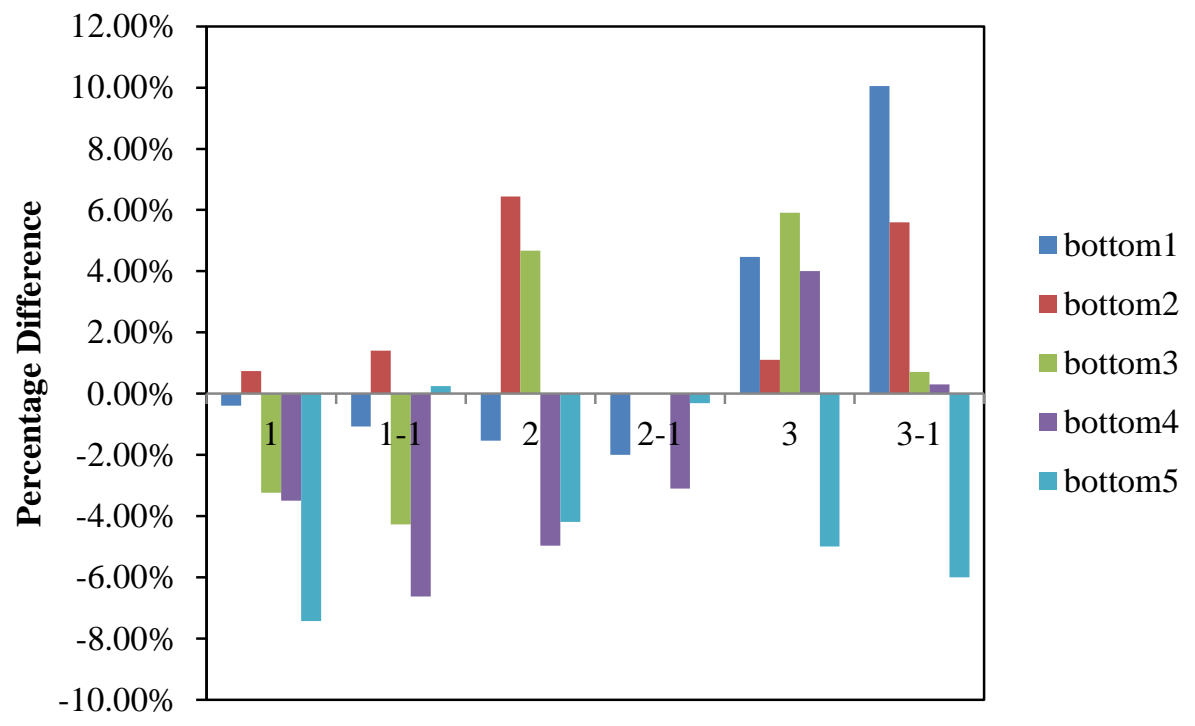

Figure 4.10 - Percentage difference between top and bottom in bottom sections (bottom percentage minus top percentage)

It was noticed that several of these bottom sections have a larger variation between top and bottom portion of that section, i.e. bottom 1 of surface 3-1 (10.05\%), as shown in Figure 4.11, bottom 5 of surface $1(-7.43 \%)$, as shown in Figure 4.12, and bottom 4 of surface 1-1 (-6.62\%). 
Figure 4.13 shows the picture of SCC filling around tendons. No visible voids could be identified around the tendons, the bond between the concrete and the tendons appeared to be good.

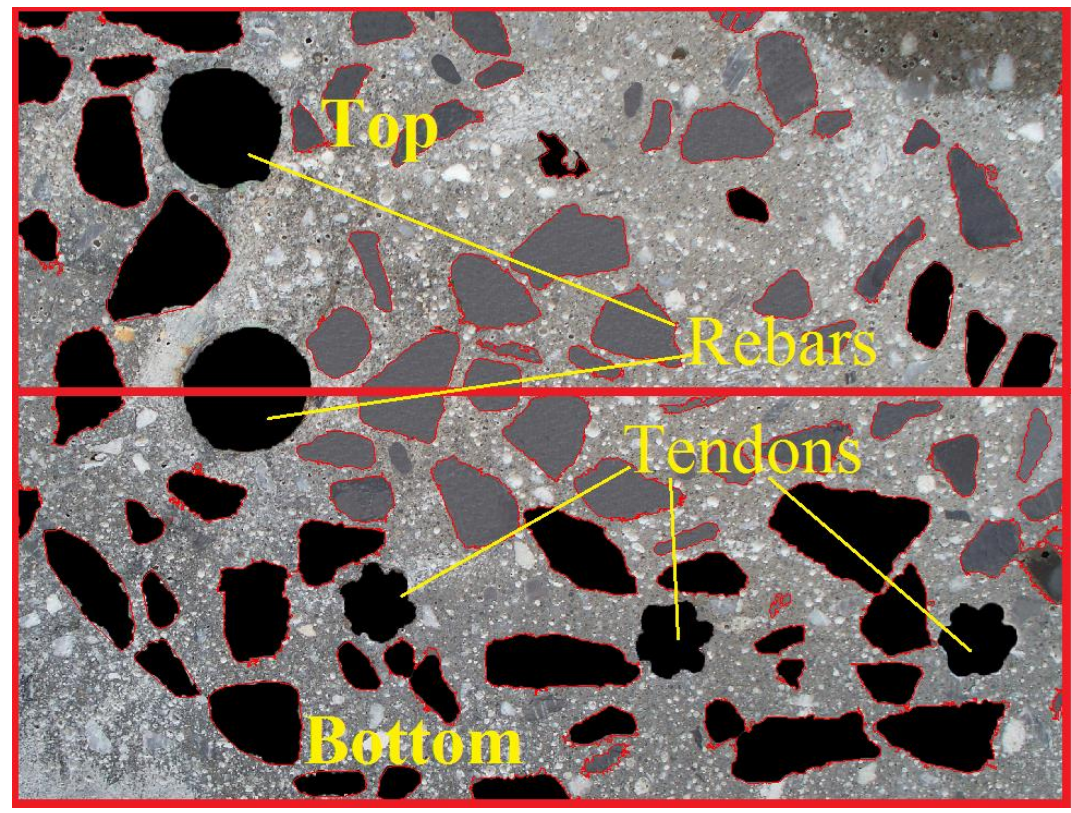

Figure 4.11 - Bottom 1 of surface 3-1

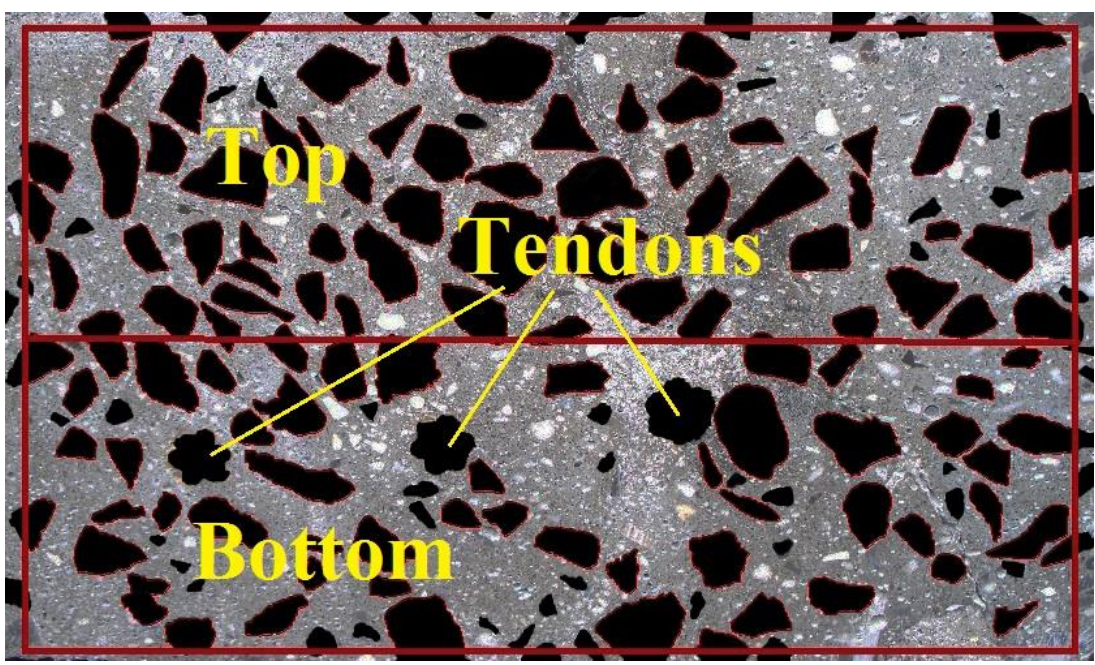

Figure 4.12 - Bottom 5 of surface 1 


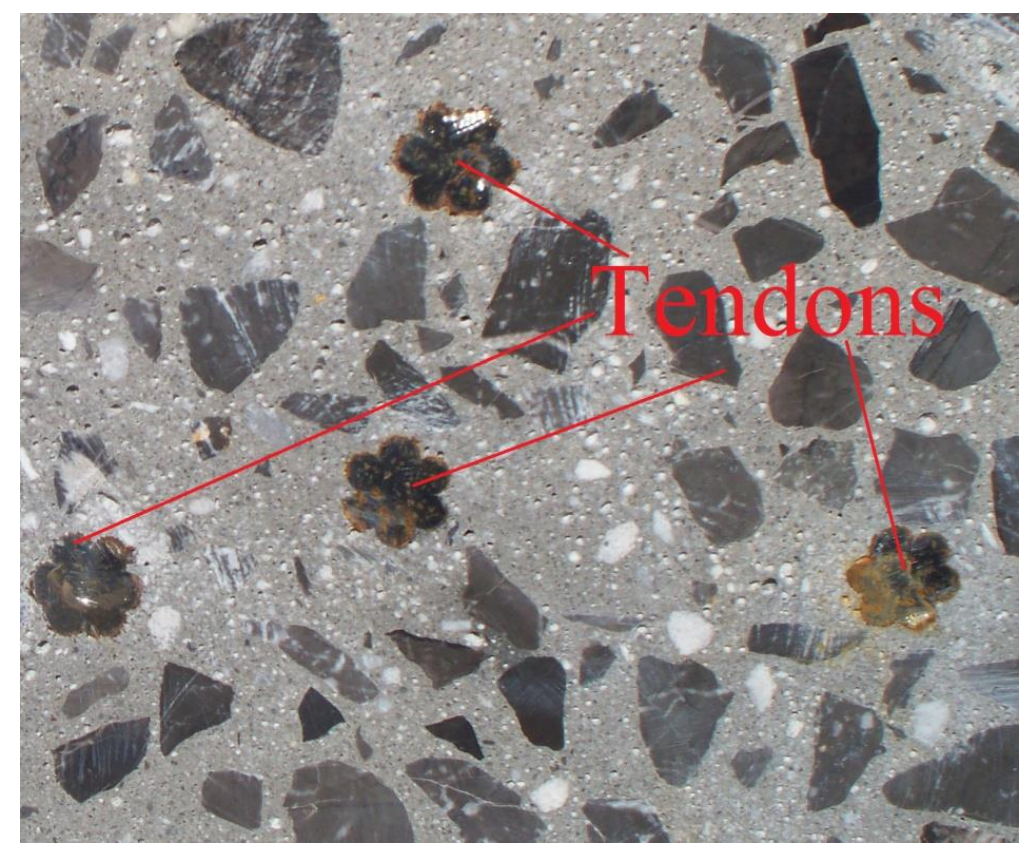

Figure 4.13 - SCC filling around Tendons

\subsubsection{Segregation Index}

Hardened visual stability index (HVSI) was used as a parameter to quantify the segregation of hardened SCC (Lang, et al., 2008), the ratings are shown in Table 4.14. Johnson (2010) defined paste ratio segregation index as a criteria to assess the segregation of hardened SCC cylinders. In this research, the cutting surface of the SCC test beam will also be used to evaluate the segregation of hardened SCC and the segregation index, P was introduced to quantify the segregation of hardened SCC which was modified from ASTM C1610.

ASTM C1610 segregation column test is usually used to estimate the static segregation of fresh SCC, the percent static segregation, $\mathrm{S}$ can be computed using the mass of the coarse aggregate remaining in the top and bottom quarter of the column as

$$
\mathrm{S}=2\left(\mathrm{CA}_{\mathrm{B}}-\mathrm{CA}_{\mathrm{T}}\right) /\left(\mathrm{CA}_{\mathrm{B}}+\mathrm{CA}_{\mathrm{T}}\right)
$$

where, $\mathrm{CA}_{\mathrm{T}}$ is the mass of coarse aggregate in the top section of the column and $\mathrm{CA}_{\mathrm{B}}$ is the mass of coarse aggregate in the bottom section of the column. In this equation, $\mathrm{S}$ is a weight ratio. The acceptable limit for the percent static segregation of the SCC used in the prestressed box test beam during production is $12 \%$ (Chen, et al., 2012). 
In this study, the area percentage of coarse aggregate was computed using JMicro Vision software, so the area percentages of the top and bottom of cutting surfaces were used. The area segregation index, $\mathrm{P}$ is an area ratio which is defined as:

$$
P=\frac{\left(C_{B}-C_{T}\right)}{C_{T o}}
$$

where, $\mathrm{C}_{\mathrm{T}}$ and $\mathrm{C}_{\mathrm{B}}$ are the coarse aggregate area percentage in top and bottom section of the analysis area, respectly, $\mathrm{C}_{\mathrm{To}}$ is the coarse aggregate area percentage by the total analysis area. In this study, $P \leq 12 \%$ is also assumed as the acceptable limit for area segregation index, which means the SCC is assumed unstable if $P$ index is greater than $12 \%$ and the SCC is stable if segregation index is less than $12 \%$.

Table 4.14 - Hardened Visual Stability Index (HVSI) (Illinois Test Procedure SCC-6)

\begin{tabular}{|l|l|}
\hline HVSI & Criteria \\
\hline $\mathbf{0}$ stable & $\begin{array}{l}\text { No paste/mortar layer on top of the cylinder, and no difference in size } \\
\text { and area percentage of coarse aggregates lengthwise. }\end{array}$ \\
\hline $\mathbf{1}$ stable & $\begin{array}{l}\text { No paste mortar layer on top of the cylinder, but slight difference in size } \\
\text { and area percentage of coarse aggregates lengthwise. }\end{array}$ \\
\hline $\mathbf{2}$ unstable & Slight paste/mortar layer- less than 1-in. (25-mm) - on top of the cylinder. \\
\hline $\mathbf{3}$ unstable & $\begin{array}{l}\text { Significant paste/mortar layer - greater than 1-in. (25-mm) - on top of } \\
\text { the cylinder, and/or clear evidence of difference in size and area } \\
\text { percentage of coarse aggregates lengthwise. }\end{array}$ \\
\hline
\end{tabular}

From the aggregate distribution results of the core specimens, those eight core samples have $6.85 \%$ average difference between top and bottom portions. The average coarse aggregate percentage of the core specimens is $34.26 \%$. The segregation index of these eight core specimens is shown in Table 4.15 which represent the top sections of the SCC test beam. The average P values can be calculated as $19.99 \%$, which is much higher than the acceptable limit. In the bottoms sections, the average segregation index calculated based on data from Table 4.8 to Table 4.13 is about $12.19 \%$ (average of all the six cutting surfaces), which is only slightly higher than the limitation and much better than the top section. This means that the bottom of the SCC test beam has a better aggregate distribution than the top section. However, as displayed in Figure 4.14, some 
of the bottom sections still have a large value of $\mathrm{P}$ value, i.e. bottom 5 of surface $1(-24.19 \%)$, bottom 4 of surface 1-1 (-20.16\%), bottom 2 od surface $2(25.12 \%)$, bottom 1 of surface 3-1 (38.13\%), bottom 2 of surface 3-1 (19.61\%) and bottom 5 of surface 3-1 (-19.58\%). These sections have a significant aggregate segregation.

Table 4.15 - Segregation index of core specimens

\begin{tabular}{|c|c|c|c|c|c|c|c|c|c|}
\hline & core1 & core2 & core3 & core4 & core5 & core6 & core7 & core8 & Average \\
\hline $\begin{array}{c}\text { Segregation } \\
\text { index, P }\end{array}$ & $24.30 \%$ & $8.84 \%$ & $2.17 \%$ & $25.31 \%$ & $15.49 \%$ & $53.08 \%$ & $9.55 \%$ & $20.93 \%$ & $19.99 \%$ \\
\hline
\end{tabular}

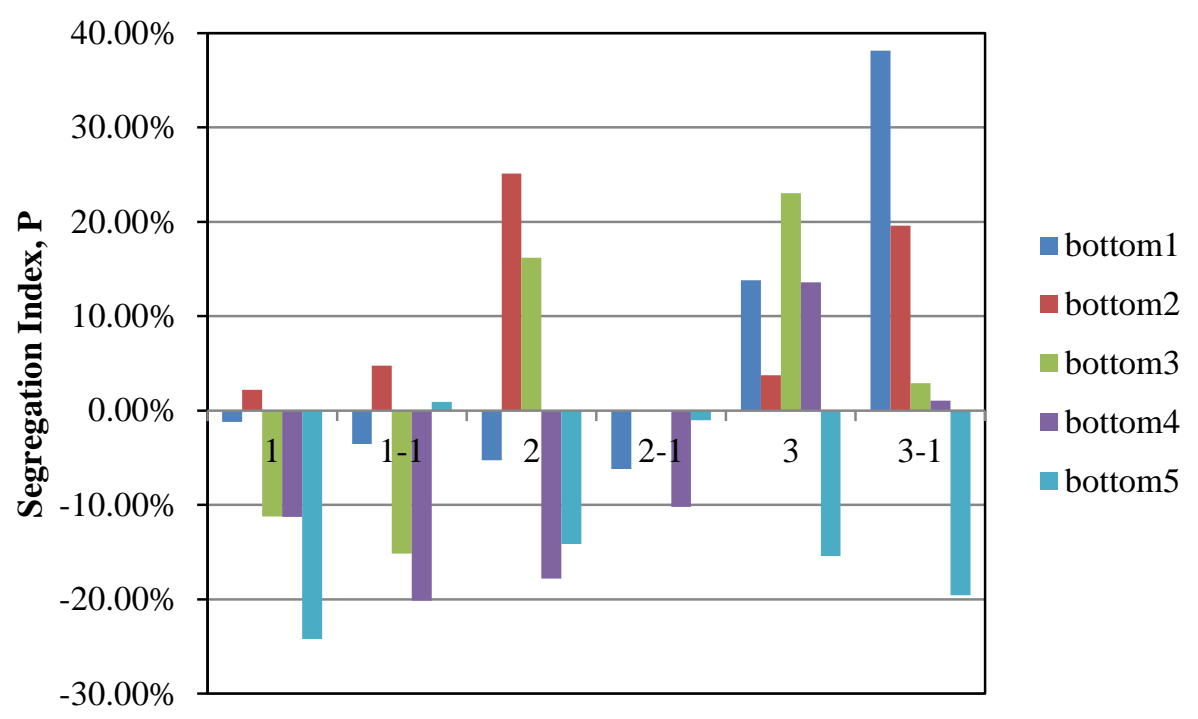

Figure 4.14 - Segregation index of the bottom sections of the SCC test beam

\subsubsection{Discussions}

A high majority of bottom sections (25 out of 30) have lower coarse aggregate percentage than the theoretical value $32.2 \%$ (assuming a specific gravity of 2.7 for the limestone), but half of top sections have an aggregate percentage higher than the theoretical value. During the casting of the SCC test beam, the fresh SCC was poured on the top surface of the box beam at the center, so the concrete flowed from the center to the sides and then dropped from the sides to the bottom section. The SCC needed to flow through the two sides of the box beam and then flowed to the bottom sections of the box beam. The saw-cut sections show that the top sections have more 
coarse aggregates than the bottom sections. Also, the two side sections on the top (top 1 and top 5) have much less coarse aggregates. This segregation might indicate sinking of coarse aggregates at the sides from the fresh SCC into the bottom section.

The non-uniform aggregate distribution in the saw-cut cross sections might indicate inhomogeneity in the SCC beam sections, which may potentially affect the concrete material properties such as creep, shrinkage and elastic modulus of the prestressed beam section. In ACI 209R report, there is a correction factor of the fine aggregate to total aggregate percentage for the calculation of creep and shrinkage. Less coarse aggregate (more fine aggregate) in concrete could increase the amount of creep and shrinkage. The non-uniform coarse aggregate distribution could also influence the bond strength between concrete and steel, and hence, introduce non-uniform stiffness (NCHRP 628, 2009). The additional creep, shrinkage and non-uniform stiffness in the bottom section of the beam might lead to more prestress losses. Larger prestress losses could result in larger deflections than the original design deflections and might induce a greater cracking potential under the service loads. Further more, aggregate segregation could affect the permeability and the quality of the interfacial zone between cement paste and aggregate (NCHRP 628), and therefore, might reduce the durability of the concrete.

\subsection{SCC air void analysis results and discussions}

After the coarse aggregate analysis of the core specimens, the surfaces of the cores were painted using black ink, and then white Barium Sulfate powder was stamped into the air voids after the ink was completely dry. A USB microscope was then used to check the preparation of the surfaces and ensure all the voids were filled completely with the powder. The surfaces were scanned using office scanner with a resolution of 3200 dpi. An automatic air void analysis was performed using the BubbleCounter program embedded within Adobe Photoshop. The air void analysis results of the eight core samples from the SCC test beam are shown in Table 4.16. The images of these eight air-void specimens are shown in APPENDIX A.

The SCC used in the Stalnaker Run bridge beam production was reported to have $5.3 \%$ air content in the fresh state. From Table 4.16, the average hardened air content of all the core samples is about $4.5 \%$ which is $0.8 \%$ lower than that in the fresh state. This reduction seems similar to the 
behavior of regular concrete. It was reported that hardened concrete tends to have $0.5 \%-1.5 \%$ lower air content than the fresh air content for normal slump concrete (Khayat, 2002). Figure 4.15 shows the air content relationship between fresh and hardened concrete from Khayat (2002) experiment.

Table 4.16 - Air void properties of core specimens from SCC beam

\begin{tabular}{|c|c|c|c|c|c|c|c|c|}
\hline & Core 1 & Core 2 & Core 3 & Core 4 & Core 5 & Core 6 & Core 7 & Core 8 \\
\hline $\begin{array}{c}\text { Hardened Air } \\
\text { content (\%) }\end{array}$ & 4.53 & 4.64 & 4.86 & 4.18 & 4.44 & 4.32 & 4.41 & 4.67 \\
\hline $\begin{array}{c}\text { Specific } \\
\text { surface (SS), } \\
\text { mm }^{-1}\end{array}$ & 20.957 & 20 & 19.048 & 16.598 & 18.265 & 22.346 & 21.688 & 22.989 \\
\hline $\begin{array}{c}\text { Spacing factor } \\
(\mathrm{SF}), \mathrm{mm}\end{array}$ & 0.4134 & 0.4293 & 0.4416 & 0.5421 & 0.4783 & 0.3961 & 0.4159 & 0.3885 \\
\hline
\end{tabular}

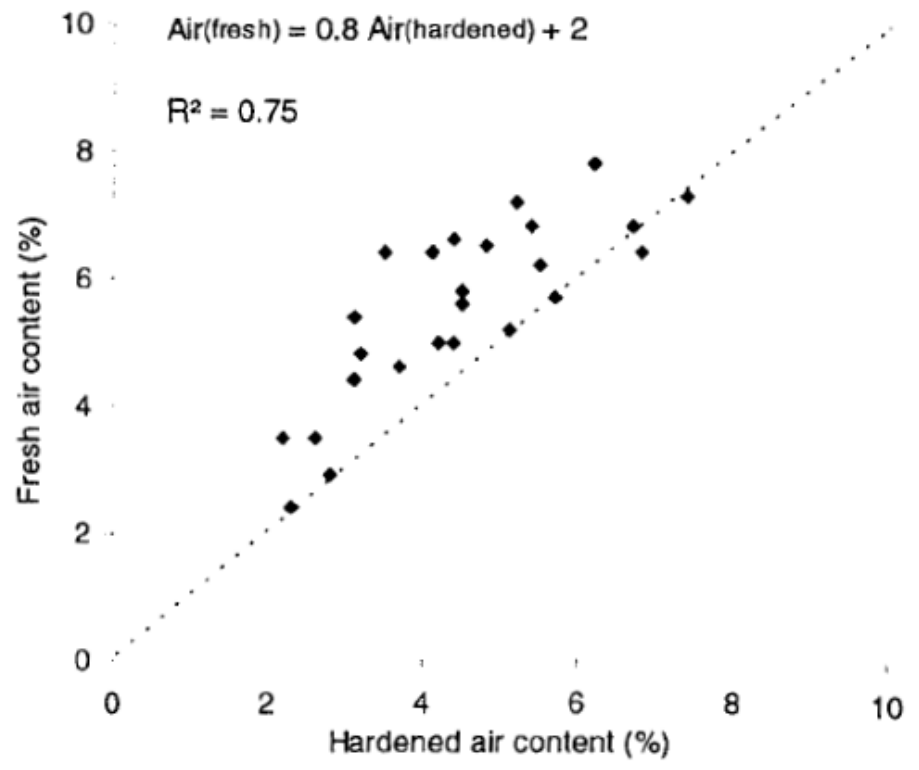

Figure 4.15 - Air content relationship between fresh and hardened concrete (Kamal H. Khayat, 2002)

ASTM C457 recommends the limitations of Specific Surface and Spacing Factor for concrete that can be considered as freeze-thaw durable. The Specific Surface, SS should be in the range of 25 to $45 \mathrm{~mm}^{-1}$ and the Spacing Factor, SF should be less than $0.2 \mathrm{~mm}$. According to these limitations, it is clear that the core specimens do not meet the ASTM recommended limitations, 
especially in regards to the spacing factors, ranging from $0.39 \mathrm{~mm}-0.54 \mathrm{~mm}$, which are significantly higher than the recommended value of $0.2 \mathrm{~mm}$, and the SS values are also outside the limitation range; according to the air void analysis results, the SCC used in the beam is inadequate to resist freeze-thaw.

The new casting SCC also exhibited a poor hardened air void distribution system with the air content which was significantly lower than the fresh value. Although the new casting SCC exhibited a better specific surface value but the spacing factor shows similar values as those from the core specimens.

Table 4.17 - Air void properties of new casting SCC

\begin{tabular}{|c|c|c|c|c|}
\hline & $\mathrm{H} 1$ & $\mathrm{H} 2$ & $\mathrm{~N} 1$ & $\mathrm{~N} 2$ \\
\hline Air content (\%) & 2.35 & 2.33 & 2.31 & 2.38 \\
\hline $\begin{array}{c}\text { Specific surface } \\
(\mathrm{SS}), \mathrm{mm}^{-1}\end{array}$ & 23.81 & 26.316 & 24.85 & 26.17 \\
\hline $\begin{array}{c}\text { Spacing factor } \\
(\mathrm{SF}), \mathrm{mm}\end{array}$ & 0.4515 & 0.4085 & 0.4451 & 0.4307 \\
\hline
\end{tabular}

The use of HRWR in concrete may influence the air void distribution in concrete, resulting in a greater volume of big air voids and less small air voids (Sieble, 1989). Pigeon (1989) also found the use of superplasticizer generally decrease the specific surface and increase the spacing factor. Ozyildirim (2004) studied the effect of HRWR admixture on the air voids in SCC and indicated that large amount of HRWR used in SCC could have adverse effect on the air-void system. The mixes of the traditional concrete and SCC used in Stalnaker Run Bridge have similar mix design, but the difference of air bubble sizes can be seen from Figure 4.16 between the traditional prestressed concrete and the SCC used in the box beams for the Stalnaker Run Bridge. The traditional concrete had more but smaller voids compared to the SCC. The voids were distributed closely. Figure 4.17 and Figure 4.18 show the air bubble size distribution of traditional concrete and SCC, it can be seen that traditional concrete air bubble size distribution is more concentrated and the bubbles are smaller than that of SCC. The air void analysis showed the traditional prestressed concrete used in the Stalnaker Run bridge beams had a smaller spacing factor in comparison with the SCC (Surface, 2013) and the traditional concrete passed the freezethaw durability testing. 

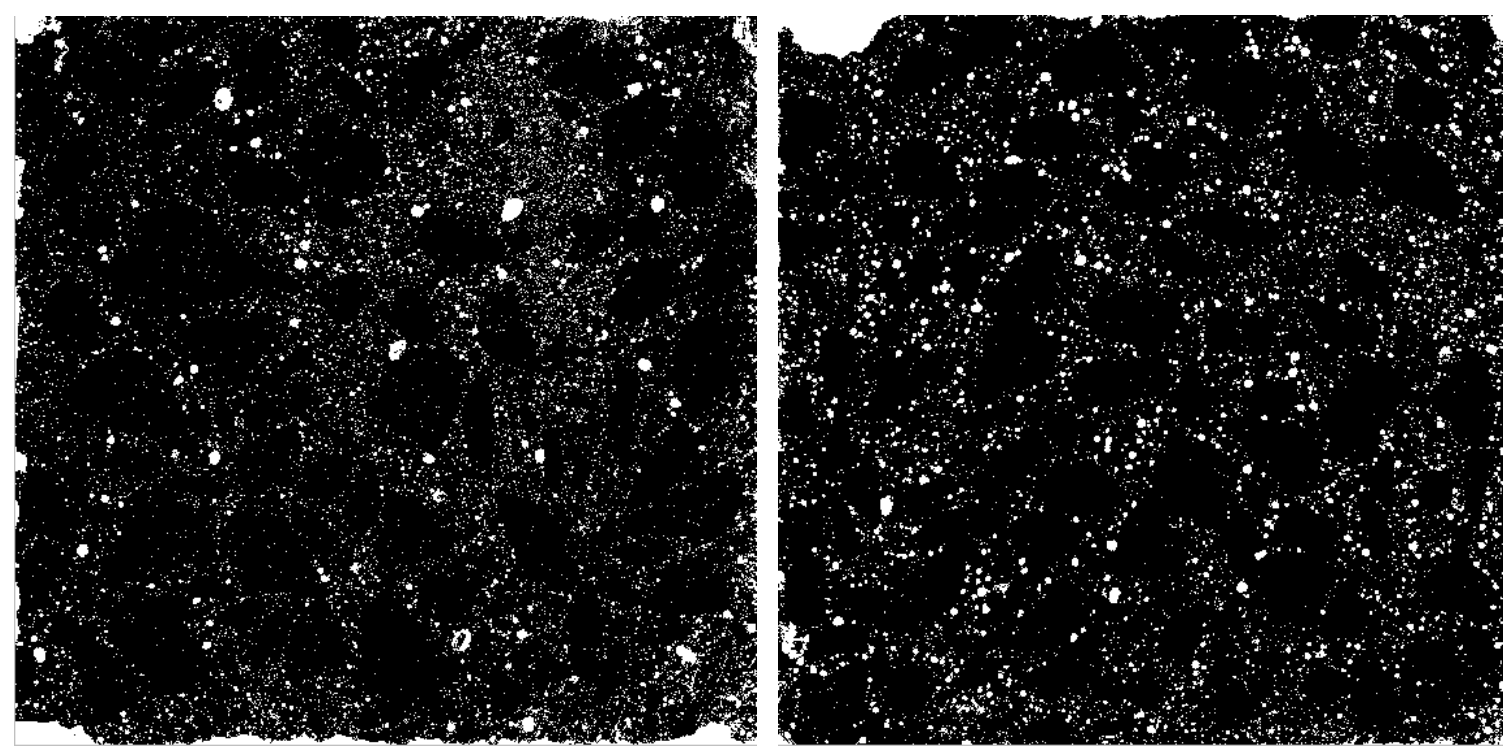

Figure 4.16 - Traditional concrete (left) and SCC (right) air void from previous results (Surface, 2013)

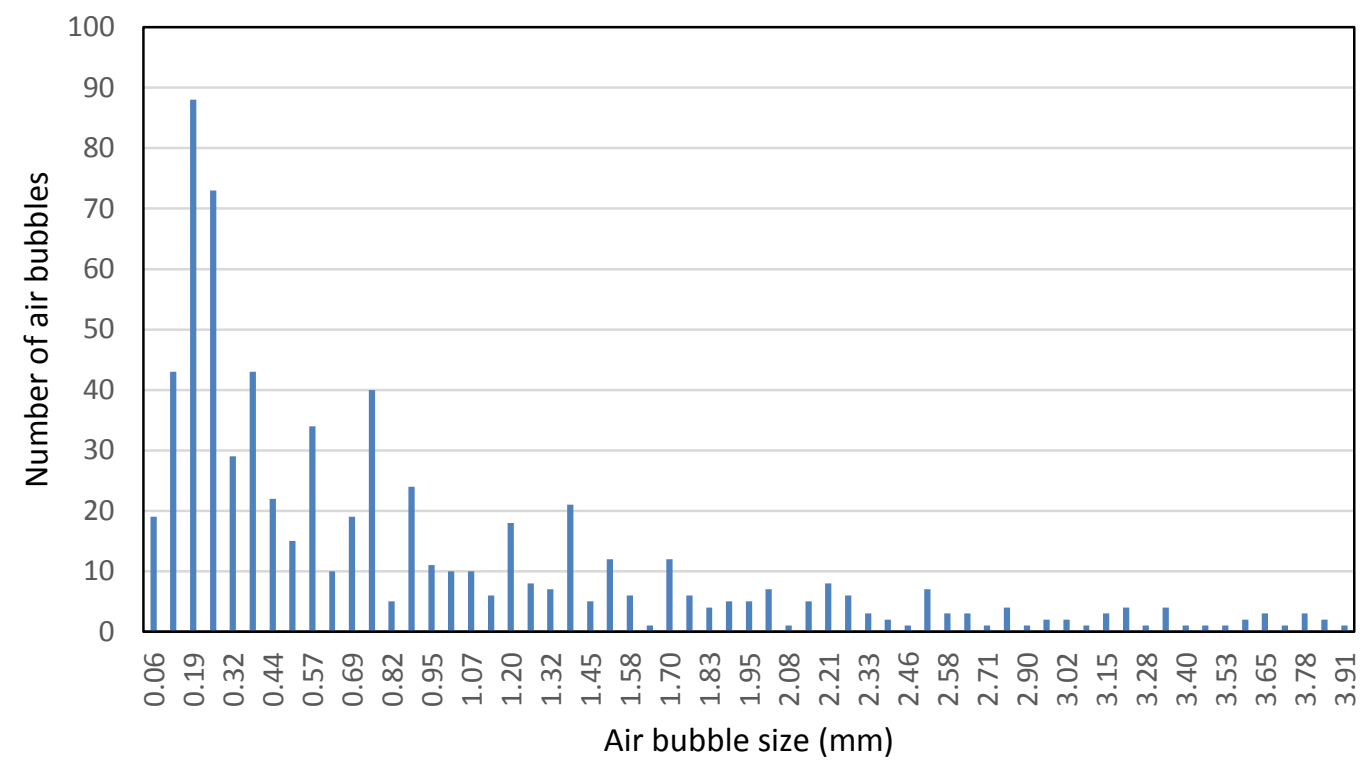

Figure 4.17 - Air bubble size distribution of traditional concrete used in Stalnaker Run Bridge (Surface, 2013) 


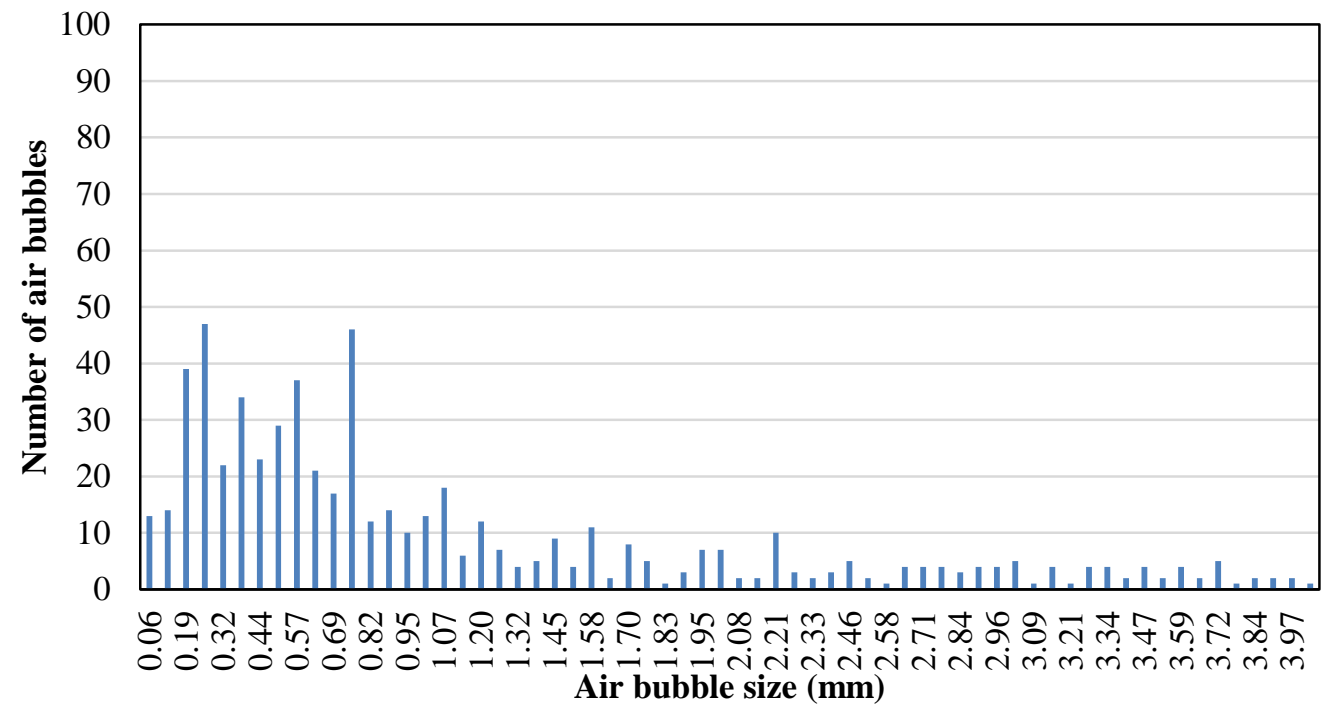

Figure 4.18 - Air bubble size distribution of SCC test beam specimen from Stalnaker Run Bridge project

\subsection{Compressive strength of the new casting SCC}

The compressive strength of the new casting SCC was tested at 1, 3, 7 and 28 days as shown in Table 4.18. It is known that lower air content concrete could have higher strength with the same water cement ratio; 1 percent increase in air content causes about 5 percent decrease in concrete strength for medium and high strength concrete (Mehta and Monteiro, 2014). The air content of the new casting SCC was about $2.3 \%$ which is much lower than that in the SCC beam (4.5\% air content). However, the results show the new casting SCC has much higher strength than that from the SCC beam, which is about 8,000 psi at 28 days. This might be because of the water cement ratio controlled for the laboratory casting (w/cm is about 0.35$)$ compared to the actual SCC beam casting (w/cm is about 0.39 ). The high temperature cured specimens showed higher compressive strength at the first day but lower strengths at 28 days as compared to the normal temperature cured specimens. It was also noticed that the new casting SCC has a high coarse aggregate percentage of about $40 \%$ (Table 4.19) based on hardened concrete image analysis, which may be due to the small batch casting. The casting in the laboratory was performed using small mixing drum, a significant amount of the paste may have stuck to the inside of the drum. The cylinders used for aggregate analysis were cast at last, which may have resulted in a higher concentration of coarse aggregate. 
Table 4.18 - Compressive strength of the new casting SCC

\begin{tabular}{|c|c|c|}
\hline & $\begin{array}{c}\text { High Temperature Cured } \\
\text { Compressive Strength, (psi) }\end{array}$ & $\begin{array}{c}\text { Normal Temperature Cured } \\
\text { Compressive Strength, (psi) }\end{array}$ \\
\hline 1 day & 12238 & 8117 \\
\hline 3 days & 13045 & 11023 \\
\hline 7 days & 13301 & 13385 \\
\hline 28 days & 13558 & 15216 \\
\hline
\end{tabular}

Table 4.19 - Coarse aggregate percentage of new casting SCC

\begin{tabular}{|c|c|c|c|c|}
\hline & $\mathrm{H} 1$ & $\mathrm{H} 2$ & $\mathrm{~N} 1$ & $\mathrm{~N} 2$ \\
\hline $\begin{array}{c}\text { Coarse Aggregate } \\
\text { percentage by area }\end{array}$ & $41.0 \%$ & $40.0 \%$ & $41.3 \%$ & $40.2 \%$ \\
\hline
\end{tabular}

\subsection{Freeze-thaw test results and discussions}

The freeze thaw testing followed the ASTM C666 procedure A, Rapid Freezing and Thawing in Water. The low temperature bound inside the freeze-thaw concrete specimens were set at $-19^{\circ} \mathrm{C}$ and the high temperature bound was set at $5{ }^{\circ} \mathrm{C}$. And each freeze thaw cycle was finished within 5 hours.

The changes of dynamic modulus tested at every 30 cycles can be seen in Figure 4.19 to Figure 4.21 using transverse frequency method. The dynamic modulus of specimens calculated using fundamental longitudinal frequency method which have similar trends as the results from transverse frequency are shown in Figure 4.22 - Figure 4.24. C1 to C4 are core specimens, H1, H2 and $\mathrm{H} 3$ are high temperature cured freeze-thaw prisms, and N1, N2 and N3 are normal temperature cured freeze-thaw prisms. 


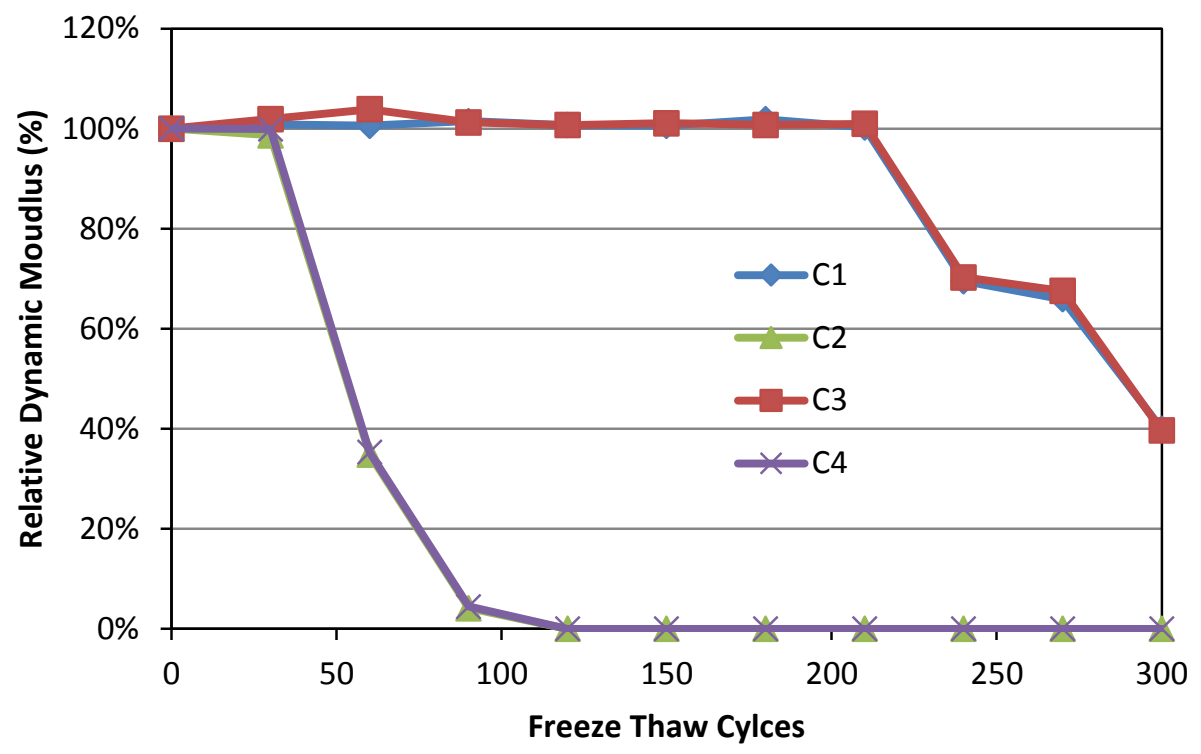

Figure 4.19 - Relative dynamic modulus of core specimens from SCC test beam using transverse frequency method

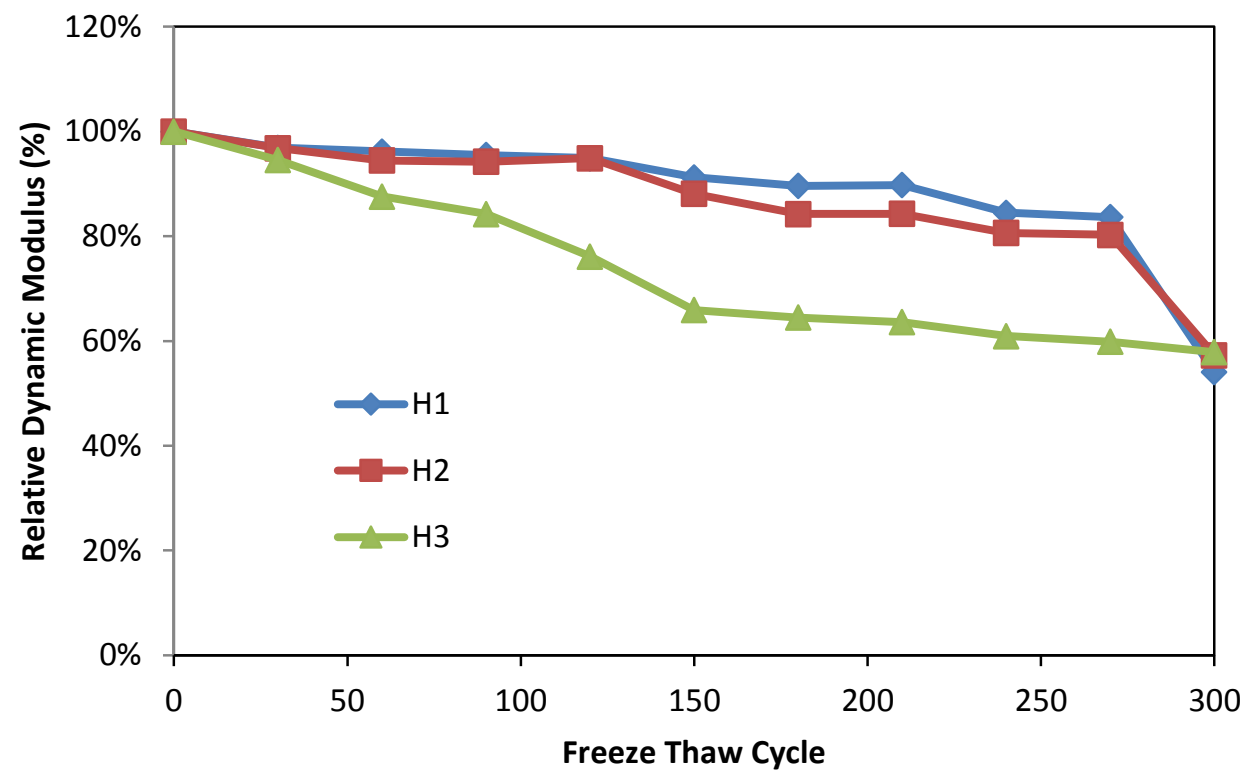

Figure 4.20 - Relative dynamic modulus of high temperature cured specimens using transverse frequency method 


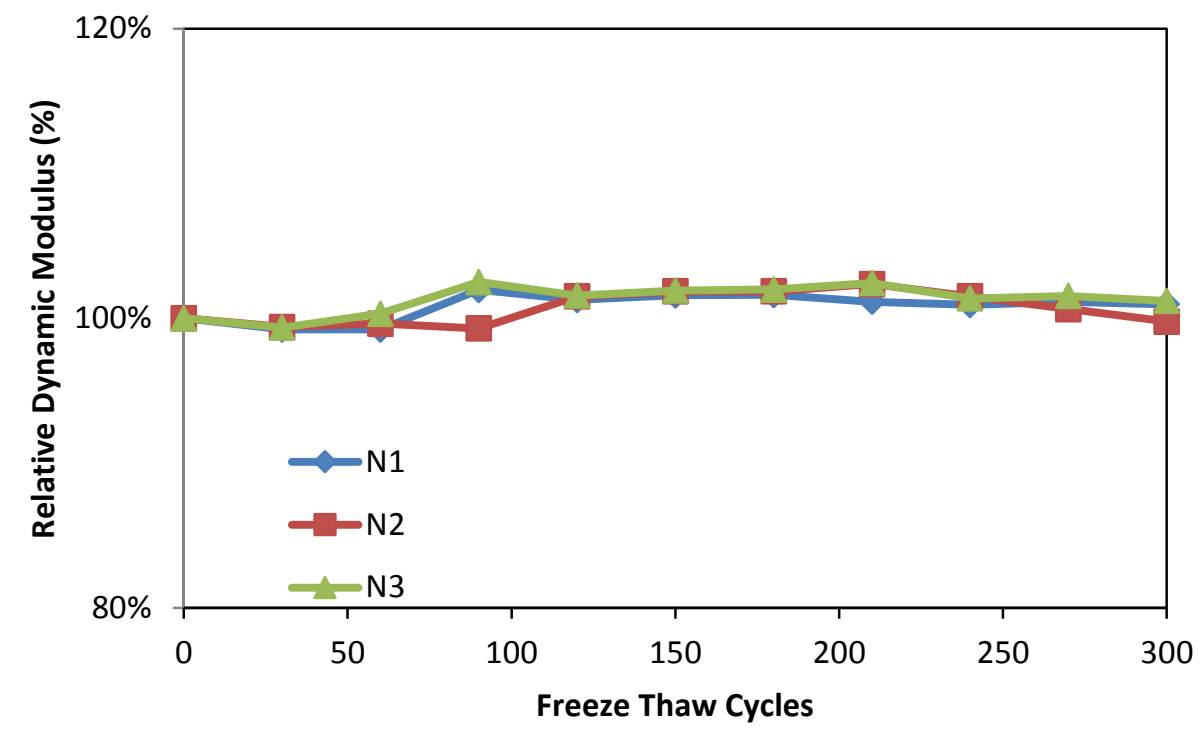

Figure 4.21 - Relative dynamic modulus of normal temperature cured specimens using transverse frequency method

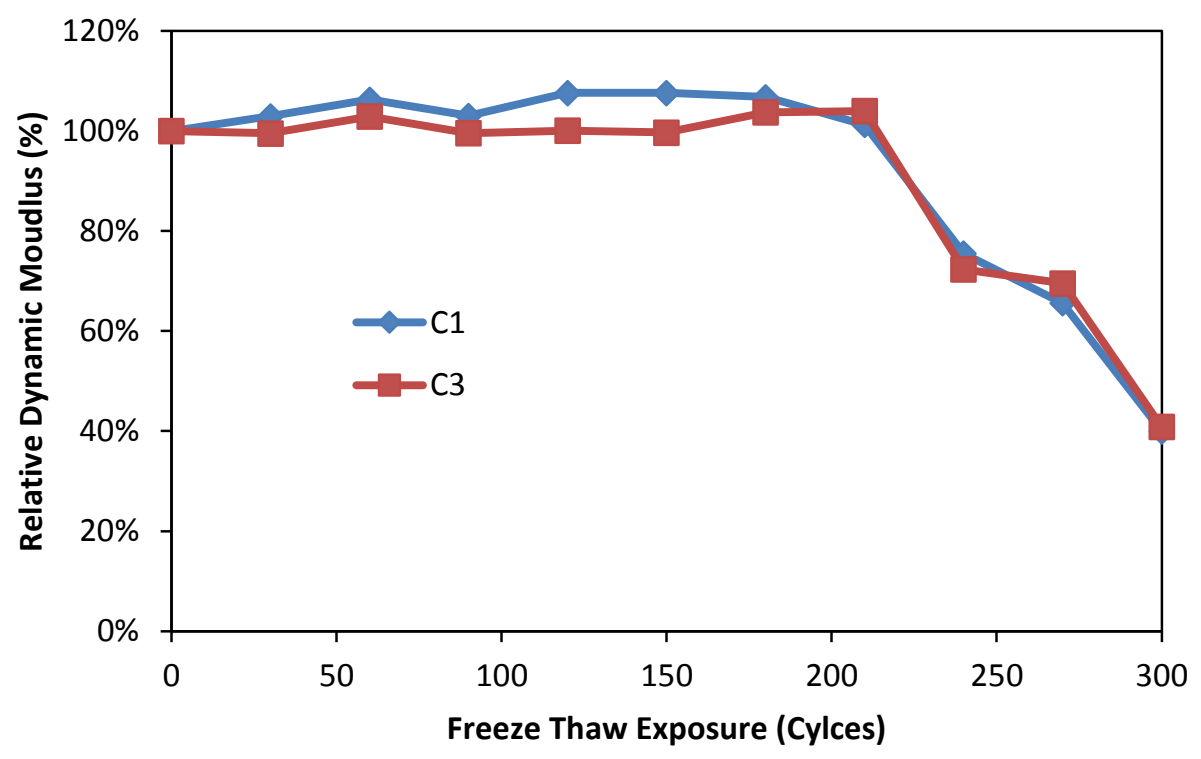

Figure 4.22 - Relative dynamic modulus of core specimens from SCC beam specimens using longitudinal frequency method 


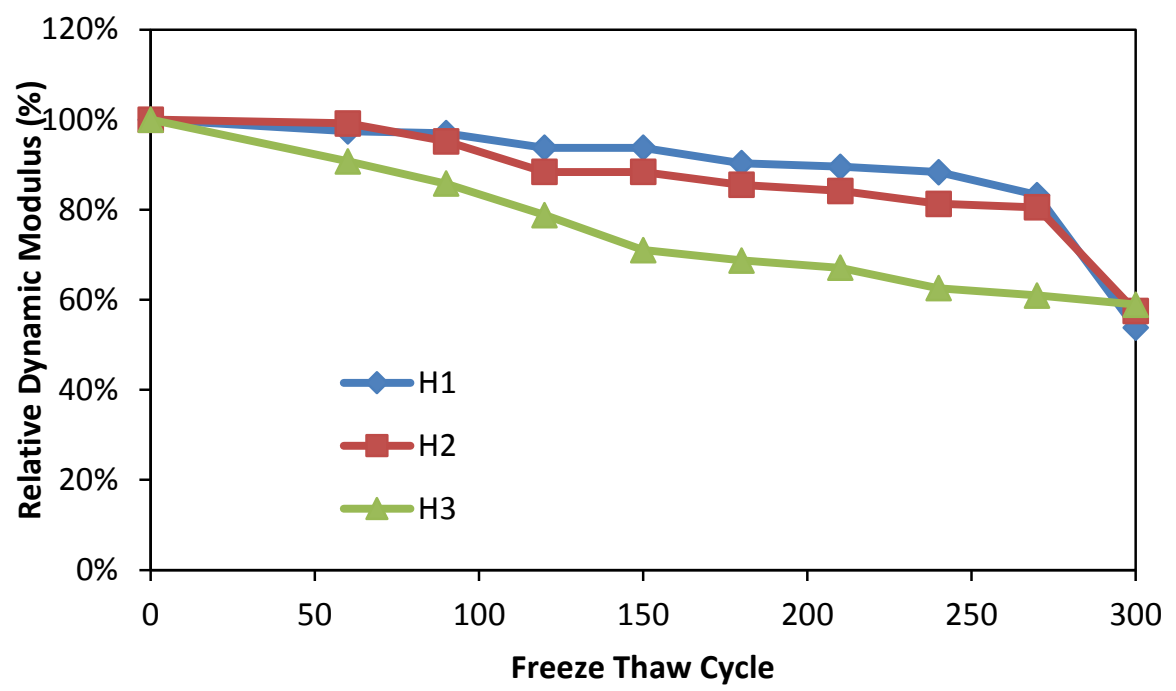

Figure 4.23 - Relative dynamic modulus of high temperature cured specimens using longitudinal frequency method

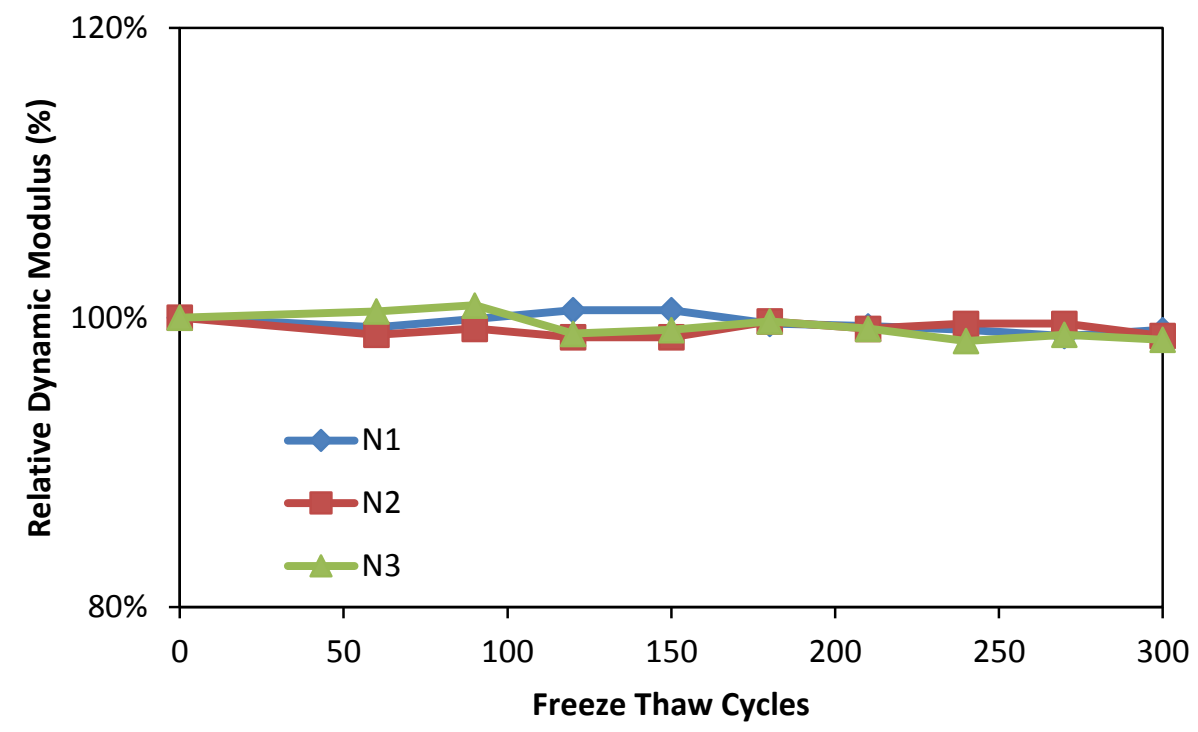

Figure 4.24 - Relative dynamic modulus of normal temperature cured specimens using longitudinal frequency method

ASTM C666 suggests specimen fails at the first occurrence of 300 cycles when its relative dynamic modulus of elasticity reached $60 \%$ of the initial modulus. From the results, the $\mathrm{C} 2$ and $\mathrm{C} 4$ failed rapidly (about 50 cycles) and the top surface of the specimens showed peeling off as 
shown in Figure 4.25. C1 and C3 failed at approximately 270 cycles and the durability factor can be calculated as 54 (using ASTM C666 equation 2) which does not meet the minimum freeze-thaw durability factor, 80 required for the SCC beams (Chen et al, 2012). Therefore, the SCC beam has potential freeze-thaw durability problem, which is consistent with the findings from previous research results (Sweet, 2014).

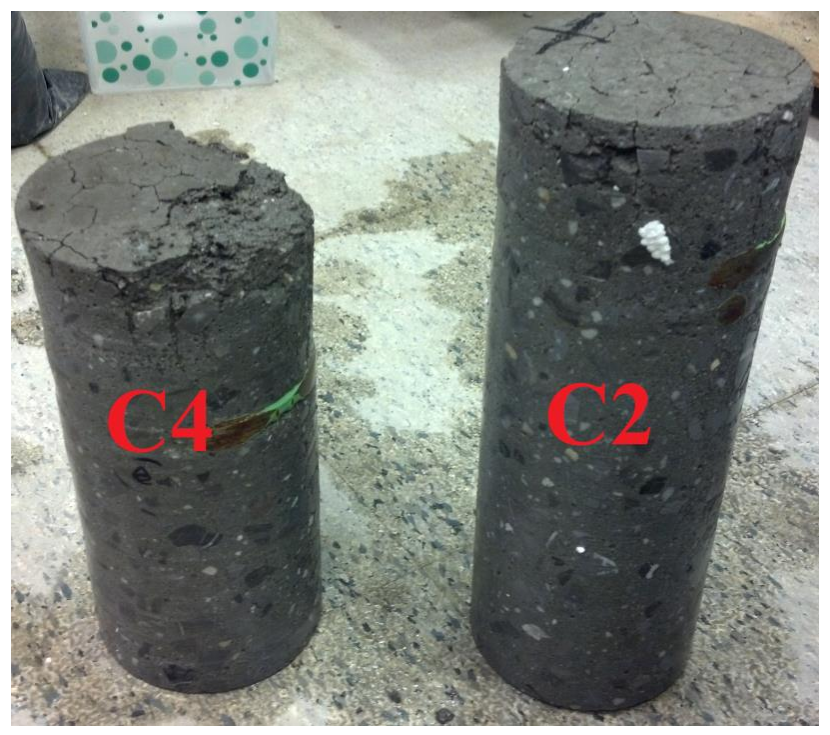

Figure 4.25 - C2 and C4 after 120 freeze-thaw cycles

For the new casting SCC sets, the specimens cured at high temperature show lower freezethaw durability compared with those cured at normal temperature. The length of the shrinkage prism was tested using length comparator at every thirty freeze-thaw cycles. Figure 4.26 shows the length change of the shrinkage prisms. The result shows the high temperature cured specimens expanded significantly (about more than $0.1 \%$ expansion at 120 cycles), however, the normal temperature cured specimens exhibited little length change. Length change test is an optional test and $0.1 \%$ expansion (length change is $0.286 \mathrm{~mm}$ ) could be used as the end limitation of the freezethaw cycles. But the length change test and relative dynamic modulus test show inconsistent results in this freeze-thaw testing. The change in length test shows the specimens failed at about 120 cycles but relative dynamic modulus test shows one specimens failed at about 270 cycles and another two specimens failed at about 300 cycles and the average durability factor can be calculated as 56.40 at 300 cycles. Shrinkage prism specimens used for length change test in this 
freeze-thaw testing have the size of 3 inches by 3 inches by 11.25 inches which is smaller than that of the freeze-thaw specimens ( 3 inches by 4 inches by 16 inches) used for dynamic modulus test. The inconsistency may be caused by the smaller size of the specimens used in the length change specimens. However, these results can still reflect the difference of freeze-thaw durability results between high temperature and normal temperature curing.

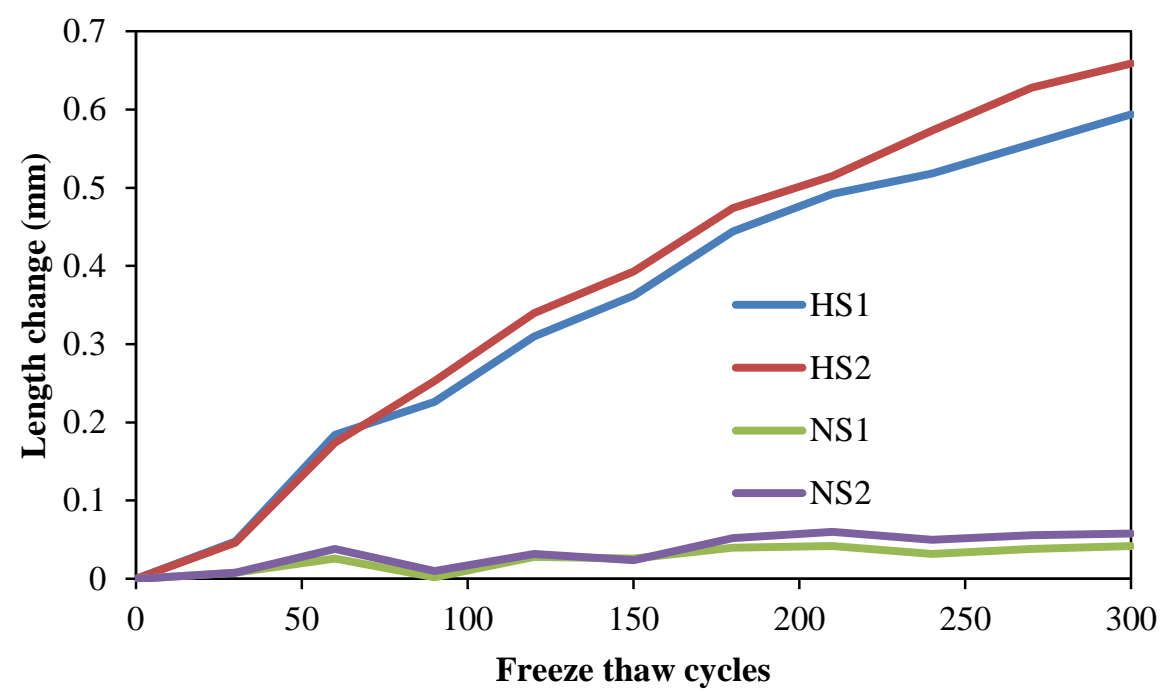

Figure 4.26 - Length change of shrinkage prisms due to freeze-thaw cycles

The spacing factor of the air-void system is one of the most important parameter to ensure concrete resisting freeze-thaw damage. Results from Kriesel (1998) showed that air-entrainment has well-known benefits on the freeze-thaw durability of concrete, and it was also possible to produce high strength $(8,000$ psi or higher) concrete with good freeze-thaw durability without airentrainment. The silica fume also has an effect on concrete's durability because of its fineness; concrete containing silica fume have exhibited good freeze thaw durability without entrained air (Philleo, 1986). Although the air void system of the new casting SCC specimens did not satisfy ASTM recommendations, the normal cured specimens still survived after 300 cycles in the freezethaw testing, possibly due to its high strength. The high temperature curing appeared to have an important effect on the freeze-thaw durability of the concrete. It was reported in the literature that high temperature curing (above $70^{\circ} \mathrm{C}$ ) could increase the permeability of concrete and have 
negative effect on concrete's durability. Researchers have found high temperature causing delayed ettringite formation (DEF) for concrete cured at $70^{\circ} \mathrm{C}$ or higher temperature, and DEF could cause the expansion and micro cracking at the interface between aggregate and cement paste. Tracy et al. (2004) found the expansion of concrete cured to $65^{\circ} \mathrm{C}$ due to DEF. The SCC beam had steam curing of temperature up to $70^{\circ} \mathrm{C}$, which might add a possible cause for low freeze-thaw durability of the SCC test beam specimens although the primary cause should be the improper air-void system in the SCC.

Under SEM, micro cracks can be seen on the surface of both high temperature cured specimens and normal temperature cured specimens the high temperature cured specimens as shown in Figure 4.27 (a) and (b) appeared to have more micro cracks than the normal temperature cured specimens shown in Figure 4.27 (c) and (d).

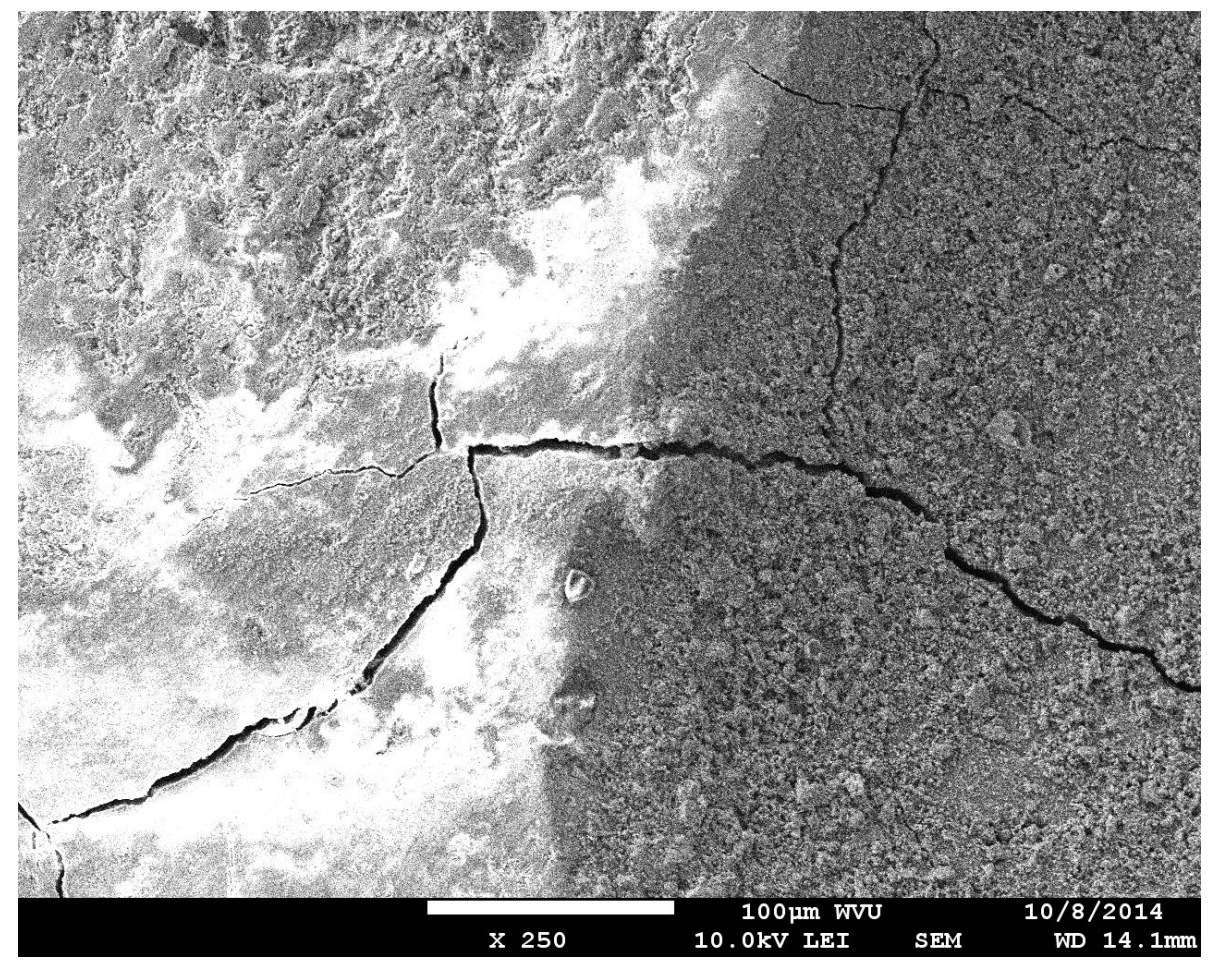

(a) 


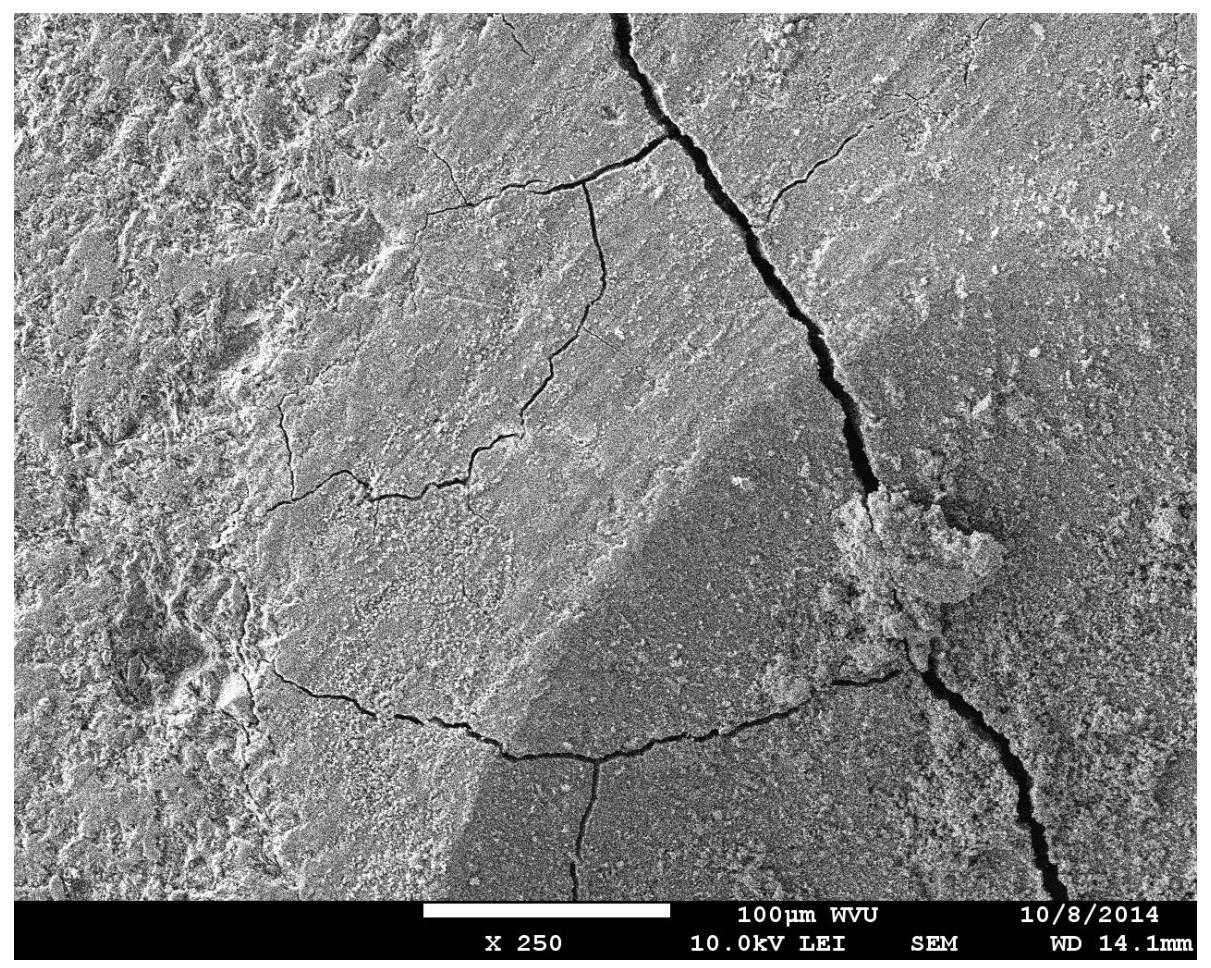

(b)

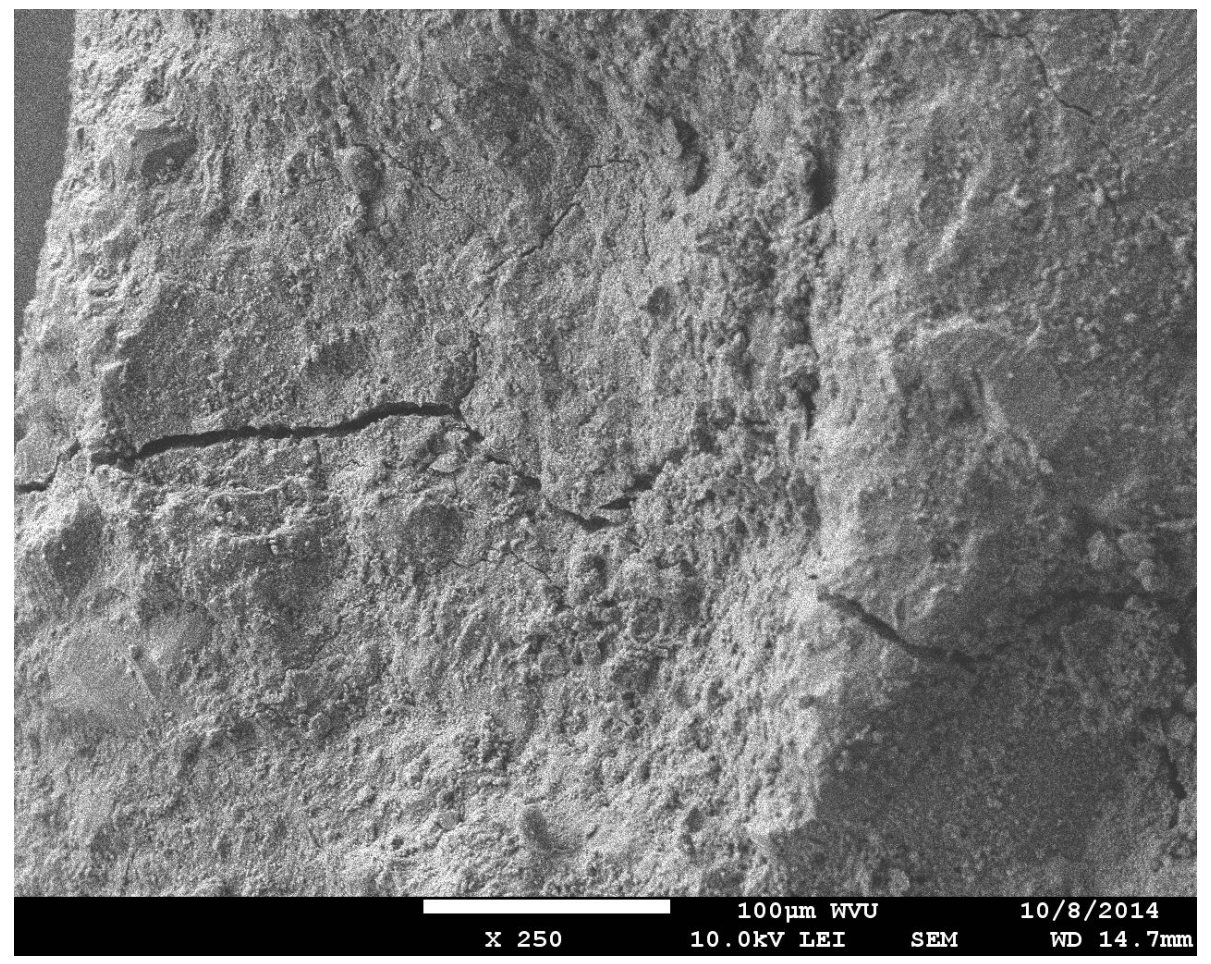

(c) 


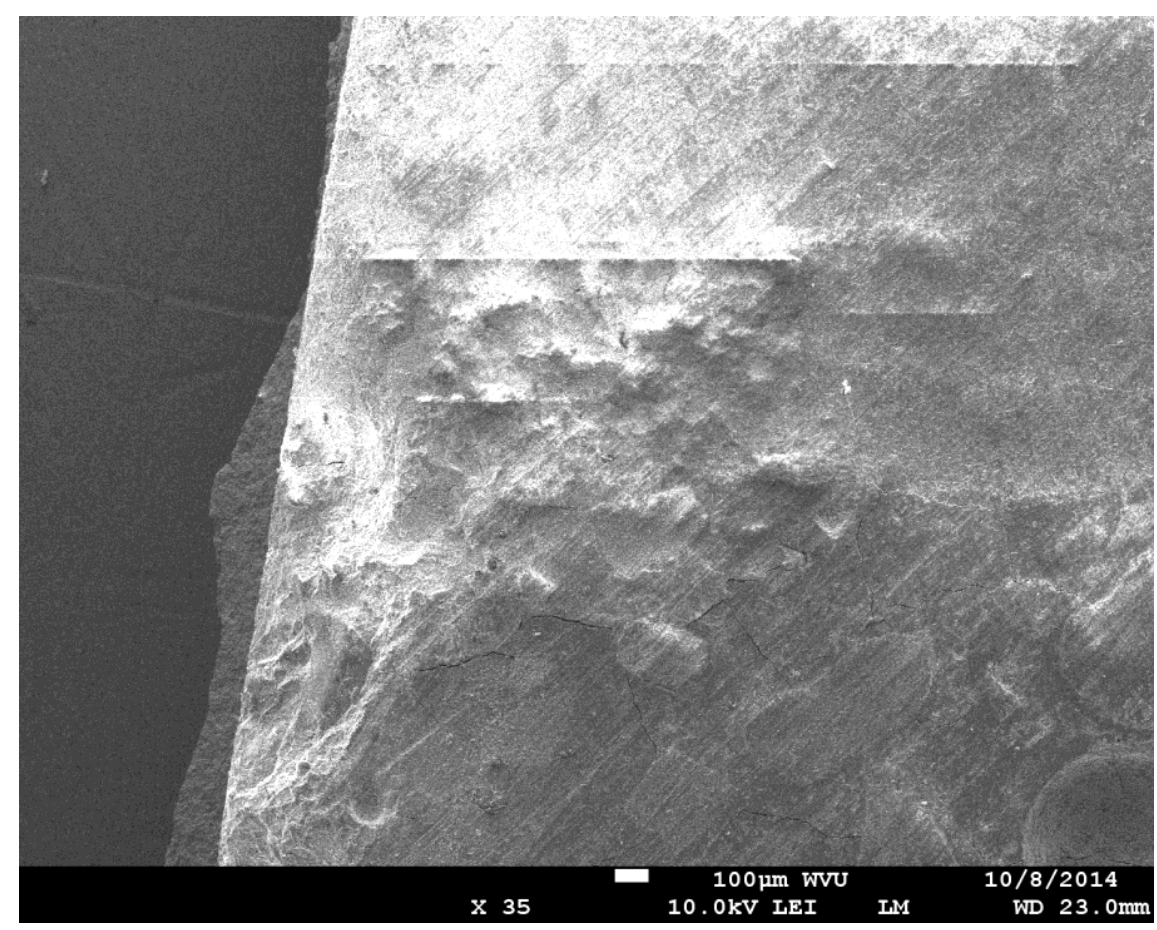

(d)

Figure 4.27 - (a), (b) High temperature cured specimen under SEM; (c), (d) Normal temperature cured specimen under SEM

\subsection{Black dots in SCC from the test beam}

A large concentration of black crystals was found in the voids in the core specimens taken from the SCC test beam, which can be seen in Figure 4.28. Most of the black dots are located in tiny voids, which are smaller than air voids but well distributed throughout the concrete. Under the microscope, it can be observed that the black crystals have many micro cracks and do not bond with the cement paste around them. These black crystals images are visible under USB digital microscope (Figure 4.28). The SEM chemical component analysis showed the black crystal has Oxygen (O), Silica (Si) and Calcium (Ca) (Figure 4.30). The black dots may contain $\mathrm{SiO}_{2} ; \mathrm{SiO}_{2}$ could react with the cement paste around it under alkaline environment and might cracked after drying shrinkage. The exact source of these black dots is not clear; it might be from some ash contamination in sand or the silica fume. It can be seen under SEM that the black dots are fractured particles (Figure 4.28 and Figure 4.29), and it is possible to have an adverse effects on the permeability and the strength of the concrete. 

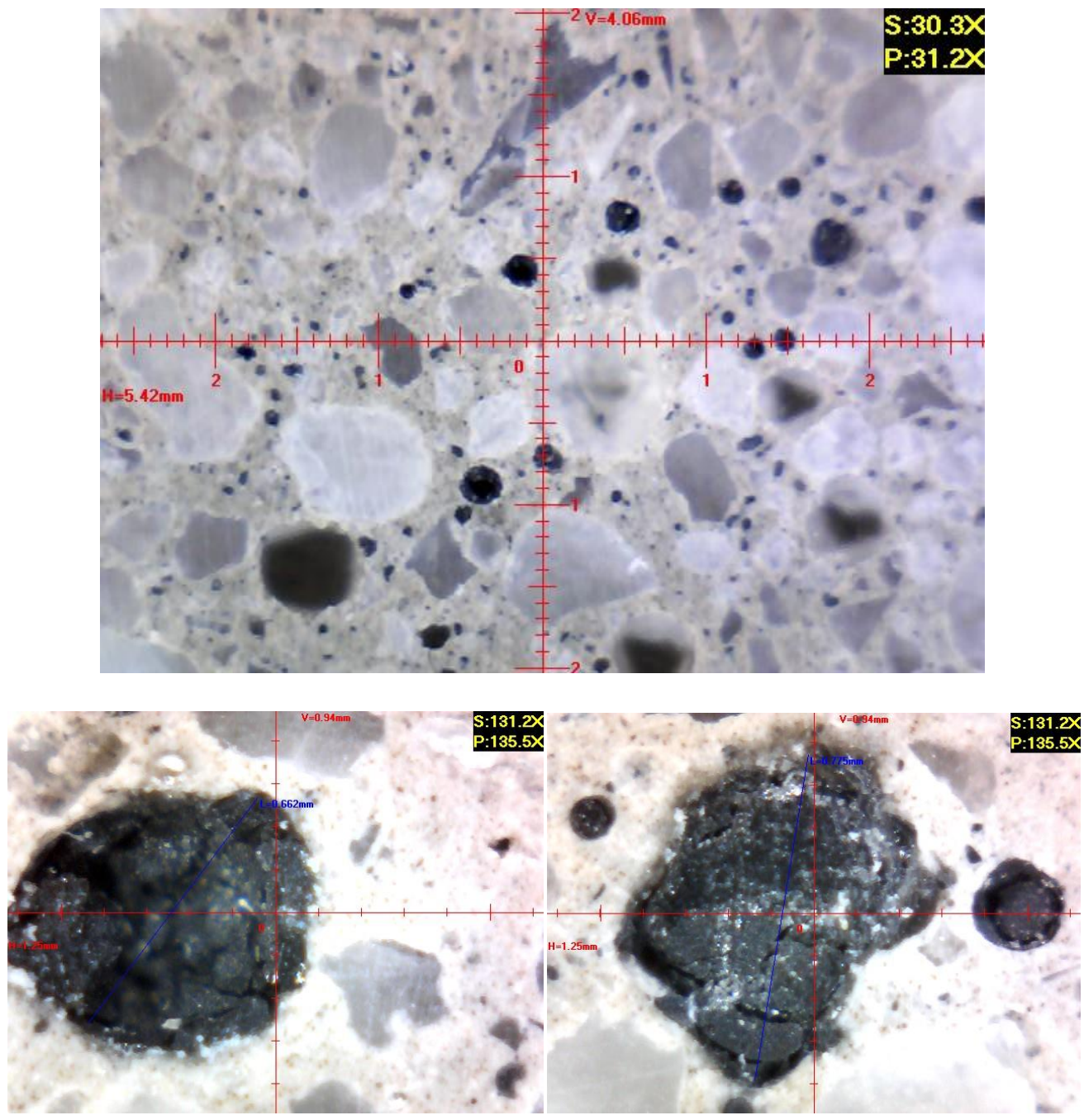

(a) black particle size of about $0.6 \mathrm{~mm}(0.02 \mathrm{in})$
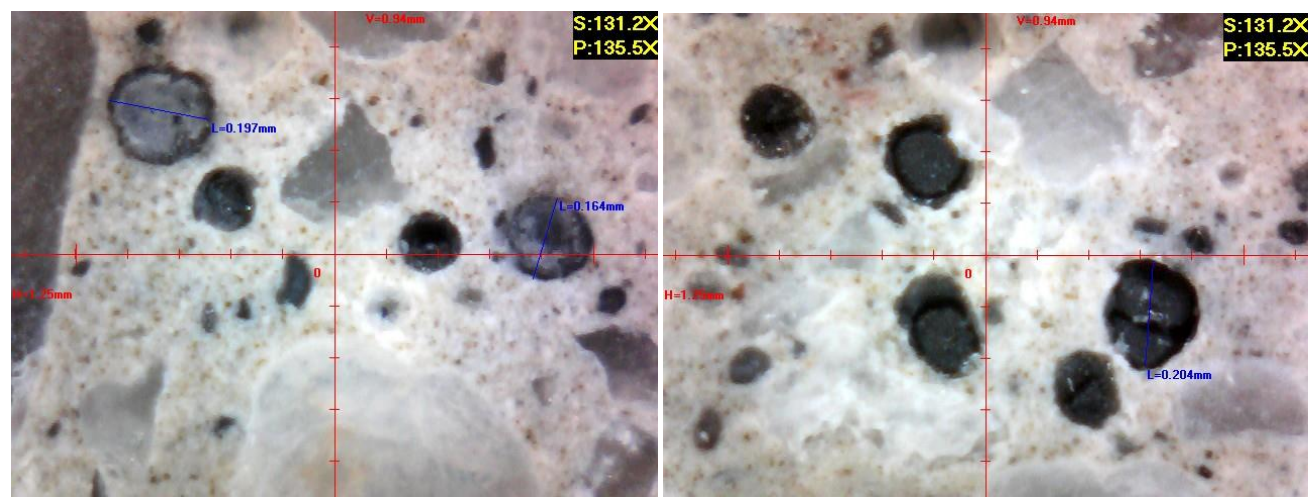

(b) black particle size of about $0.1 \mathrm{~mm}$ (0.004 in)

Figure 4.28 - Black dots in SCC 


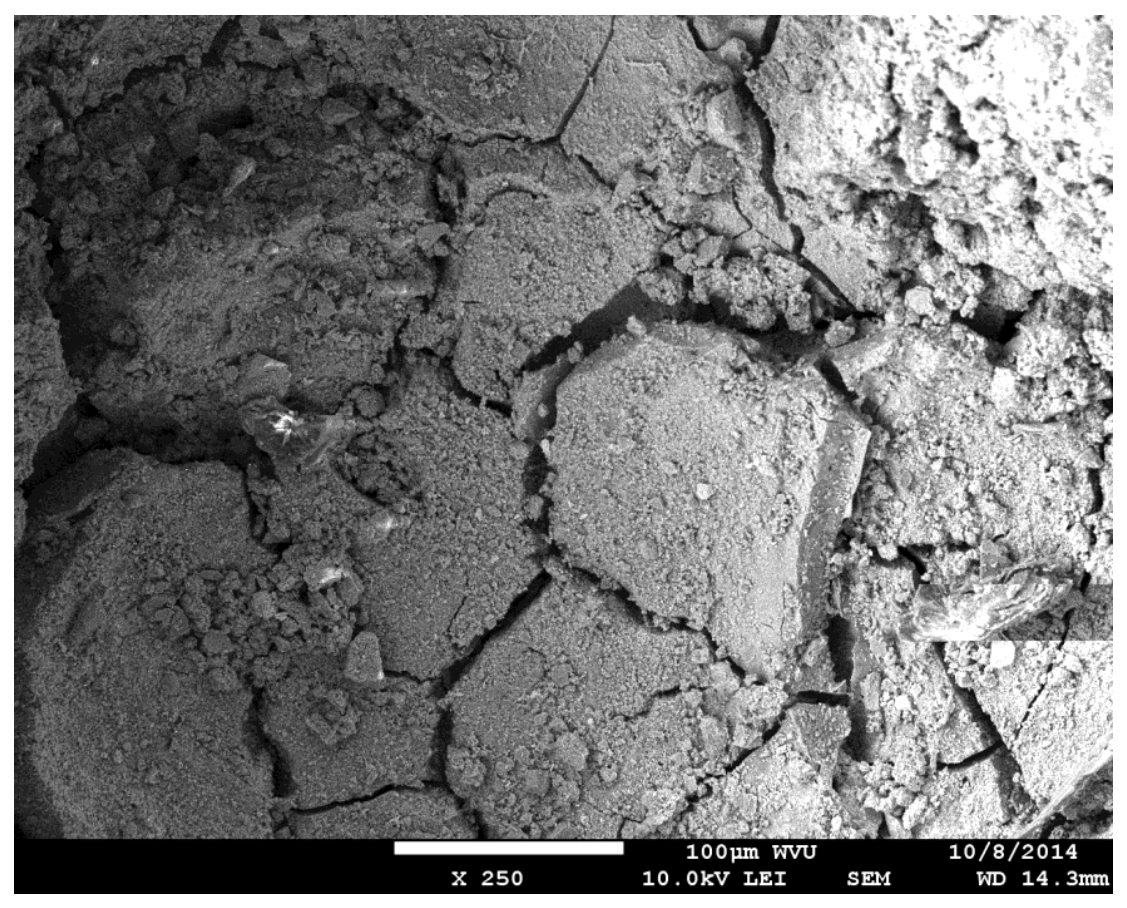

(a) scale: $100 \mu \mathrm{m}$

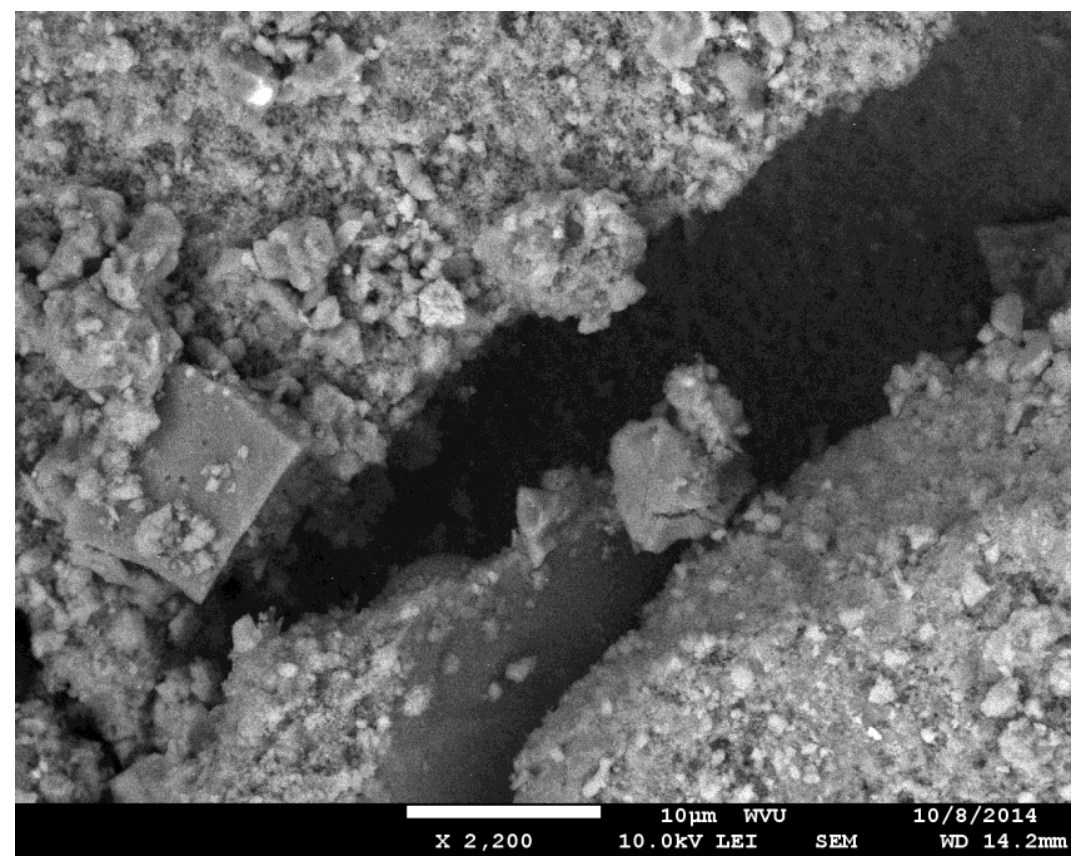

(b) scale: $10 \mu \mathrm{m}$ 


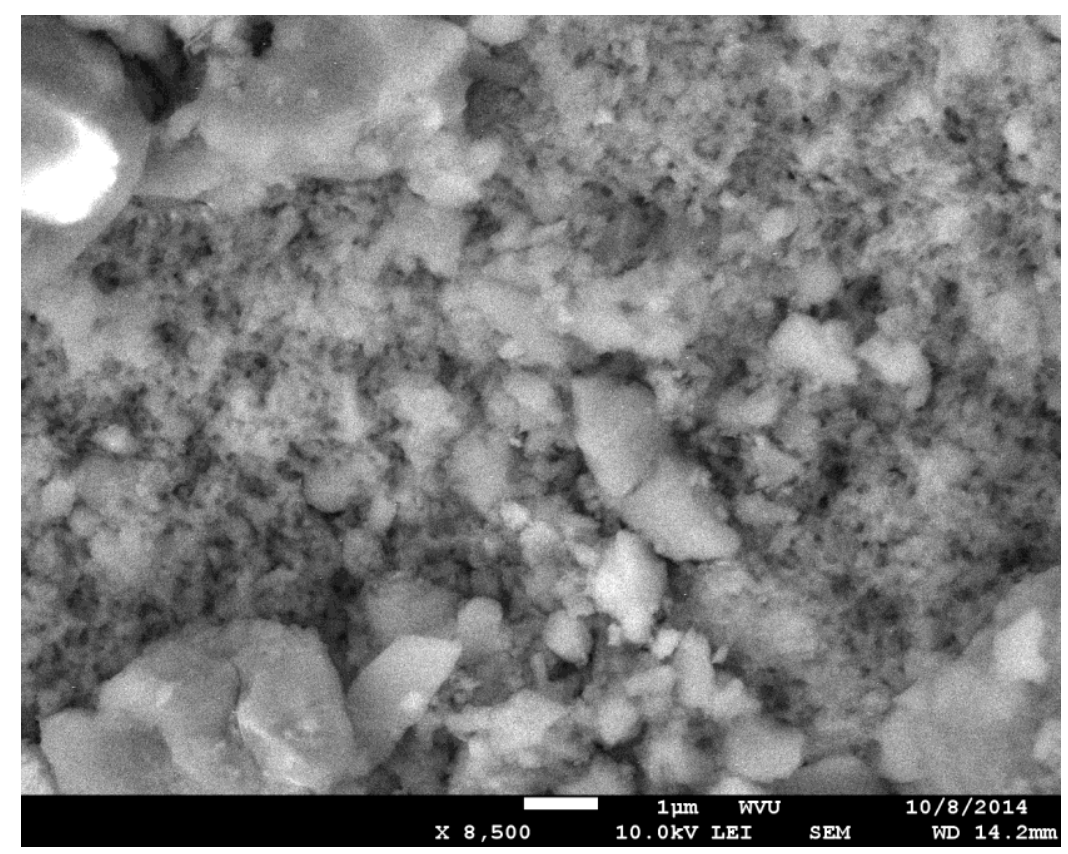

(c) scale: $1 \mu \mathrm{m}$

Figure 4.29 - SEM pictures of the black dots in SCC in three scales (a) $100 \mu \mathrm{m}$ (b) $10 \mu \mathrm{m}$. (c) $1 \mu \mathrm{m}$.

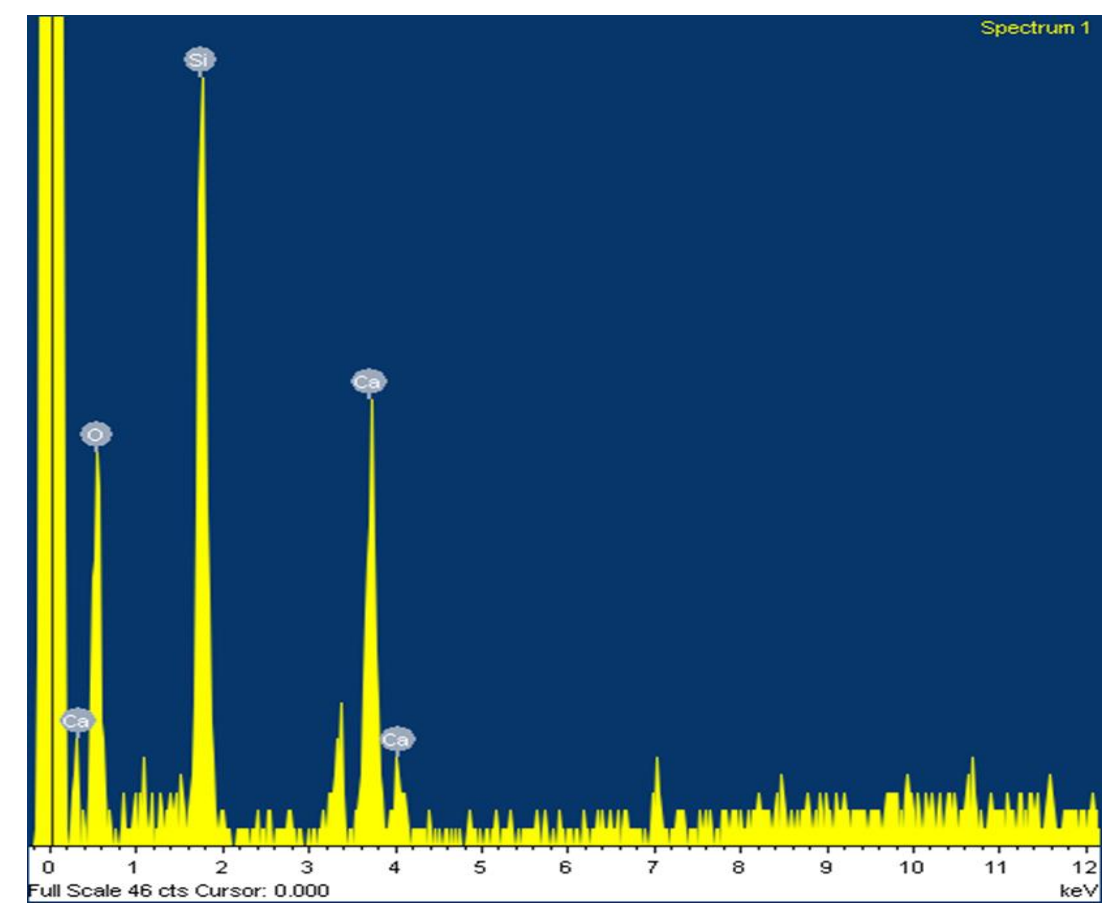

Figure 4.30 - SEM chemical components analysis of black dots 


\subsection{RCPT results and discussions}

After the 6-hour test, the total charge passed of each specimen can be calculated using Equation 3.1. The core specimens have a larger diameter (more than 4 inches) than the standard size (95 mm, $3.74 \mathrm{inch}$ ); the values for total charge passed were modified by the following equation based on ASTM C1202:

$$
Q_{s}=Q_{x} *\left(\frac{95}{x}\right)^{2}
$$

Where: $Q_{s}=$ charge passed through a 95 -mm diameter specimen,

$$
\begin{aligned}
& Q_{x}=\text { charge passed through } x(\mathrm{~mm}) \text { diameter specimen, and } \\
& x=\text { diameter }(\mathrm{mm}) \text { of the nonstandard specimen. }
\end{aligned}
$$

The temperature of the solution in RCPT cells increases with the continuous electricity flow passing through the specimens (Carbrera 1990; Whiting, 1992; Stanish, 1997). The first 30minute charge multiplied by 12 could be used as an option to minimize the temperature effect. Both 6 hours total charge passed and the result calculated by the first 30 minutes charge passed as well as silver nitrate sprat test results are shown in Table 4.20.

For silver nitrate spray test, the specimens were removed from the RCPT cells after the testing and split into two pieces. The exposed surfaces were then sprayed immediately after the splitting with a $0.1 \mathrm{M}$ silver nitrate $\left(\mathrm{AgNO}_{3}\right)$ solution. The silver nitrate reacted with free chloride ions and the color changed (Figure 4.32). The penetration depths $x_{\mathrm{d}}$ were measured and can be used to calculate the non-steady-state migration coefficient $\left(D_{n s s m}\right)$ from the following equation (NT BUILD 492):

$$
D_{n s s m}=\frac{R T}{z F E} \cdot \frac{x_{d}-\alpha \sqrt{x_{d}}}{t}
$$

In Table 4.20, $\mathrm{H} 1$ and $\mathrm{H} 2$ are high temperature curing specimens; $\mathrm{N} 1$ and $\mathrm{N} 2$ are normal temperature curing specimens; Core 1 and Core 2 are core specimens taken from the SCC test beam in 2009 and cured in Laboratory; B1 to B5 are new core specimens taken from the SCC test beam; the beam was exposed to outside climate since 2012. These core specimens recently extracted from the SCC test beam show total charge passed ranging between 2,000 to 4,000 
Coulomb, indicating moderate permeability. The measured RCPT values were also confirmed by the results from the silver nitrate tests of the RCPT specimens (B1 to B5), showing the corresponding chloride migration coefficients (Table 4.20). The RCPT results of Core 1 and Core 2 had a larger variation, showing lower permeability than that from the B1-B5 specimens.

The passed charges were ranging from 209 to 452 Coulombs in the newly casted concrete specimens, and the chloride ion permeability of the new casting specimens can be determined to be "very low" based on ASTM C1202 (Table 4.21). However, it was noted that the high temperature curing appeared to have a clear effect on the RCPT values, which showed an increase in concrete permeability.

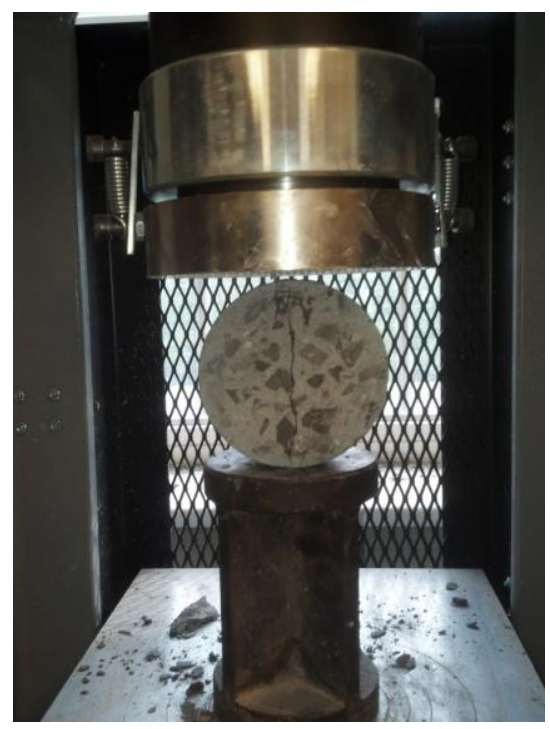

Figure 4.31 - Splitting of the RCPT specimen

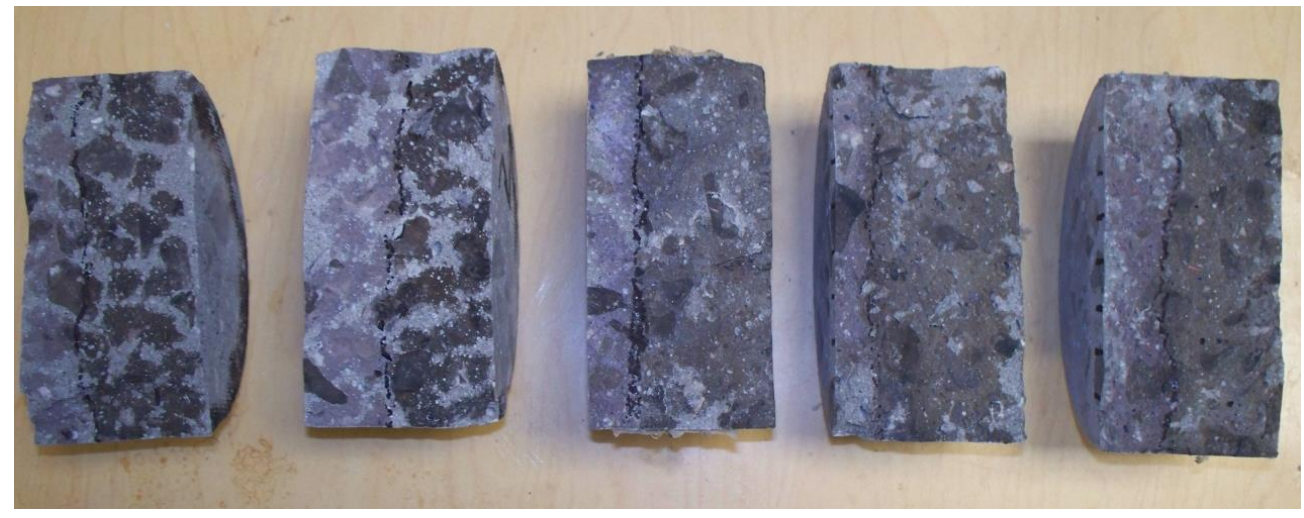

Figure 4.32 - PCPT specimens after silver nitrate test

Table 4.20 - Results of Rapid Chloride Penetration Testing 


\begin{tabular}{|c|c|c|c|c|c|c|c|c|c|}
\hline \multirow[t]{2}{*}{ Specimen } & \multirow[t]{2}{*}{ Age } & \multirow{2}{*}{$\begin{array}{l}\text { Diameter } \\
(\mathrm{mm})\end{array}$} & \multirow{2}{*}{$\begin{array}{l}\text { Initial } \\
\text { Current } \\
(\mathrm{mA})\end{array}$} & \multirow{2}{*}{$\begin{array}{l}\text { Final } \\
\text { Temp. } \\
\left({ }^{\circ} \mathrm{C}\right)\end{array}$} & \multicolumn{2}{|c|}{$\begin{array}{c}\text { Total charge } \\
\text { passed, } \\
\text { (Coulomb) }\end{array}$} & \multirow{2}{*}{$\begin{array}{c}\text { Chloride Ion } \\
\text { Penetrability } \\
\text { (ASTM } \\
\text { C 1202) }\end{array}$} & \multirow{2}{*}{$\begin{array}{l}\text { Penetration } \\
\text { depth } \\
(\mathrm{mm})\end{array}$} & \multirow{2}{*}{$\begin{array}{c}\text { Chloride } \\
\text { migration } \\
\text { coefficien } \\
\left(10^{-12}\right. \\
\left.\mathrm{m}^{2} / \mathrm{s}\right)\end{array}$} \\
\hline & & & & & $6 \mathrm{~h}$ & $\begin{array}{l}30 \min \\
x \quad 12\end{array}$ & & & \\
\hline H1 & $4.0 \mathrm{mo}$. & 101.6 & 20 & 25.2 & 452 & 432 & Very low & & \\
\hline $\mathrm{H} 2$ & $4.5 \mathrm{mo}$. & 101.6 & 19 & 25.6 & 414 & 410 & Very low & & \\
\hline N1 & $4.0 \mathrm{mo}$. & 101.6 & 8 & 25.0 & 209 & 184 & Very low & & \\
\hline $\mathrm{N} 2$ & $4.5 \mathrm{mo}$. & 101.6 & 9 & 23.6 & 225 & 205 & Very low & & \\
\hline Core 1 & $4.5 \mathrm{yr}$. & 105.9 & 53 & 26.9 & 1648 & 1198 & Low & & \\
\hline Core 2 & $4.5 \mathrm{yr}$ & 105.9 & 83 & 36.5 & 2218 & 1906 & Moderate & 14.23 & 13.1 \\
\hline B1 & $4.5 \mathrm{yr}$ & 101.6 & 116 & 41.2 & 3579 & 2689 & Moderate & 15.89 & 15.1 \\
\hline B2 & $4.5 \mathrm{yr}$ & 106.9 & 126 & 44.4 & 4093 & 2938 & High & 25.14 & 24.5 \\
\hline B3 & $4.5 \mathrm{yr}$. & 106.9 & 110 & 40.1 & 2862 & 2549 & Moderate & 14.43 & 13.6 \\
\hline B4 & $4.5 \mathrm{yr}$ & 106.9 & 65 & 38.2 & 2279 & 1652 & Moderate & 10.42 & 9.5 \\
\hline B5 & $4.5 \mathrm{yr}$. & 106.9 & 140 & 47.5 & 3820 & 3218 & Moderate & 18.27 & 17.5 \\
\hline
\end{tabular}

Table 4.21 - Chloride Ion Penetrability based on Charge Passed (ASTM C1202)

\begin{tabular}{ll}
\hline Charge Passed (coulombs) & Chloride lon Penetrability \\
\hline$>4,000$ & High \\
$2,000-4,000$ & Moderate \\
$1,000-2,000$ & Low \\
$100-1,000$ & Very Low \\
$<100$ & Negligible \\
\hline
\end{tabular}

Table 4.22 - Previous RCPT results

\begin{tabular}{|c|c|c|c|c|c|c|c|}
\hline \multirow{2}{*}{ Specimen } & \multirow{2}{*}{ Age } & \multirow{2}{*}{$\begin{array}{l}\text { Initial } \\
\text { Current } \\
(\mathbf{m A})\end{array}$} & \multirow{2}{*}{$\begin{array}{l}\text { Final } \\
\text { Temp. } \\
\left({ }^{\circ} \mathrm{C}\right)\end{array}$} & \multicolumn{2}{|c|}{$\begin{array}{l}\text { Total charge } \\
\text { passed, } \\
\text { (Coulomb) }\end{array}$} & \multirow{2}{*}{$\begin{array}{l}\text { Chloride Ion } \\
\text { Penetrability } \\
\text { (ASTM C } \\
\text { 1202) }\end{array}$} & \multirow{2}{*}{$\begin{array}{c}\text { Chloride } \\
\text { migration } \\
\text { coefficient } \\
\left(10^{-12} \mathrm{~m}^{2} / \mathrm{s}\right)\end{array}$} \\
\hline & & & & $6 h$ & $\begin{array}{c}30 \text { min } \\
\times 12\end{array}$ & & \\
\hline SCC & 2 months & 131.0 & 48.0 & 3808 & 2636 & Moderate & 15.1 \\
\hline SCC & 4 months & 91.4 & 39.3 & 2719 & 1936 & Moderate & $13.1 *$ \\
\hline
\end{tabular}


Table 4.22 shows the previous RCPT result at two and four months after the SCC beam production in September 2009. It has been reported in the literature that the hydration and water cement ratio have an effect on concrete's capillary porosity due to the hydration products may reduce the capillary porosity (Dyer, 2014). With the increase of the age, the permeability of concrete should usually decrease. Core 1 and Core 2 (at 4.5 year age) shows a lower permeability than the previous RCPT results when concrete was at 4 month of age. B1 and B5 exhibited moderate permeability but very close to high and B2 has high permeability.

The new core specimens (B1 to B5) were taken from different locations on the top surface of the box beam. From the coarse aggregate analysis, the top section of the SCC test beam had a large variation in coarse aggregate percentage at different locations and different height of the same location. B1, B2 and B3 were taken from different locations, the cores were about 5 inches in height, about 1.5 inches at the top and bottom of the core specimens were cut and 2 inches thickness disc specimens were left for RCPT. B4 and B5 were from the same location but B4 was the top of the core specimen and B5 was the bottom of the core specimen. The results suggest that segregation of the coarse aggregates may have an effect of the permeability; higher coarse aggregate contents resulted in higher permeability (Shi, 2004). From Table 4.1, the top area always has lower aggregate content than the bottom area. It was also noted that there is a strong correlation between the chloride migration coefficient and the initial current measured for concrete without mineral admixtures (Yuan, et al, 2008). As shown in Figure 4.33, the new core specimens (B1 to B5) have a linear correlation between total charge passed and chloride migration coefficient, and it can also shows some correlation between the chloride migration coefficient and the initial current, even though the SCC contains silica fume. 


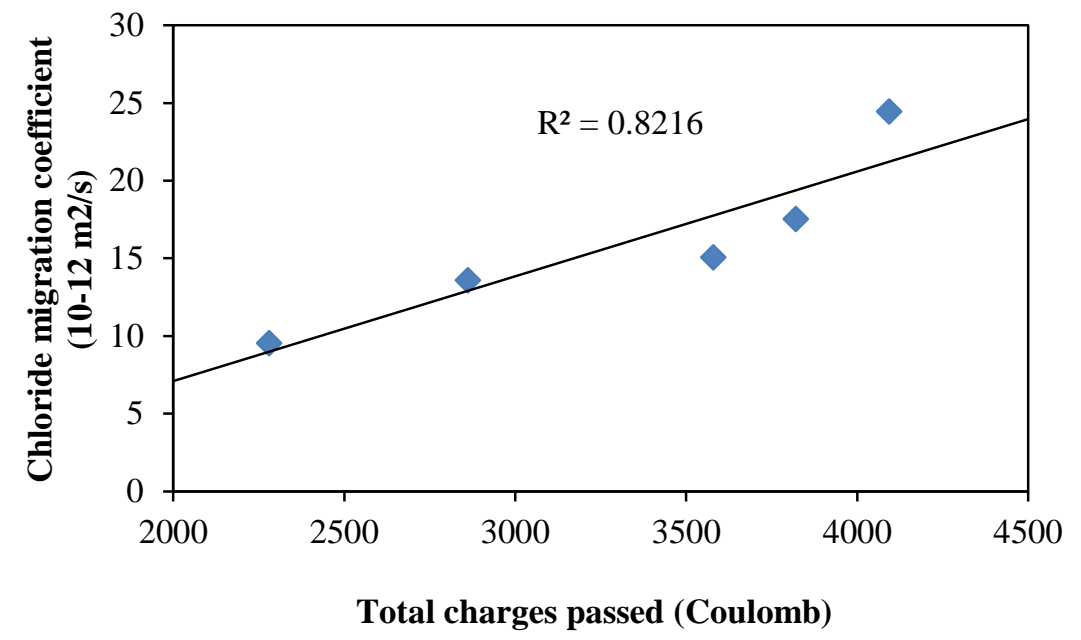

(a)

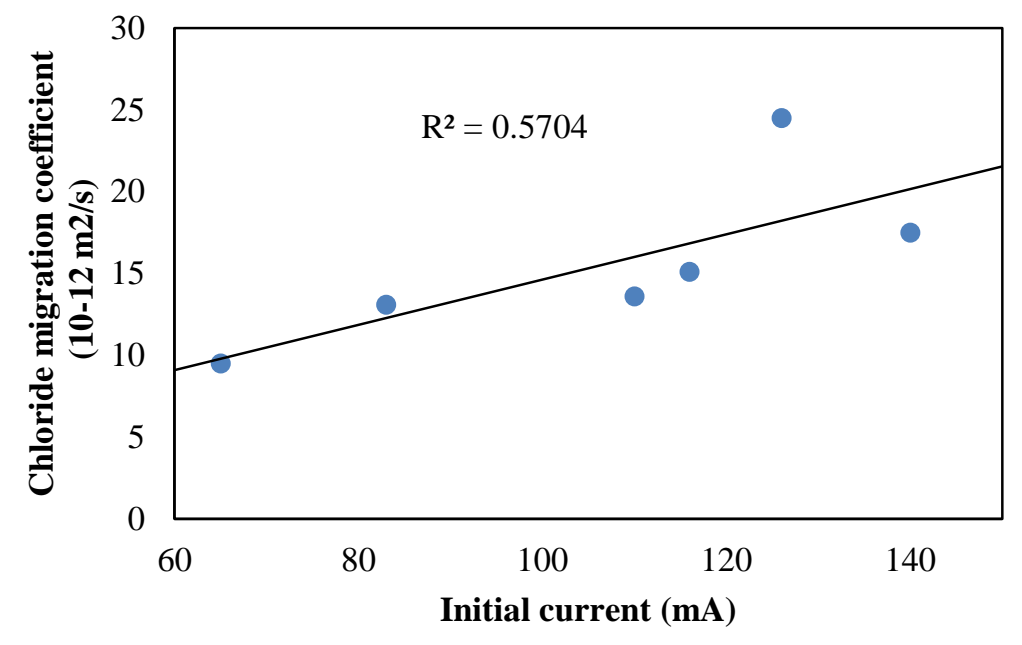

(b)

Figure 4.33 - RCPT results from Specimens B1 to B5 (a) Relationship between total charges passed and chloride migration coefficient; (b) Relationship between initial current and chloride migration coefficient.

Bentz (2007) developed a JavaScript-based virtual test method to evaluate the RCPT value of concrete, which can be accessed through the internet. The predicted total charge passed using the virtual RCPT software is 421 coulombs for the current SCC mix design, which is close to the results obtained from the newly cast SCC specimens. The silica fume has a significant effect on the permeability of concrete; silica fume has a larger fineness compared to cement that would lead 
to a large reduction in concrete diffusivity by densifying the microstructure and reducing capillary porosity, especially for concrete with relatively lower w/c ratio (w/c < 0.4) (Bentz, 2000). The virtual RCPT does not consider the effect of curing condition on concrete's permeability change. In the experiment by Acquaye (2006) with high temperature curing (160 and $200{ }^{\circ} \mathrm{F}$ ), the 28 -day compressive strength was reduced by $34 \%$ and $62 \%$, and a significant increase of permeability was found using RCPT. The increase of permeability at high temperature curing was reported by Lothenbach et al. (2007), explaining coarsened pore structure and heterogeneous distribution of hydration products due to high temperature. It was also reported from experimental results (Gergely et al., 2006) that concrete having more air content has higher permeability. The exact reason why the SCC test beam specimens have moderate RCPT values is unknown, however, a possible explanation might be the combined effects due to high temperature curing, the black particles contaminations, high w/cm ratio, high air content and aggregate segregation.

The bottom of the SCC beams for the Stalnaker Run Bridge is exposed to outdoor climates and the concrete clear cover is about 2 inches. Most of the high strength strands were located at the bottom section of the beams, which may cause damage to the bridge if the strands were to corrode. The freeze-thaw cycling also could accelerate the penetration of chloride ions. Fortunately, the bottom of the beam is underneath the bridge, which will keep the steel reinforcement away from the de-icing salts in winters.

One of the possible methods to prevent concrete from deicing salt damage is concrete coating. It was reported that laboratory and preliminary field tests were conducted by Palle and Hopwood (2006) to develop standard specifications to qualify coating products. The test methods include standard testing such as ASRM D5894, ASTM D4541, ASSHTO T260\&T259, and ASTM E96. Their test results show that several coatings have good ability to protect structural concrete from deicing salt damage. However, no freeze-thaw testing was performed on the concrete with the coating in their study. 


\section{CHAPTER 5 CONCLUSIONS}

The full-scale SCC test beam was saw-cut at three sections for the investigation of the SCC filling ability and the segregation resistance. The results from the coarse aggregate distribution analysis of the hardened concrete indicate segregation behavior in the core specimens and the sawcutting cross sections. A majority of bottom sections have an aggregate percentage lower than the theoretical value of $32.2 \%$. The saw-cut sections show that the top sections have more coarse aggregates than the bottom sections. Also, the two side sections on the top (top 1 and top 5) have shown much less coarse aggregates. The average segregation index $(\mathrm{P})$ of the top section is about $20 \%$ which is higher than the acceptable limit of $12 \%$; however, the average segregation index of the bottom section is about $12.19 \%$, which is only slightly higher than the limitation, showing that the bottom of the SCC test beam have a better aggregate distribution than the top section. The non-uniform aggregate distribution in the saw-cut cross sections might indicate inhomogeneity in the SCC beam sections, which may potentially affect the concrete material properties such as creep, shrinkage and elastic modulus of the prestressed beam section.

The hardened air void analysis of the SCC test beam yielded results exceeding the ASTM limits. ASTM C457 recommends the Specific Surface, SS should be in the range of 25 to $45 \mathrm{~mm}^{-}$ 1 and the Spacing Factor, SF should be less than $0.2 \mathrm{~mm}$. The results from eight core specimens extracted from the SCC beams show the spacing factors ranging from $0.39 \mathrm{~mm}$ to $0.54 \mathrm{~mm}$, which are significantly higher than the limitation, and the SS values ranging from 16.6 to $23.0 \mathrm{~mm}^{-1}$ which are also outside the limitation; the air-void results show that the SCC used in the beam is inadequate to resist freeze-thaw. The traditional prestressed concrete used in Stalnaker Run Bridge showed better air void system compared to SCC samples; the air voids were distributed closely with higher small air bubble number, resulting a smaller spacing factor.

The RCPT and freeze-thaw testing of the core samples from the beam show consistent results with previous results obtained during the beam production. The SCC core specimens from the beam failed at 270 cycles of freeze-thaw test with a durability factor of 54 which is much smaller than the required durability factor $(>80)$. The RCPT results show that the SCC test beam has moderate permeability to resist chloride ion penetration. Under the microscope, a large amount of black particles was found filled in voids; the black dots were fractured and were not bonded with the cement paste around them. The poor air-void system might be the main reason that the 
SCC test beam specimens failed in the freeze-thaw testing since the traditional concrete beam having same curing condition but better air-void system survived in the freeze thaw testing.

Using the same mix design as the SCC beam, the new SCC casting in the laboratory showed higher compressive strength compared to the SCC beam. The compressive strength of high temperature cured concrete was higher at the first 3 days but lower at the 28 days compared to those from the normal temperature cured specimens. The results show that high temperature curing has a significant effect on concrete freeze-thaw durability and permeability. The high temperature cured specimens failed at 270 cycles but the normal temperature cured specimens survived in the freeze thaw testing. All the new casting specimens show low chloride ion penetrability in RCPT, however, the RCPT value of high temperature cured specimens exhibited two times the penetrability value compared to that of normal temperature cured specimens. 


\section{CHAPTER 6 RECOMMENDATIONS}

The results show the SCC full-scale test beam from the Stalnaker Run Bridge project has freeze-thaw durability problem, and the freeze-thaw failure may cause the increase of permeability of the SCC beams. Hence, it's necessary to continue searching for methods to prevent the SCC beams on the bridge from freeze-thaw failure during their service life. One of the possible methods to prevent concrete from deicing salt damage is concrete coating; further experiments are recommended to investigate the effect of the coating on concrete freeze-thaw durability.

Additionally, the method to quantify segregation of hardened concrete using Segregation Index during this study might be limited. Further study is needed to quantify the information of coarse aggregate gradation distribution. The air void system analysis using flat scanner and Bubble Counter program could be affected by scanner type, light condition, powder color and the threshold setting. A faster and more accurate method to verify the threshold setting needs to be developed. Several castings of SCC in the laboratory have shown higher compressive strength than the SCC test beam due to $w / \mathrm{cm}$ ratio; further research is recommended to find a method to verify $w / \mathrm{cm}$ quickly after concrete mixing for a better on-site quality control. The effects of steam curing and the chemical admixture on SCC's air-void system and its relationship with the freeze-thaw durability also need further investigation. 


\section{REFRENCES}

Acquaye, L., "Effect of High Curing Temperatures on the Strength Durability and Potential of Delayed Ettringite Formation in Mass Concrete Structures", Ph.D. dissertation, University of Florida, 2006.

Ba, M. F., Qian, C. X., Guo, X. J. et al, "Effects of Steam Curing on Strength and Porous Structures of Concrete with Low Water/Binder Ratio," Construction and Building Materials, 25 (2011) 123128.

Baranowski, K., Sweet, J. and Chen, H. L., "Assessment of the Effects of the Coal Resource Transportation System (CRTS) on Bridges Conditions in District 9." RP-220 Final Report, WVDOH, November 2009.

Bentz, D., “A virtual rapid chloride permeability test”, Cement \& Concrete Composites 29 (2007) 723-731.

Bentz, D., "Influence of silica fume on diffusivity in cement-based materials II. Multiscale modeling of concrete diffusivity", Cement Concrete Res 2000; 30:1121-9.

Bentz, D., Jensen, O., Coats, A. and Glasser, F., "Influence of silica fume on diffusivity in cementbased materials I. Experimental and computer modeling studies on cement pastes", Cement Concrete Res 2000; 0:953-62.

Cabrera, J.G., Claisse, P.A., "Measurement of Chloride Penetration into Silica Fume Concrete", Cem. Concr. Compos. 12 (1990) 157-161.

Carlson, J., "Advancement on the Application of a Flat-Bed Scanner for Hardened Portland Cement Concrete Air Void Analysis”, Master Thesis, Michigan Technological University, 2005.

Carlson, J., Sutter, L., Peterson, K., and Van Dam, T., "An Update on Application of a Flat-Bed Scanner for Performing ASTM C457," Proceedings of the 27th International Conference on Cement Microscopy, 2005, International Cement Microscopy Association, Victoria, British Columbia, Canada.

Chen, H. L., Baronowski, K. and Sweet, J., Exploration of Placement Techniques on the Properties of Self Consolidating Concrete", The 3rd Congress of the International Federation for Structural Concrete (fib), Washington DC, May 29-June 2, 2010.

Chen, H. L., Sweet, J. and Baronowski, K., "Testing of Self-Consolidating Concrete for Drilled Shafts in a Rural Bridge Replacement in West Virginia", The 3rd Congress of the International Federation for Structural Concrete (fib), Washington DC, May 29-June 2, 2010.

Chen, H. L., Sweet, J., Yikici, T. and Lin, Y., "RP221C Supplemental Tasks for 'Feasibility and Implementation of Self-Consolidating Concrete", Draft final report, WVDOH RP221C, 2012.

Chini, A. and Acquaye, L., "Effect of Elevated Curing Temperatures on the Strength and Durability of Concrete," Materials and Structures 38 (August-September 2005) 673-679.

Development of a Guide for Cast-in-Place Applications of Self-consolidating Concrete, Nebraska Department of Roads (NDOR), November 2007. 
Diamond, S., "Delayed Ettringite Formation - Processes and Problems," Cement and concrete composite 18(1996) 205-215.

Dyer, T., “Concrete Durability”, CRC Press 2014, ISBN: 978-0-415-56475-5.

Fang, C. X., Labi, S., "Evaluating the Static Segregation Resistance of Hardened SelfConsolidating Concrete using Image Processing Technology," 86th Annual Meeting of the Transportation Research Board, 2006.

Gergely, J., Bledsoe, J., Tempest, B. and Szabo, I., "Concrete Diffusion Coefficients and Existing Chloride Exposure in North Carolina", North Carolina Department of Transportation Research and Analysis Group, Research Report FHWA/NC/2006-26.

Guidelines for Viscosity Modifying Admixtures for Concrete, EFNARC, September 2006.

Hover, K. C., "Air content and density of hardened concrete. Significance of Tests and Properties of Concrete and Concrete-Making Materials," (ASTM STP169D), 288-308, 2006.

Ianssen, D. and Snyder, M., "Resistance of concrete to Freezing and Thawing," Strategic Highway Research Program, National Research Council, Washington, DC 1994.

Investigation into Freezing-Thawing Durability of Low-Permeability Concrete with and without Air Entraining Agent, National concrete Pavement Technology Center, June 2009.

Janssen, D., and Snyder, M., "Resistance of Concrete to Freezing and Thawing", National Academy of Sciences, 1994.

Johnson, D., Johnson, G. and Robertson, I., "Quantifying Segregation in Self-Consolidation Concrete through Image Analysis", University of Hawaii, Research report UHM/CEE/10-04, May 2010Michel Pigeon, Patrick Plante and Michel Plante, "Air-Void Stability Party I: Influence of Silica Fume and Other Parameters", ACI Materials Journal, Title No. 86-M44, 1989.

Khayat, K. and Assaad, J., "Air-Void Stablity in Self-Consolidating Concrete," ACI materials journal, Vol.99, July 2002, pp408-416.

Khayat, K. H. and Mitchell, D., "Self-Consolidating Concrete for Precast, Prestressed Concrete Bridge Elements", Report 628, National Cooperative Research Program (NCHRP): Transportation Research Board, 2009.

Kriesel, R., Snyder, M. and French, C., "Freeze-Thaw Durability of High-Strength Concrete", Final report, Minnesota Department of Transportation, 1998.

Lange, D. A., Struble L. J., Dambrosia M. D., Shen, L., et al., "Performance and Acceptance of Self-Consolidating Concrete: Final Report", Illinois Center for Transportation, UILU-ENG-20082007.

Ley, K., Felice, R. and Freeman, M. J., "Concrete Pavement Mixture Design and Analysis (MDA): Assessment of Air Void System Requirement for Durable Concrete", National Concrete Pavement Technology Center, 2012.

Lothenbach, B., Winnefeld, F., Alder, C. et al, "Effect of Temperature on the Pore Solution, Microstructure and Hydration Products of Portland Cement Pastes", Cement and Concrete Research 37 (2007) 483-491. 
Mehta, P. K. and Monteiro, P., "Concrete Microstructure, Properties, and Material”, Fourth Edition, Chap. 5, PP. 113-137, 2014.

Nezami, S., "Assessment of Flatbed Scanner Method for Quality Assurance Testing of Air Content and Spacing Factor in Concrete," Master thesis, University of Toronto, 2013.

NT BUILD 492, Chloride Migration Coefficient from Non-steady-state Migration Experiments; 1999.

Ozyildirim, C., "Air-Void Characteristics of Concretes in Different Applications", Transportation

Research Record: Journal of the Transportation Research Board, No. 1893, TRB, National Research Council, Washington, D.C., 2004, pp. 70-74.

Palle, S. and Hopwood, T., "Coatings, Sealants and Fillers to Address Bridge Concrete Deterioration and Aesthetics - Phase 1," Kentucky Transportation Center, Research Report KTC03-36/SPR 291-04-1F, December 2006.

Philleo, R., "Freezing and thawing resistance of high-strength concrete", Washington, D.C.: Transportation Research Board, 1986.

Powers, T.C. and Willis, T.F., "The Air Requirement of Frost Resistance Concrete," Highway Research Board Proceedings. Highway Research Board. (1994 ) Vol. 29, pp184-211.

Radlinski, M., Olek, J., Zhang, Q. H. and Peterson, K., "Evaluation of the Critical Air-Void System Parameters for Freeze-Thaw Resistant Ternary Concrete Using the Manual Point-Count and the Flatbed Scanner Methods," Journal of ASTM International, Vol. 7, No. 4, 2010.

Ramezanianpour, A. and Hooton, R., "Evaluation of Two Automated Methods for Air-Void Analysis of Hardened Concrete," Journal of ASTM International, Vol. 7, No. 2, 2010.

Ramezanianpour, A.A., Khazali, M.H. and Vosoughi, P., "Effect of steam curing cycles on strength and durability of SCC: A case study in precast concrete", Construction and Building Materials 49 (2013) 807-813.

RILEM Technical Committee, "Final Report of RILEM TC 205-DSC: Durability of SelfCompacting Concrete," Materials and Structures (2008) 41:25-233.

Scott, M., "Determining the Air Void Parameters of Concrete Using Digital Image Analysis of Polarized Light Micrographs," Master thesis, 1997.

Shi, C.J., "Another Look at the Rapid Chloride Permeability Test (ASTM C1202 or ASSHTO T277)”, FHWA Resource Center. Federal Highway Administration, Baltimore, MD, 2003.

Stanish, K.D., Hooton, R.D., Thomas, M.D.A., "Testing the Chloride Penetration Resistance of Concrete: A Literature Review”, FHWA Contract DTFH61-97-R-00022, 1997, pp. 1-30.

Stark, J. and Bollmann, K., "Delayed Ettringite Formation in Concrete", Nordic Concrete Research, NCR, Meeting, Tech. Committee of NCR, Oslo, 1999, pp. 4-28.

Stark, J., and Bollmann, K., "Delayed Ettringite Formation in Concrete", Bauhaus-University Weimar / Germany. 
Sweet, J. and Chen, H. L., "Implementation of Self-Consolidating Concrete in caisson construction for the Stalnaker Run Bridge," Construction \& Building Materials, Volume 34, September 2012, Pages 545-553.

Sweet, J., "Implementation of Self-Consolidating Concrete for Bridge Applications", Ph.D. dissertation, West Virginia University, 2014.

The European Guidelines for Self-Compacting Concrete, Specification, Production and use, BIBM, CEMBUREAU, ERMCO, EFCA, EFNARC, 2005.

Tracy, S., Boyd, S. and Connolly, J., "Effect of Curing Temperature and Cement Chemistry on the Potential for Concrete Expansion Due to DEF", PCI journal, 2004.

Whiting, D. and Mitchell, T.M. "History of the Rapid Chloride Permeability Test", Transp. Res. Rec. 1335 (1992) 55-62.

Yang, C.C. and Cho, S.W., "The Relationship between Chloride Migration Rate for Concrete and Electrical Current in Steady State Using the Accelerated Chloride Migration Test," Materials and Structures, Vol. 37, August-September 2004, pp456-463.

Yuan, Q., Schutter, G., Shi, C. and Audenaert, K., "The Relationship between Chloride Diffusion and Migration Coefficients in Concrete", Proceedings of the 1st international conference on microstructure related durability of cementitious composites, Nanjing, China, RILEM Proceedings PRO 61, vol. 1RILEM Publications, Bagneux, France (2008), pp. 553-563.

\section{Standards and Specifications:}

AASHTO T 84 Specific Gravity and Absorption of Fine Aggregate, American Association of State Highway and Transportation Official, Publication Date: Jan 10, 2010.

ACI 237, 2007, Self-Consolidating Concrete, Building Code Requirements for Masonry Structures, American Concrete Institute, Detroit, Michigan; American Society of Civil Engineers, Reston, Virginia; and The Masonry Society, Boulder, Colorado.

ASTM Standard C1202, 2012, "Standard Test Method for Electrical Indication of Concrete's Ability to Resist Chloride Ion Penetration," ASTM International, West Conshohocken, PA, 2012, DOI: 10.1520/C1202-12, www.astm.org

ASTM Standard C1610, 2010, "Standard Test Method for Static Segregation of SelfConsolidating Concrete Using Column Technique," ASTM International, West Conshohocken, PA, 2010, DOI: 10.1520/C1610_C1610M-10, www.astm.org

ASTM Standard C1611, 2011, "Standard Test Method for Slump Flow of Self-Consolidating Concrete," ASTM International, West Conshohocken, PA, 2010, DOI: 10.1520/C1611_C1611M09B, www.astm.org

ASTM Standard C1621, 2009, "Standard Test Method for Passing Ability of Self-Consolidating Concrete by J-Ring," ASTM International, West Conshohocken, PA, 2009, DOI: 10.1520/C1621_C1621M-09B,www.astm.org

ASTM Standard C1712, 2009, "Standard Test Method for Rapid Assessment of Static Segregation Resistance of Self - Consolidating Concrete Using Penetration Test," ASTM International, West Conshohocken, PA, 2009, DOI: 10.1520/C1712-09, www.astm.org 
ASTM Standard C192, 2013, "Standard Practice for Making and Curing Concrete Test Specimens in the Laboratory," ASTM International, West Conshohocken, PA, 2013, DOI: 10.1520/C0192_C0192M-13a, www.astm.org

ASTM Standard C215, 2008, "Standard Test Method for Fundamental Transverse, Longitudinal, and Torsional Resonant Frequencies of Concrete Specimens," ASTM International, West Conshohocken, PA, 2008, DOI: 10.1520/C0215-08, www.astm.org

ASTM Standard C231, 2010, "Air Content of Freshly Mixed Concrete by the Pressure Method," ASTM International, West Conshohocken, PA, 2010, DOI: 10.1520/C0231_C0231M-10, www.astm.org

ASTM Standard C457, 2012, "Standard Test Method for Microscopical Determination of Parameters of the Air-Void System in Hardened Concrete," ASTM International, West Conshohocken, PA, 2012, DOI: 10.1520//C0457_C0457M-12, www.astm.org

ASTM Standard C566, 2013, "Standard Test Method for Total Evaporable Moisture Content of Aggregate by Drying," ASTM International, West Conshohocken, PA, 2013, DOI: 10.1520/C0566-13, www.astm.org

ASTM Standard C666, 2008, "Standard Test Method for Resistance of Concrete to Rapid Freezing and Thawing," ASTM International, West Conshohocken, PA, 2008, DOI: 10.1520/C666_C0666M-03R08,www.astm.org 
APPENDIX A - Images for air-void analysis

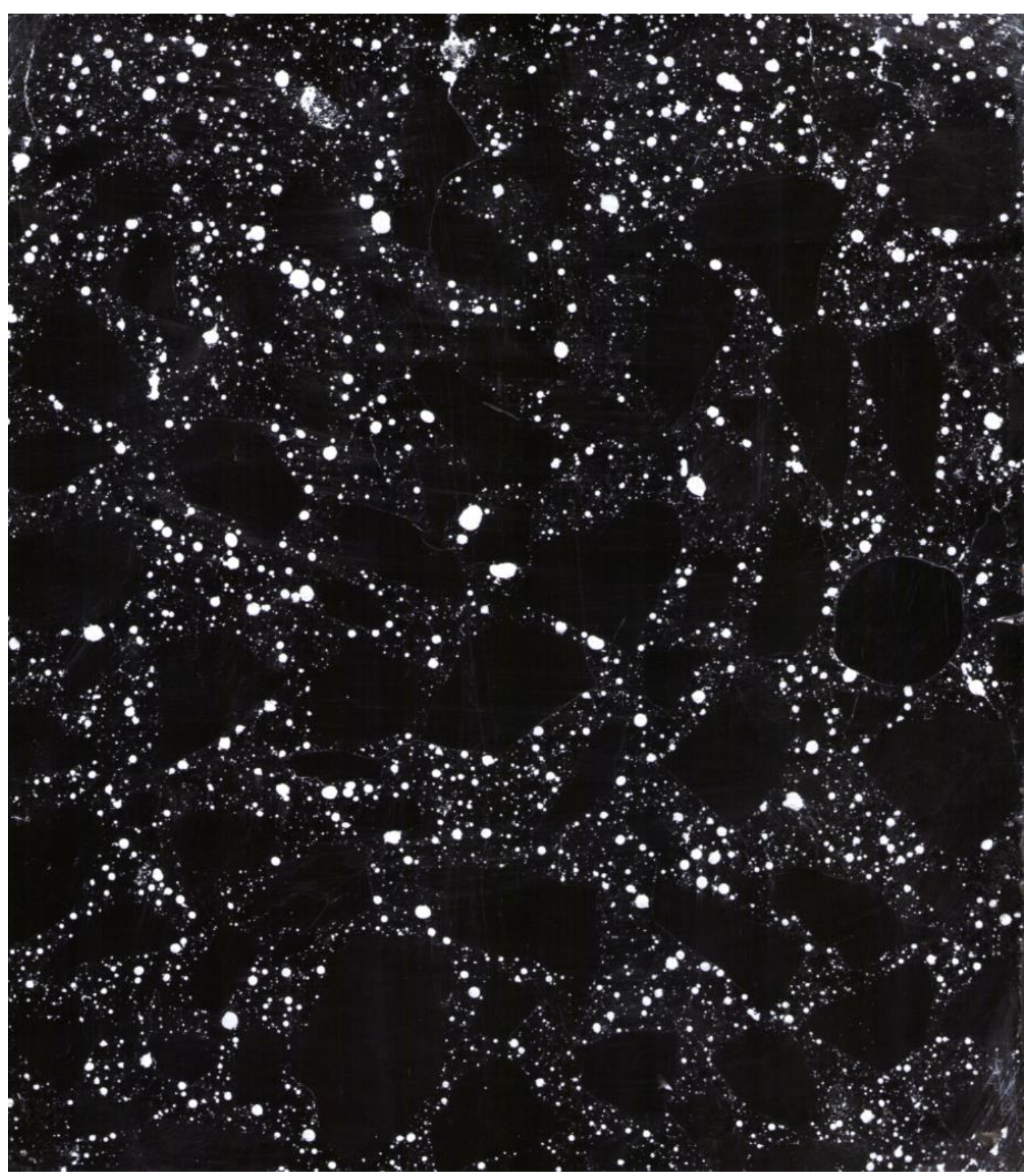

Core 1 


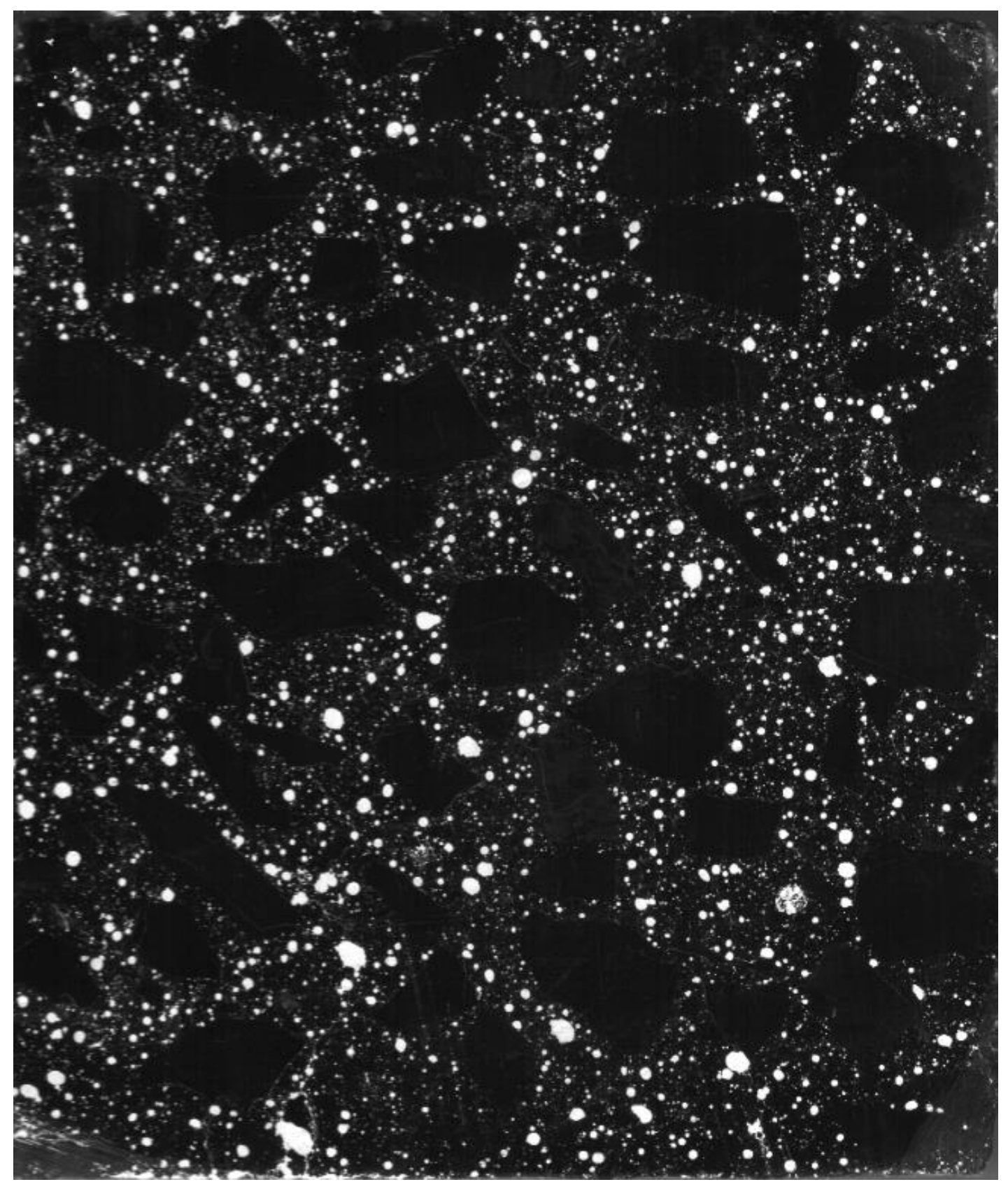

Core 2 


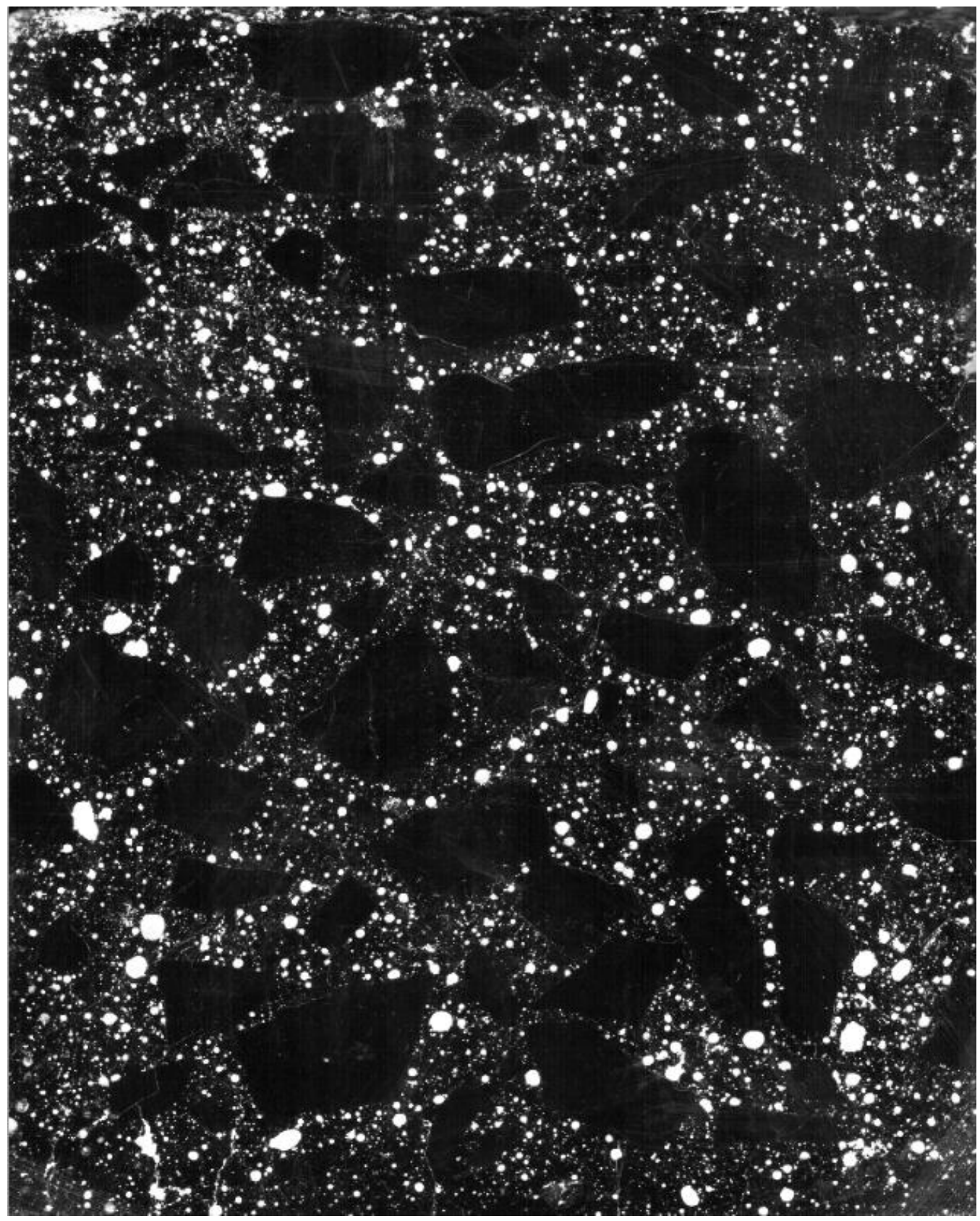

Core 3 


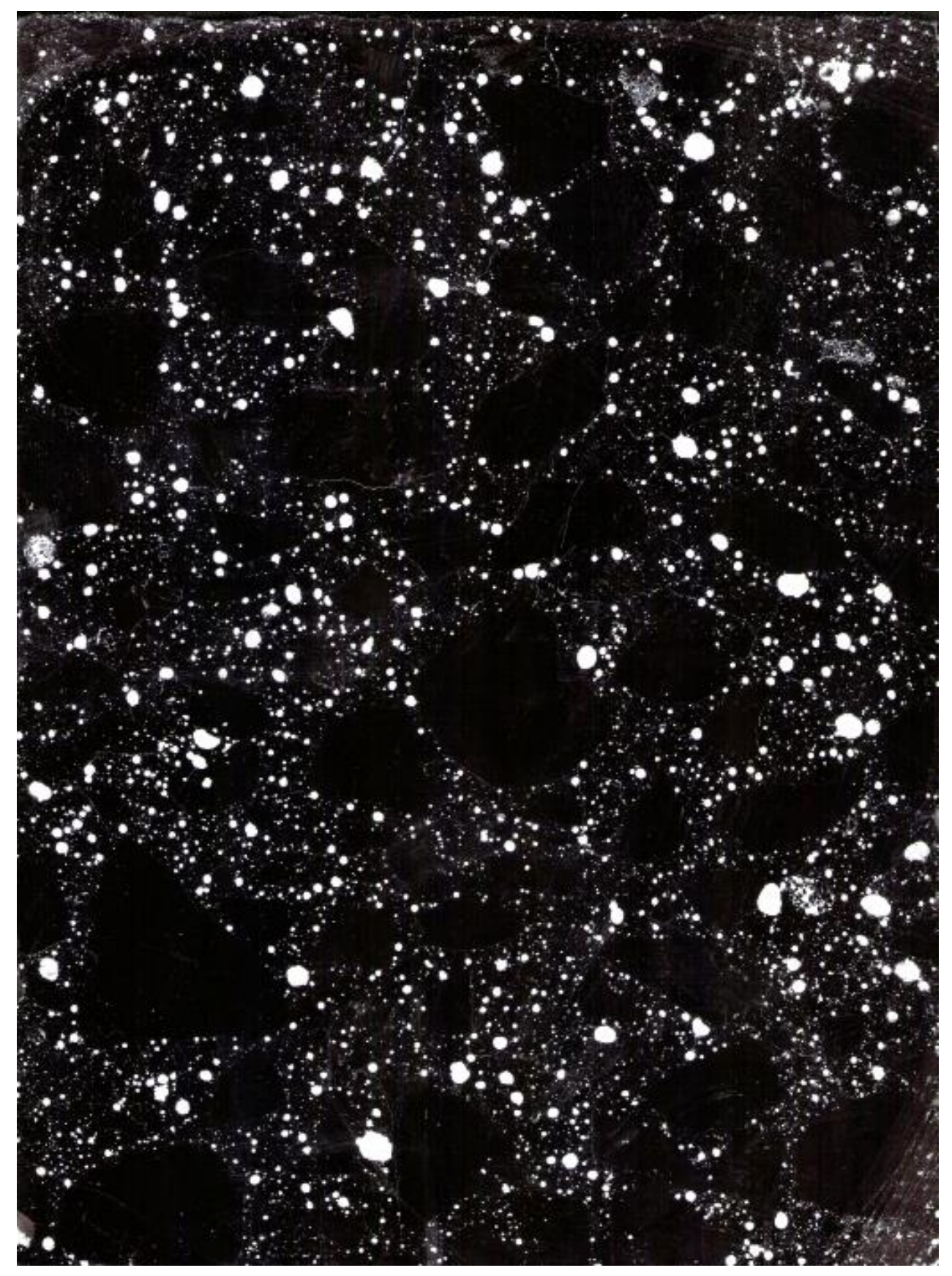

Core 4 


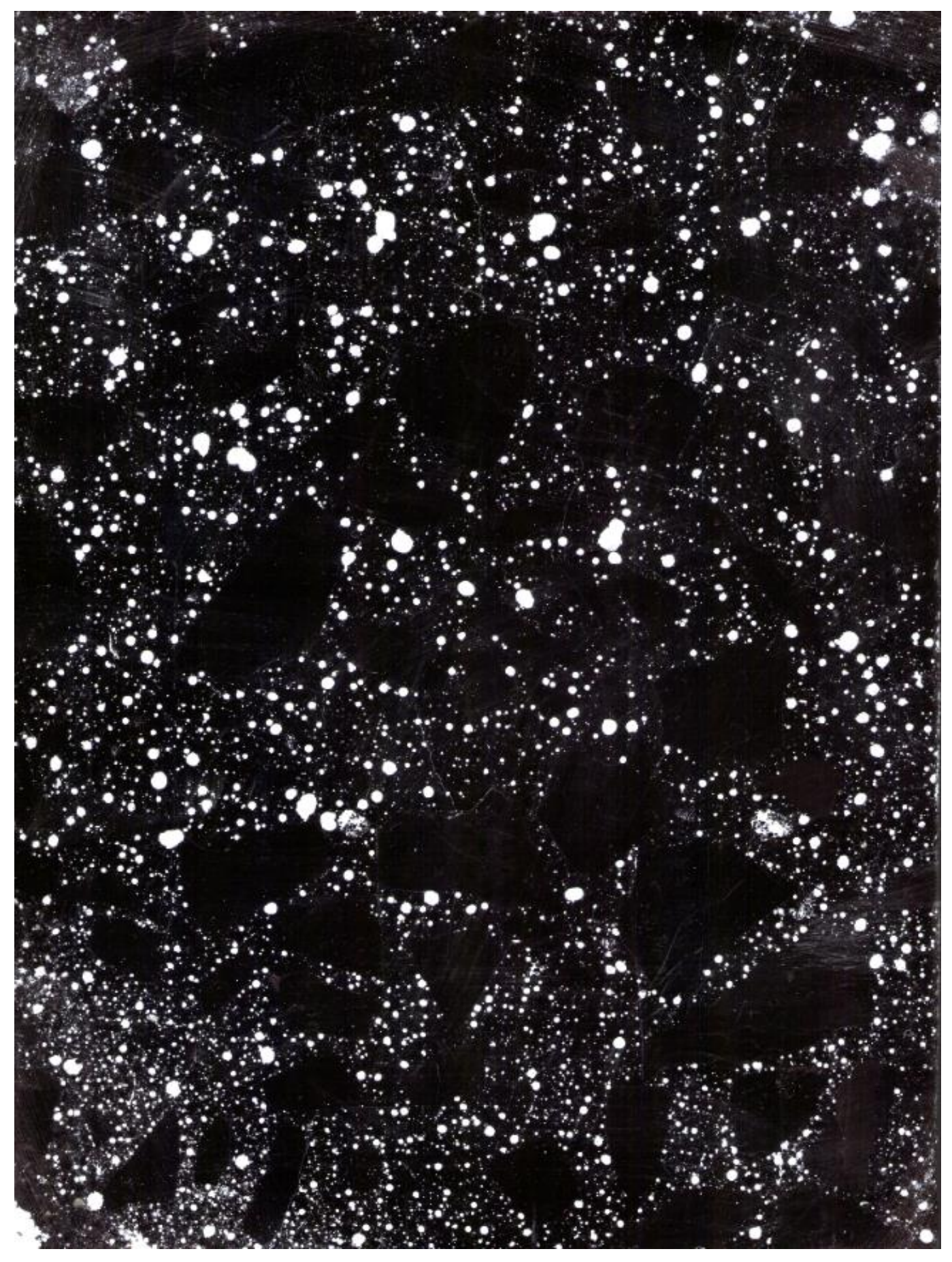

Core 5 


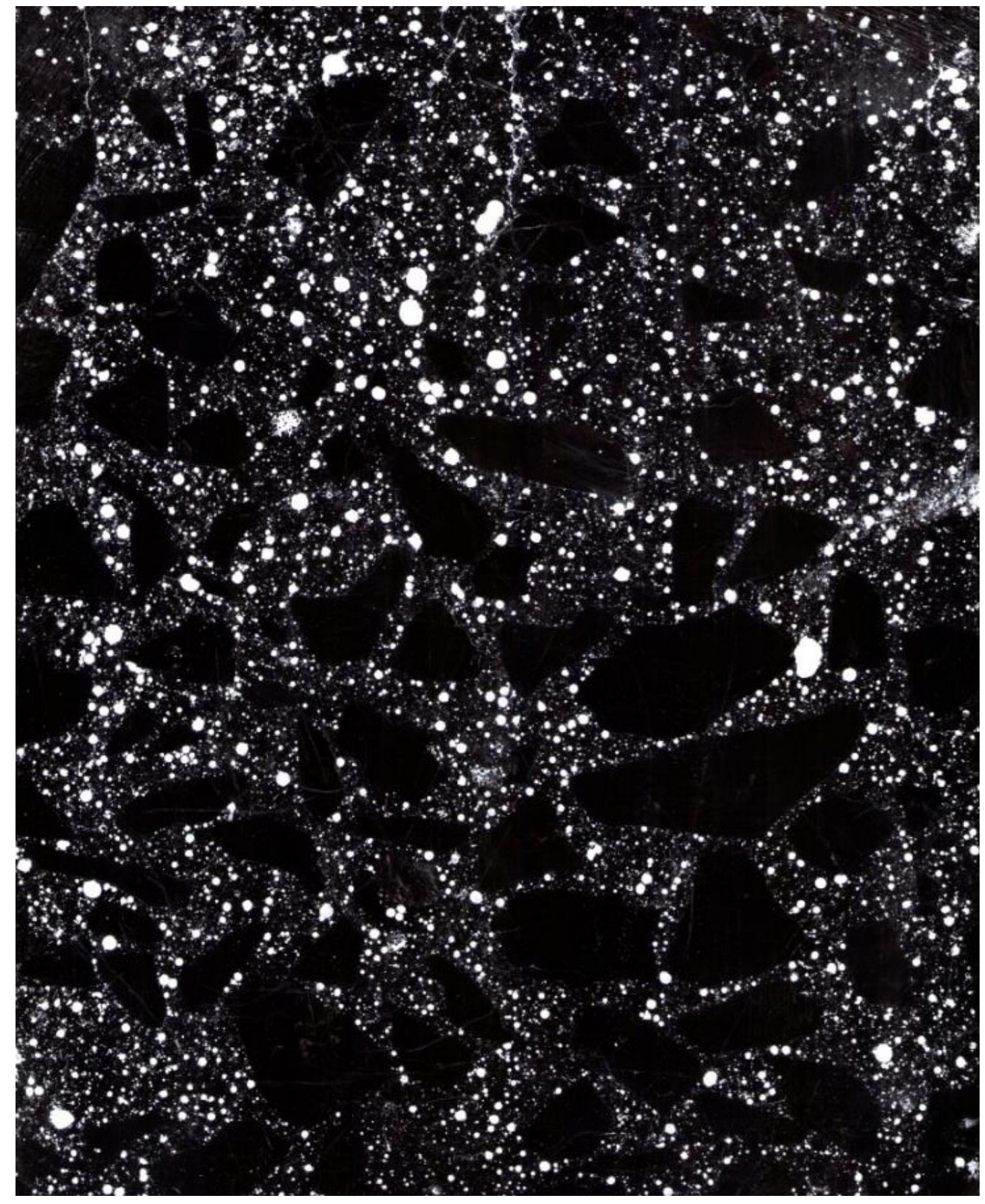

Core 6 


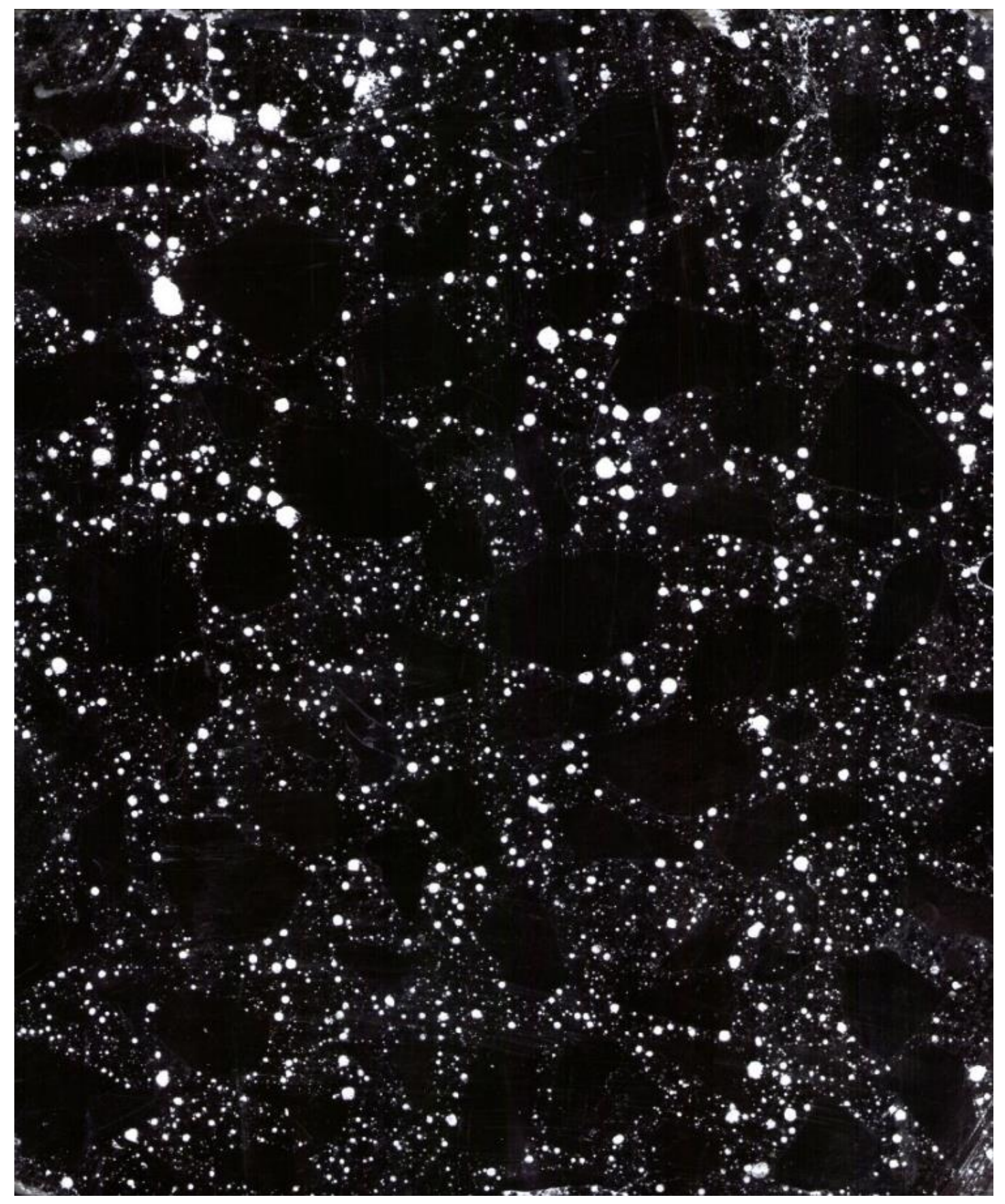

Core 7 


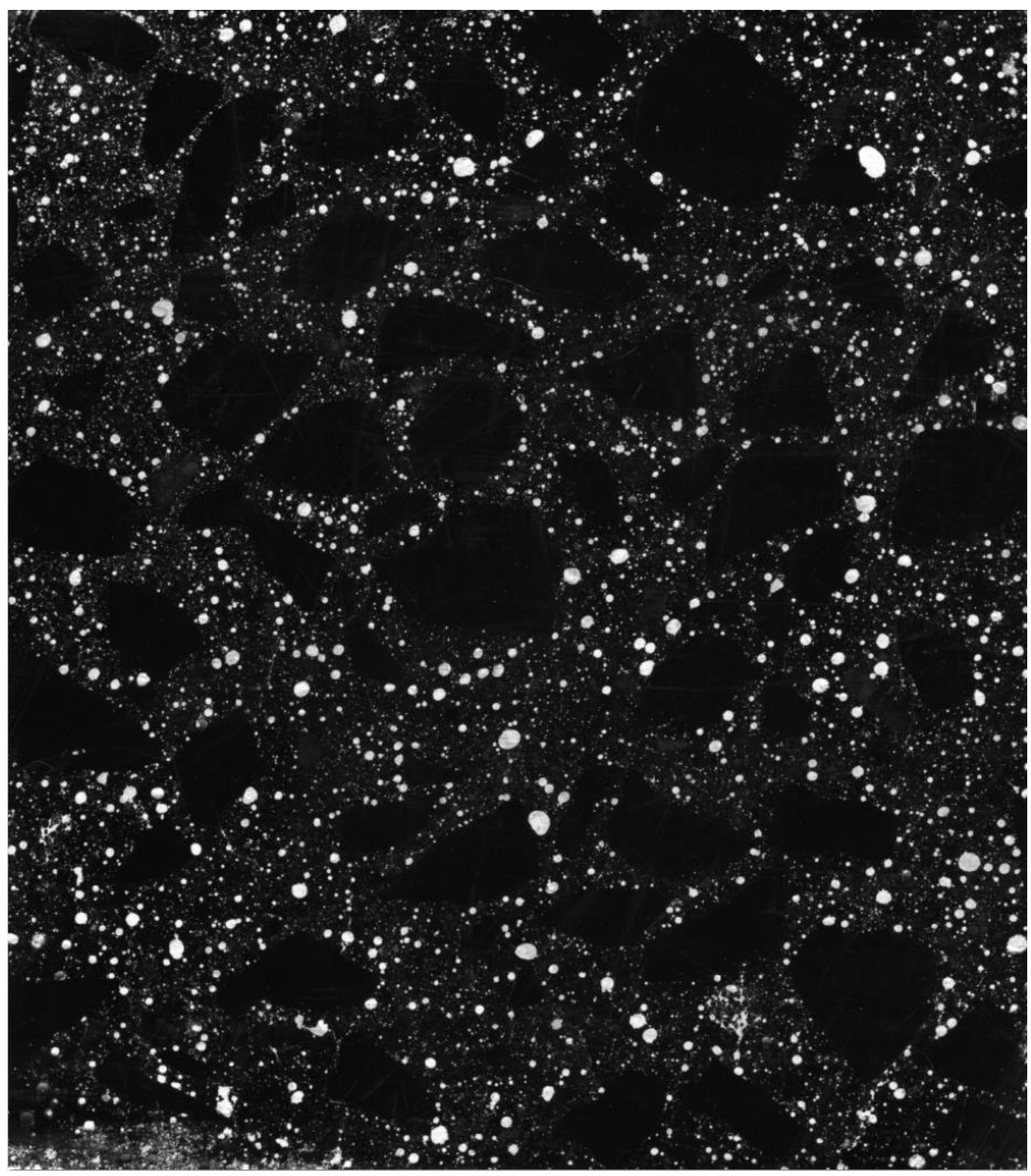

Core 8 


\section{Vita}

Zhanxiao Ma was born in Henan, China. He received the bachelor degree at North China University of Water Resources and Electric Power, Zhengzhou, China, majoring in Hydraulic Engineering in April 2011. In August, 2012, he entered the Graduate School at West Virginia University. 